NBER WORKING PAPER SERIES

\title{
ARE SYRINGE EXCHANGE PROGRAMS HELPFUL OR HARMFUL? NEW EVIDENCE IN THE WAKE OF THE OPIOID EPIDEMIC
}

\author{
Analisa Packham \\ Working Paper 26111 \\ http://www.nber.org/papers/w26111 \\ NATIONAL BUREAU OF ECONOMIC RESEARCH \\ 1050 Massachusetts Avenue \\ Cambridge, MA 02138 \\ July 2019
}

I am especially grateful to Katherine Wells, who provided substantial data work and excellent research assistance. I am also grateful to Lisa Roberts for providing data and for many useful conversations about the interworkings of the Portsmouth syringe exchange program. I thank Jennifer Doleac, Erin Krupka, Jevay Grooms, Ajin Lee, Michelle Segovia, Chuck Moul, Jeffrey DeSimone, David Powell, Barton Willage and participants of the Southern Economics Association 2018 Meeting and 2019 Texas Economics Crime Workshop for useful feedback on work in progress. The views expressed herein are those of the author and do not necessarily reflect the views of the National Bureau of Economic Research.

NBER working papers are circulated for discussion and comment purposes. They have not been peer-reviewed or been subject to the review by the NBER Board of Directors that accompanies official NBER publications.

(C) 2019 by Analisa Packham. All rights reserved. Short sections of text, not to exceed two paragraphs, may be quoted without explicit permission provided that full credit, including () notice, is given to the source. 
Are Syringe Exchange Programs Helpful or Harmful? New Evidence in the Wake of the Opioid Epidemic

Analisa Packham

NBER Working Paper No. 26111

July 2019

JEL No. I10,I18,K42

\begin{abstract}
In light of the recent opioid crisis, many public health entities have called for an expansion in syringe exchange programs (SEPs), which provide access to sterile syringes and facilitate safe needle disposal for injection drug users. This paper investigates the effects of recent SEP openings on HIV diagnoses and drug-related overdoses in the wake of the opioid crisis. I find that SEP openings decrease HIV diagnoses by up to 18.2 percent. However, I present new evidence that SEPs increase rates of opioid-related mortality and hospitalizations, suggesting that needle exchanges alone may be less effective than other interventions at stimulating recovery.
\end{abstract}

\author{
Analisa Packham \\ Department of Economics \\ Vanderbilt University \\ 2301 Vanderbilt Place \\ Nashville, TN 37235 \\ and NBER \\ analisa.packham@vanderbilt.edu
}




\section{Introduction}

In 2016, over 64,000 people in the United States died of a drug overdose, with two-thirds of overdoses involving opioids. The US is in the midst of an opioid crisis, with the US Drug Enforcement Agency declaring in 2015 that drug overdose deaths had reached "epidemic levels" (U.S. Department of Justice, 2015). Consequently, the increase in injection drug use has led to greater risk of illness due to needle sharing. In recent years, acute cases of hepatitis C infections increased by 150 percent, and HIV diagnoses for white males aged 25-34 increased in 2013, reversing a decades-long trend (Centers for Disease Control and Prevention, 2015).

In light of this epidemic, many public health entities, including the CDC and some state and local health departments, have called for an expansion in syringe exchange programs (SEPs), which provide access to sterile syringes and facilitate safe disposal of used needles for injection drug users. Given that HIV and hepatitis $\mathrm{C}$ are both spread via shared needles, and that over one-third of injection drug users report having shared a needle in the past year, proponents of SEPs argue that there is scope for such programs to reduce the spread of bloodborne illness and create new opportunities for drug counseling (Centers for Disease Control and Prevention, 2016).

From an economic standpoint, SEPs have the potential to create large positive externalities by reducing the stock of used needles on the streets and preventing the spread of disease. Conversely, by providing clean needles to drug users, reducing the stigma of using drugs and/or creating a safe environment for networking with other users, SEPs may also generate untended consequences. In particular, lowering the cost of obtaining needles and other supplies incentivizes drug users to inject more frequently, potentially exacerbating rates of opioid misuse and abuse.

In this paper, I test the causal relationships between SEP openings and drug-related health and crime outcomes. Because no official national directory of SEPs exist, I construct a handcollected dataset on program locations and opening dates to identify areas exposed to SEPs within the last ten years. In particular, using health outcomes data from the CDC, I compare rates of HIV, drug- and opioid-related deaths, opioid-related overdoses, and drug-related crime in counties with SEP openings to other counties without SEPs before and after the initial year of implementation. I find that SEPs decrease the number of HIV cases in some areas, and that this effect grows over time. However, estimates also indicate that SEP openings increase drugrelated mortality. Most notably, I find that SEPs increase drug-related mortality rates by 11.6 percent and opioid-related mortality rates by 25.4 percent, and provide some evidence that SEPs lead to a higher rate of emergency room visits and in-patient stays for drug-related complications. Effects are largest in rural and high-poverty areas, suggesting that those with larger geographic or financial obstacles to substance abuse treatment are most affected by such programs. I also find that arrests for drug possession increase 1-2 years 
after an opening, further indicating that SEPs may lead to more drug use and do not necessarily create a more accepting legal environment for injection drug users.

These findings contribute to a recent and growing literature on policies targeting opioid availability and abuse. In the past two decades, a number of state-level policies have been implemented with varying degrees of effectiveness. In particular, recent work has documented that prescription drug monitoring programs (PDMPs), which electronically record patients receiving opioids into a state-wide registry, decrease the number of oxycodone shipments, opioid abuse among young adults, and misuse for Medicare Part D patients (Buchmueller and Carey, 2018; Dave, Grecu, and Saffer, 2017; Mallatt, 2017). On the other hand, there is some evidence that PDMPs cause patients to substitute towards heroin and fentanyl when prescription pills become unavailable, implying that PDMPs lead to increases in illicit drug use (Mallatt, 2017).

In an effort to prevent misdoses from leading to death, all states have legalized civilian access to naloxone, a drug that can reverse the symptoms of opioid use when administered during an overdose. While Rees, Sabia, Argys, Latshaw, and Dave (2017) finds that Naloxone Access Laws, which allow lay people to administer naloxone, lead to significant reductions in opioid-related deaths, Doleac and Mukherjee (2018) finds that naloxone access leads to more opioid-related ER visits and increases in drug-related crimes, with no average effects on mortality.

Other state-level legal restrictions, including prescription limits, patient ID laws, doctor shopping restrictions, and pain clinic regulations have been ineffective at preventing opioid use (Meara, Horwitz, Powell, McClelland, Zhou, O’Malley, and Morden, 2016, Bao, Pan, Taylor, Radakrishnan, Luo, Pincus, and Schackman, 2016) 1 Despite this limited success of state-level policies, new studies show that policies aimed at physician training may be a promising way to prevent overprescribing; for example, Schnell and Currie (2017) documents that physician education plays a role in prescribing behavior, suggesting that better medical training can lead to fewer opioid prescriptions $2^{2}$

While much of the current literature has focused on the availability of opioids and other supply-side restrictions, this paper analyzes the causal effects of demand-side policies and estimate to what extent providing sterile needles, hygiene kits, and referral options for drug counseling in a non-judgmental setting can address the spread bloodborne illness and opioid misuse. More specifically, this paper builds on existing studies by using a unique dataset on SEP openings to measure the effects of SEPs on HIV diagnoses, drugrelated mortality, opioid-related hospitalizations, and drug-related crime in the wake of the opioid crisis.

\footnotetext{
${ }^{1}$ For a comprehensive review of earlier studies analyzing the effectiveness of state policies, see Haegerich, Paulozzi, Manns, and Jones (2014). Less than $10 \%$ of the studies evaluating the effects of PDMPs, clinical guidelines, naloxone distribution programs, use experimental or quasi-experimental approaches to evaluate provider or patient behavior. Findings on the effects of PDMPs on are mixed, and there is little evidence that insurance interventions, drug take-back events, pill mill legislation, clinical guidelines, or education campaigns affect prescribing behavior or drug use.

${ }^{2}$ Moreover, there is some evidence to suggest that marijuana legalization can reduce opioid prescriptions for Medicare patients (Bradford, Bradford, Abraham, and Adams 2018.
} 
Previous research on SEPs is largely correlational, and focuses on syringe sharing during the AIDS crisis in the 1980s and 1990s. These studies generally find that the programs are associated with reductions in the spread of HIV and reduced syringe sharing behavior, and are not correlated with an increase in the amount of drugs used by current drug users or an increase in new drug users (General Accounting Office 1993; World Health Organization, 2004, DeSimone, 2005). Moreover, some studies report that SEPs result in fewer discarded contaminated syringes, indicating that the benefits of preventing the spread of HIV through contaminated syringes are not limited to people who inject drugs (General Accounting Office, 1993 DeSimone, 2005) 3 However, SEPs are documented to be less effective in reducing hepatitis $\mathrm{C}$, implying that existing conclusions regarding SEP cost-effectiveness to date may be overstated (Pollack, 2001).

Importantly, the data from the complied studies include small sample sizes (often looking at data from only one syringe exchange clinic) and self-reported data regarding individuals' drug use rates, and do not typically consider spillover effects or externalities on those not directly treated. Additionally, many studies use data from other countries, such as Canada, Sweden, or New Zealand to serve as a comparison group for drug rates in the US. These findings are problematic for addressing causality, given that other developed countries have differing policies on the operations of SEPs. For example, New Zealand's syringe services are fee-based while Australia distributes syringes free-of-charge and supplies syringe vending machines that allow injection-drug users to obtain clean syringes at any time of the day (Sean Cahill and Nathan Schaefer 2009). And many countries, including Canada, provide free substance abuse treatment to injection drug users, obscuring the true effects of needle exchange.

Moreover, the recent opioid crisis differs from the AIDS crisis in many ways, provoking a need for the reexamination of the effectiveness of harm reduction policies. For example, the opioid epidemic is dramatically escalating; among men aged 25-44, opioid-related mortality more than doubled every year from 2013-2016, representing a sharper increase than any year during the AIDS epidemic. The effects of the opioid epidemic are larger-reaching and are more broadly distributed among US counties than the AIDS epidemic, affecting not only cities, but rural and suburban areas as well. And increases in opioid-related mortality have been exacerbated by the influx of illicit fentanyl in the US, a drug that is 80 to 100 times stronger than morphine and up to 50 times more potent than heroin (Waitemata District Health Borad 2014).

Lastly, although many studies attribute SEPs with reductions in bloodborne illness over time, since HIV

\footnotetext{
${ }^{3}$ Specifically, General Accounting Office $\sqrt{1993}$ includes information on various compilations of medical studies that had been performed throughout the 1990s in the United States, Australia, Canada, the Netherlands, Sweden, and the United Kingdom. DeSimone (2005) uses survey data from 1989-1995 to analyze the causal effect of the introduction of needle exchange programs (NEPs) in 9 large US cities. Using a probit regression analysis, he finds that the presence of a NEP is associated with a 13 percent reduction in drug injection, and argues that these estimates may be reflective of broader public health interventions occurring concurrently with the introduction of NEPs, while also noting that contact with NEPs can serve as a gateway to drug counseling and/or substance abuse treatment.
} 
rates have been falling significantly throughout the US during the last two decades, other factors likely also contributed to the decline in disease. The goal of this paper is to separate out the effects of a SEP opening from the effects of these other factors to better understand the way in which SEPs can affect health. To do so, I use administrative data on health and crime outcomes from 2008-2016 to estimate the effects of SEPs on HIV diagnoses, mortality, opioid-related hospital visits, and drug-related crimes using an approach that compares changes in counties with a recent SEP opening to changes observed in other US counties without SEPs. The results of these analyses indicate that SEPs can lead to significant reductions in HIV rates. However, I also find that SEPs lead to increases in drug-related overdoses. Estimates indicate that a SEP opening corresponds to a 11.6 percent increase in drug-related mortality, driven by increases in synthetic opioid-related mortality, with larger effects in rural and high-poverty areas. These findings indicate that while SEPs are successful at reducing bloodborne illness, they may unintentionally encourage more opioid use by reducing the physical, mental, or networking costs of injecting drugs.

The remainder of this paper is organized as follows. In the next section I provide background information on the history and daily operations of syringe exchange programs. Next I describe the empirical approach I use to estimate the effects of SEPs on HIV cases and drug-related overdoses. I then discuss the results of my analysis before providing some concluding thoughts.

\section{Background on Syringe Exchange Programs (SEPs)}

SEPs, also known as syringe services programs, are community-based public health programs that provide harm reduction services and supplies such as sterile needles, syringes, and other injection and disposal equipment and safe needle disposal. Comprehensive programs also offer HIV counseling, testing, and education, as well as referrals to substance treatment facilities or other medical and mental health services. Because such programs serve as a branch for harm reduction and are not designed to treat addiction or other medical conditions, few SEPs provide medically assisted treatment or any type of in-patient care (Jarlais, Guardino, Nugent, and Solberg, 2014).

In the US, clients are not required to provide proof of income, health insurance, or drug usage to receive supplies, and nearly all programs allow clients to receive more syringes than deposited. About 82 percent of SEP budgets are from public funding sources, through provisions from city, county, or state governments (Jarlais, Guardino, Nugent, and Solberg, 2014). While the federal government has the ability to prohibit federal funding to support SEPs, states have authority to determine regulations for the existence, operation, and local funding of SEPs. Currently, SEPs are legal in 26 states and the District of Columbia, permitted 
in 9 states, and illegal in 15 states (LawAtlas, 2017) 4

Since the early 2000s, more communities have opened SEPs in an effort to curtail the spread of HIV and hepatitis C. Figure 1 shows how the number of SEPs has changed over time, according to the most recent data from the North American Syringe Exchange Network. In 1998, there were 131 SEPs, but by the end of 2013, there were 204 known SEPs. This trend is mirrored in new locales; in 1998 only 77 cities had an SEP, but by 2013, 116 did, suggesting that over half of SEPs opened in areas that previously had no program (Jarlais, Guardino, Nugent, and Solberg, 2014).

To further demonstrate how the usage of SEPs has changed over time, Figure 1 also shows the number of syringes exchanged, in millions. Since 1998, the number of needles exchanged has increased by $155 \%$, with the largest increases occurring from 2005-2013. That both the number of SEPs and syringes exchanged has increased dramatically over the course of the last twenty years has important implications for the effects on drug use and spread of bloodborne illness. Most obviously, one would expect that the exchanges reduce the proportion and/or number of used syringes improperly disposed. However, if the cost of obtaining needles is substantially lower, drug use could increase as a result, potentially leading to more misdoses and more needle sharing. Given that both the number of opioid-related deaths have been increasing steadily over time and that the number of new HIV cases has in recent years reversed a decades-long downwards trend for some groups (see Figure 2), it is important to disentangle outside factors simultaneously contributing to these trends to determine how much these health outcomes would be affected in the absence of SEPs.

Because there is no national reporting system for SEPs or their clients, I cannot track how a SEP opening affects the number or composition of patients at each center. Nonetheless, in an attempt to speak to the daily activities of SEPs and visitor characteristics, in Table A1 I present 2018 visit-level data on client attributes and equipment and services received for a rural, Midwest SEP located in Portsmouth, Ohio. I note that these data are not representative of the entire US, but may shed light on program-level operations in an area of the country that has been largely affected by the opioid epidemic.

Overall, client characteristics mirror those of the population of Portsmouth, with the SEP assisting almost all white clients and client age averaging 37.8 years old 5 Notably, over 22 percent of clients report having previously sought addiction treatment, with approximately one-third of patients reporting having previously overdosed.

Like many other SEPs, the Portsmouth program is open only one day of the week (Fridays). Although a

\footnotetext{
${ }^{4}$ States with permitted programs include those states where local units have interpreted state laws to allow syringe access services or where no law explicitly prohibits syringe exchange. States where SEPs remain illegal include Alabama, Arkansas, Florida, Georgia, Idaho, Iowa, Kansas, Missouri, Mississippi, Nebraska, Oklahoma, South Carolina, South Dakota, Texas, and Wyoming (LawAtlas 2017).

${ }^{5}$ The median age in Portsmouth is 36.8 , and the city is 90.0 percent White United States Census Bureau 2016.
} 
majority of clients are from the city of Portsmouth, nearly one-third travel from other areas ${ }^{6}$ This implies that spillovers may exist to nearby counties. Therefore, in all analyses I use county of residence to determine rates of HIV diagnoses and mortality.

According to self-reported survey data, most users inject heroin, although those reporting having injected fentanyl has been increasing over time, which reflect trends in the general US population. Of those visiting the SEP, one-fifth have been diagnosed with hepatitis $\mathrm{C}$, and 1 percent have been diagnosed with HIV. Despite the fact that SEPs offer drug counseling and referrals to substance treatment facilities, only 1 percent of clients in Portsmouth accepted a referral during the sample period, suggesting that clients are either not interested in treating their addiction, have little resources to afford medical care, are not able to access facilities due to capacity constraints, and/or that referrals are not the main focus of SEP facilities.

\section{Empirical Approach}

In this section I provide a detailed description of the data used in my analysis as well as strategies for estimating the causal effects of SEPs.

\subsection{Data}

Data on SEP locations as of 2017 is from the North American Syringe Exchange Network (NASEN), a nonprofit organization that previously maintained a directory of SEPs by state as a public health information resource 7 In particular, these data contain the name and address of the program, as well as contact information, when available. To gather data on the timing of SEP openings, I used these listings to hand collect information on program dates by recording open dates listed on the NASEN website, researching the history of individual programs when they provided a website, contacting listed representatives for programs, and comparing yearly coverage maps of United States syringe service programs provided by the Foundation for AIDS Research (AMFAR) ${ }^{8} \mathrm{I}$ then geocoded each clinic location to identify which counties were offering SEP programs before 2009, and those that experienced openings in the following 8 years, which serve as the treatment group for this analysis. In doing so, I identified 86 SEP openings in 79 counties between

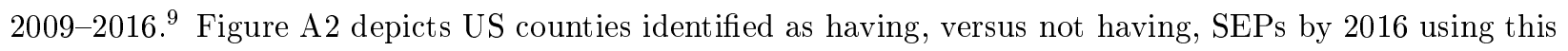
approach, while Figure A3 maps SEPs that opened between 2009-2016 and those that opened prior to 2009

\footnotetext{
${ }^{6}$ See Figure A1 for a map of client zip codes. Almost all clients that disclose their zip code during a SEP visit report living in Portsmouth or West Portsmouth. However, some visitors travel from nearby zip codes in Ohio and Kentucky. The largest travel distance recorded is 250 miles, with nearly 200 records of visitors traveling over 100 miles to the SEP.

${ }^{7}$ These data were available only for a $2-3$ years before they were removed from the website and NASEN does not release these data upon request. Therefore, previous and more current directories are unavailable.

${ }^{8}$ Excellent research assistance, provided by Katherine Wells, was highly valuable in this venture.

${ }^{9}$ Refer to Figure 1 for a visual representation of the variation in county SEP openings during this period.
} 
to show the variation in recent SEP openings.

One shortcoming of these data is that if a clinic opened and closed before 2017, and is not uniquely identifiable from the city-level AMFAR maps, I do not observe that location in the data 10 Moreover, since there are programs that have not authorized NASEN to release their records due to differences in state law that may provide partial funding to SEPs, allow their operation, or prohibit them altogether, my data do not capture any programs that are working without an address, undetected, and/or in defiance with state law 11 I note that if I am not able to observe other SEP openings, this limitation in the data will bias the estimates towards zero.

I use data on HIV cases and drug overdose deaths from two main administrative datasets. To measure the effect of a SEP opening on county-level HIV diagnoses, I use data from the Center for Disease Control and Prevention's NCHHSTP Atlas, which is the only comprehensive source of annual, county-level sexually transmitted infection data to date. The data include counts of HIV diagnoses per county of residence and are available only for 2008-2016 ${ }^{12}$ The primary advantage of these data is that I am able to observe new HIV diagnoses instead of existing cases to analyze how SEPs change the spread of disease over time.

One limitation of the CDC Atlas is that HIV data for counties with less than 5 HIV cases or populations less than 100 are censored to ensure confidentiality of personally identifiable information. Because HIV is a relatively rare event, this results in suppression for approximately 75 percent of county-year observations. To improve the quality of the data and reduce the number of censored cells, I additionally include available data from each state's HIV Surveillance Program separately. Of the 50 states in which I requested data, 34 states provided uncensored data 13

Notably, data on HIV diagnoses does not contain information on transmission at the county-level. According to the CDC, transmission via injection drug use comprises nearly 10 percent of total HIV cases. However, if syringe sharing leads to greater probability of HIV contraction via needles, it would also increase the chances of contracting the disease through contact with improperly disposed needles and sexual intercourse. Therefore, estimates using all available HIV diagnoses data could overstate the true effects of SEP on HIV spread through this method but also maintain the advantage of picking up any potential spillover

\footnotetext{
${ }^{10}$ Although data on closures is unavailable, the net increase in SEPs and client caseloads over time combined with a web search of news articles of existing SEPs suggests that very few programs shuttered during this sample period.

${ }^{11}$ There is no official national registry of SEPs in the United States, and some do not disclose their operational status to NASEN publicly to avoid shut down. Seventeen states prohibit syringe distribution (AL, AZ, AR, FL, GA, ID, KS, MS, MO, NE, ND, OH, OK, PA, SD, TX, WV) with some exceptions for local laws (LawAtlas 2017).

${ }^{12} \mathrm{HIV}$ cases are classified as those with confirmed diagnoses of infection or intection classified as stage 3 (AIDS) in a given year.

${ }^{13}$ These states include Alabama, Arizona, California, Colorado, Connecticut, Florida, Hawaii, Illinois, Iowa, Kansas, Louisiana, Maryland, Massachusetts, Michigan, Missouri, Montana, Minnesota, Mississippi, Nevada, New Hampshire, New York, North Carolina, Ohio, Oklahoma, Oregon, Pennsylvania, South Carolina, Tennessee, Texas, Utah, Vermont, Virginia, Washington, and Wisconsin. In instances where a state did not provide data, and the observation is censored, I assign the number of new counts to be zero, although I note that the results are not sensitive to this choice. Because South Dakota does not report HIV diagnoses to the CDC in any year, this state is dropped for all analysis of HIV rates.
} 
effects 14

Data on drug- and opioid-related fatal overdoses is from restricted-use CDC mortality files. These individual-level data contain information on county of residence, cause of death, as well as age, race, ethnicity, and gender. Drug-related deaths are defined and categorized by ICD-10 underlying cause of death codes X40-X44, X60-X64, X85, Y10-Y14 and Y352 15 To identify opioid- and other drug-related deaths, I use death certificate data on immediate or contributory causes of death, referred to as "T-codes". In particular, to measure effects of SEPs on opioid-related overdoses, I consider T-codes 40.0-40.4 and T40.6 ${ }^{16}$ Because drug-related deaths are a relatively rare event in some areas, I omit from the analysis counties that experience zero reported occurrences in any year during the sample period ${ }^{17}$

While nearly all of the analysis focuses on HIV cases and drug-related deaths, I also consider effects on opioid-related emergency room visits, in-patient stays, and drug-related crimes, to estimate more comprehensive effects of SEPs. By focusing on hospitalization outcomes, I evaluate to what extent SEPs increase drug misuse but do not result in death, which may serve as a better proxy for drug use than mortality. This is especially important given that a large majority of SEPs distribute naloxone to prevent fatal overdoses. Annual, state-level hospitalization data is from the Healthcare Cost and Utilization Program (HCUP) State Emergency Department Databases (SEDD) and State Inpatient Databases (SID). The SEDD contain discharge information on all emergency department visits that do not result in admission, while the SID contain information on patients initially seen in the emergency room then admitted to the hospital. HCUP data is not available for every state, and I therefore drop some states in these analyses.

To address whether SEPs change the legal climate surrounding drug use and/or increase arrests due to the concentration of injection drug users, I additionally test the effects of SEP openings on drug-related arrests. These variables may also serve as a proxy for drug use if possession or sales arrests increase after a SEP opening, assuming police attitudes remain unchanged. Crime data is from the FBI Uniform Crime Reports (UCR), which represent an annual compilation of crime statistics reported by local law-enforcement

\footnotetext{
${ }^{14}$ Conversely, if SEPs increase awareness and HIV testing, any estimated reductions in HIV rates may be understated. While 87 percent of SEPs report offering HIV testing, data on takeup is not available (Jarlais, Guardino, Nugent, and Solberg 2014.

${ }^{15}$ In particular, codes X40-X44 represent accidental poisoning by and exposure to analgesics, antipyretics, and antirheumatics, antiepileptic, sedative-hypnotic, antiparkinsonism, and psychotropic drugs, narcotics and psychodysleptics [hallucinogens], and other unspecified drugs not elsewhere classified, X60-X64 accounts for intentional self-poisoning by and exposure to analgesics, antipyretics and antirheumatics, antiepileptic, sedative-hypnotic, antiparkinsonism and psychotropic drugs, narcotics and psychodysleptics [hallucinogens], and other and unspecified drugs not elsewhere classified, X85 is assault by drugs, medicaments and biological substances, and Y11-Y14 represent poisoning by and exposure to sedative-hypnotic, antiepileptic, antiparkinsonism psychotropic drugs, psychodysleptics [hallucinogens], narcotics, and other and unspecified drugs not elsewhere classified, undetermined intent.

${ }^{16}$ Specifically, T40.0 includes opium, T40.1 includes heroin, T40.2 includes semisynthetic opioids, such as oxycodone and hydrocodone, T40.3 includes methadone, T40.4 includes synethetic opioids, such as fentanyl, and T40.6 includes other and/or unspecified opioids. I refer to Ruhm $(2017)$ on how to properly account for and impute drug-related mortality where at least one specific drug category is identified on a death certificate, although I note that the main results are not sensitive to these adjustments.

${ }^{17}$ Estimates across all columns in Tables 2 and 3 are insensitive to this omission. Reported magnitudes are more conservative when using this approach.
} 
agencies that cover 95 percent of the US population. I focus on the UCR county-level dataset, comprised only of reported crimes that ended in arrest. In particular, I limit my analysis to drug-related arrests, including sale or manufacturing of opium and drug possession.

Using data in conjunction with population counts from the National Cancer Institute's Surveillance, Epidemiology, and End Results Program (SEER), I construct rates of HIV diagnoses and all drug-related outcome variables for my analysis. I additionally include population counts from SEER to construct countylevel measures of demographics, including the fraction of the county population that are black and the fraction Hispanic. To control for economic conditions over time, including those related to economic despair, I use data from the Bureau of Labor Statistics on county-level unemployment rates and poverty rates. Finally, I construct several policy indicator variables using data from Meara, Horwitz, Powell, McClelland, Zhou, O'Malley, and Morden (2016) to help capture the broader policy environment surrounding opioid access in a given state and year. Specifically, these policy controls are state-by-year indicator variables that account for opioid prescription limits, prescription drug monitoring programs, and other requirements to prevent illicit opioid-seeking behavior, including tamper resistant prescription forms, ID requirements, pharmacist verification, and laws to prevent "doctor shopping". I also control for good Samaritan laws, which legally protect individuals while they are assisting others in danger, paraphernalia laws, in which a state bans

drug paraphernalia with no exceptions related to syringes or SEPs, using data from the LawAtlas Policy Surveillance Program, and Naloxone Access Laws, using information on state policy changes from Doleac and Mukherjee (2018).

Summary statistics for variables used in the county-level analysis are shown in Table 1. In Column 1, I display means for counties that experienced SEP openings from 2009-2016 (i.e. treated counties), and in Column 2 I display means for counties without SEPs (i.e. comparison counties). Means for all HIV cases, opioid-related deaths and hospitalization are all larger for the treatment counties; however drug-related crime is lower in these areas, suggesting that SEPs are more likely to exist in areas with more drug use and more legal leniency.

\subsection{Identification Strategies}

My primary approach for estimating the effects of SEPs is a dynamic difference-in-differences design that compares counties with a SEP opening from 2009-2016 to other US counties without a SEP, although below I provide evidence that my results are robust to various other comparison groups. The identifying assumption underlying this approach is that changes in health and crime outcomes in the comparison counties provide a good counterfactual for the changes that would have been observed in the treated counties in the absence 
of the SEP.

In particular, the main results are based on OLS models of the following form:

$$
y_{c t}=\alpha_{c}+\alpha_{t}+\beta X_{c t}+\theta S E P_{c t}+s_{s t}+C_{c} * t+u_{c t}
$$

where $y_{c t}$ is the HIV rate, drug- or opioid-related mortality rate, or crime rate in a county $c$ in year $t$, $S E P_{c, t-k}$ is an indicator variable that takes a value of one for counties with a SEP opening from 2009-2016 during and after the first SEP opening and zero otherwise, $\alpha_{c}$ are county fixed effects to control for any systematic, time-invariant differences across counties, $\alpha_{t}$ are year fixed effects to control for shocks to health and crime outcomes that are common to all counties in a year, and $X_{c t}$ can include time-varying county-level economic variables, county-level demographic controls, and state-level policy controls. These controls help address the possibility that the opening of a SEP and my outcomes of interest are related to local economic conditions and/or state-level initiatives that may affect the supply or demand of opioids. Additionally, $s_{s t}$ represents state-by-year interaction terms to account for aggregate time-varying shocks, like changes in the national drug policy, as well as state-specific shocks, including state funding for drug-related initiatives, Medicaid generosity, or state-level strategies for law enforcement. To more directly account for the concern that differences in the pre-existing trends between counties with SEPs and those without SEPs might bias the estimations derived from the above equation, in some specifications I also include county-specific linear time trends, $C_{c} * t$. All county-level analyses allow errors to be correlated within counties over time when constructing standard-error estimates.

Importantly, I include only counties that have an opening between 2009-2016 in the treatment group, as a way to ensure that all treated counties contain at least one year of pre-period data to test for diverging pretrends. In some specifications, I additionally show results from OLS models that include indicator variables for treated counties prior to the SEP opening. I do so in an effort to verify that mortality rates and HIV rates did not deviate from expected levels relative to other US counties with SEPs in the years before the clinic opening, which would otherwise cast doubt on the notion that the latter provide a good comparison group.

Some outcome variables, such as opioid-related emergency room visit rates and in-patient stay rates, are only available at the state level. Therefore, when analyzing these outcomes, I estimate analogues to Equation 1. collapsing my dataset to a state-by-year panel. In doing so, I define the treatment year to be the year in which the first SEP opens during the sample period, and compare changes in hospitalization outcomes in states with a SEP opening to changes in hospitalization outcomes in other US states.

Given the discrete nature of HIV cases and overdose deaths, and because I sometimes have county-year 
cells with zeroes, I additionally show estimates from a Poisson model, as well as models that convert outcome variables using an Inverse Hyperbolic Sine transformation ${ }^{18}$ I also present weighted-least squares estimates to further consider how these effects vary by population size. Moreover, I show results from models that partial out pre-treatment trends from the full panel, in an effort to construct outcome variables that are robust to county-specific linear trends while avoiding weighting issues present in some dynamic differencein-differences model (Borusyak and Jaravel, 2017).

I also present estimates which allow the estimated effects to vary across years with a set of indicator variables rather than considering the coefficient on a single "post-treatment" indicator for three main reasons. First, the nature of disease and addiction would suggest that any effect on the spread of HIV and/or mortality could appear some time after the program's implementation. Second, I may expect that as a SEP gains clients and notoriety over time, effects accumulate as drug users continue to use SEPs and share fewer needles, leading to both a lower propensity for disease to spread and fewer individuals that have contracted the disease. Lagged indicator variables therefore will allow us to trace the dynamic pattern of the spread of illness and drug-related overdoses as a result of the opening of a SEP. Third, I estimate models that include county-specific linear time trends. Since estimating a time-varying treatment effect implies an effect on trends, by allowing the estimated effects to vary over time in a non-parametric fashion, I attempt to mitigate bias from "overcontrolling," as suggested by Wolfers (2006). Finally, I also present event-study figures for effects on mortality rates using additional years of pre-period data to better inform these estimates and provide support for the notion that including county-specific trends is reasonable in this setting.

\section{Main Results}

\subsection{HIV Diagnoses}

To show the effects of SEP openings on HIV rates, I first present graphical analyses that correspond to the preferred difference-in-differences identification strategy. Figure 3 plots the difference-in-differences coefficient estimates and their corresponding 95\% confidence intervals from Equation 1 comparing HIV rates in counties with a SEP opening to other US counties without a SEP. Since every treated county has at least one year of data before the SEP opening in my sample, I estimate effects relative to the year before treatment, $t=-1$. Points left of the vertical line indicate the differences in treatment and control counties prior to the introduction of a SEP. Notably, these estimates are statistically indistinguishable from zero, providing some evidence to support the notion that trends in HIV rates were not diverging in the years before treatment,

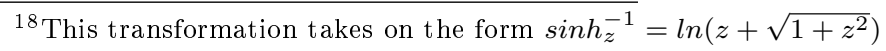


i.e. that counties without SEPs provide a good counterfactual for counties with SEP openings. Figure 3 also provides initial evidence that the HIV rate in counties with SEP openings decreased relative to other counties following an opening, although lagged estimates from the preferred specification are fairly imprecise 19

In Table 2 I provide model-based estimates from Equation 1. Column 1 shows the estimated effects from a baseline model which controls for year and county fixed effects. Estimates indicate that the introduction of a SEP reduced HIV diagnoses rates by 12.7 percent, corresponding to approximately 1 fewer HIV case per county per year, on average.

In Column 2, I present estimates after adding demographic and economic controls. Estimates are statistically similar to the ones in Column 1, and indicate a reduction of 11.2 percent. Column 3 addresses the fact that other state-level policies affecting access to opioid prescriptions and the legal climate of drug paraphernalia changed during the sample period, 2008-2016, which could bias the results. To account for these changes, I control for time-varying indicator variables for states with prescription limits, tamper resistant prescription forms, ID requirements, prescription drug monitoring programs, good Samaritan laws, paraphernalia laws, and other physician requirements, including required verification, and exams. These estimates are smaller than those in Column 1, implying that states with higher HIV rates are more likely to implement opioid-related policies. Due to the fact that state-level initiatives appear relevant in this context, in Column 4 I include state-by-year fixed effects to control for shocks common to areas within a state. Estimates are similar to those reported in Columns 2-3 and indicate a statistically insignificant decrease of 8.5 percent.

Columns 5 and 6 include county-specific linear time trends that account for pre-existing trends in HIV rates. These trends may be especially important to account for, if, for example, treated counties have different outcomes levels pre-adoption and are following a different trajectory than comparison counties prior to SEP adoption. Estimates in Columns 5 and 6 are smaller in magnitude than those in Columns 1-4. However, I note that the estimated effect in Column 5 is statistically similar to that in Column 1 , and, based on these estimates, I cannot rule out reductions in HIV rates smaller than 18.1 percent. Finally, Column 6 presents estimates controlling for a one-year leading indicator variable to more formally address the idea that the trends in HIV rates in treated and comparison counties are not diverging in the year prior to the SEP opening. Indeed, the estimate for the lead is statistically insignificant, providing some additional support for the identification assumption.

I note that although the average effects, reported in Table 2 are statistically insignificant, these effects mask the lagged effects shown in Figure 3 -specifically that HIV rates appear to differentially fall in treated

\footnotetext{
${ }^{19}$ For a figure of difference-in-differences estimates using a longer panel of pre-period data, comparing counties with SEP openings from 2009-2016 to those without SEPs, see Figure A4 I note that since HIV data from the CDC and many state agencies is not available prior to 2008, any estimates on HIV diagnoses should be taken with caution.
} 
counties over time. Therefore, these estimates provide weak evidence that SEPs are successful in reducing the spread of bloodborne illness due to syringe sharing. Below, I present estimates for various subgroups of counties to show that these effects are not identical across geographies or types of counties.

Importantly, in my above analysis, I provide estimates for HIV diagnoses based on CDC data and data from state and local governments. One main limitation of these data is that while drug overdoses have been increasing and HIV cases related to injection drug use has been decreasing (e.g. Figure 20, the county-level data available for HIV diagnoses does not distinguish by cause of infection. Because of this, the causal effect of the opening of an SEP on the rate of new HIV cases may be difficult to isolate in areas where sexual transmission of HIV accounts for the majority of new cases. Moreover, the opening of a SEP may result in more individuals getting tested for HIV. Nonetheless, the main estimates presented in Column 5 indicate that SEPs may prevent approximately 6.1 percent of HIV cases reported by injection drug users. At the upper bound, these estimates imply that SEPs could reduce all cases reported by injection drug users, or over 10 percent of all HIV cases. Although this estimate seems large, the nature and spread of disease paired with potential externalities of removing used needles from the street and limiting the number of HIV-positive sexual partners could have compounding effects. At the very least, SEPs do not seem to results in additional HIV diagnoses.

\subsection{Drug-Related Mortality}

The evidence presented above indicates that SEPs achieve their intended goal by preventing the spread of bloodborne illness. If SEPs provide also drug counseling and resources for injection drug users to seek treatment, such programs could discourage drug use and facilitate recovery. However, three arguments support the notion that SEPs simultaneously create adverse effects, leading to higher death rates from overdose. First, programs distribute free supplies, including needles, sharps containers, and personal hygiene items, which lowers the expected cost of using injection drugs. Second, SEPs provide a safe space to interact with other users, increasing networking opportunities and reducing stigma. Third, communities that build a SEP may attract nearby drug users and/or signal that they also support more police leniency for drug users, lowering the legal risk of using opioids. Below, I test to what extent opening a SEP affects drug- and opioid-related mortality and present evidence consistent with the presence of moral hazard.

I first present a graphical analysis of the effects of SEPs on drug- and opioid-related mortality over time. Figure 4 plots the difference-in-differences coefficient estimates from Equation 1, comparing changes in mortality in counties with a SEP opening to changes in mortality in counties without a SEP. Prior to the introduction of a SEP, estimates are all statistically similar to zero, indicating that mortality trends in 
each group were not diverging prior to the program opening. In the first three years of the SEP, estimates indicate a 9.1-18.8 percent increase in drug-related mortality and a 23.0-42.1 percent increase in opioidrelated mortality, with effects increasing over time.

In Table 3 I display point estimates from Equation 1 for drug-related mortality, opioid-related mortality, and illicit opioid-related mortality, which specifically includes heroin- and synthetic opioid-related deaths. Importantly, drug-related mortality includes all opioid-related mortality as well as other types of drug-related deaths, although opioid-related deaths account for over 60 percent of this category. Opioid-related mortality is further defined using "T-codes," or cause-of-death codes T40.0-40.4 and T40.6, which are commonly used to define opioid-related deaths. These codes include heroin and fentanyl deaths as well as misdoses from prescription opioids. However, since SEPs are targeted towards injection drug users, and nearly all SEP clients report using heroin and/or fentanyl, I also present estimates for illicit opioid-related mortality, which includes heroin-related mortality (T40.1) and synthetic opioid-related mortality (T40.4), which I consider as a measure of fentanyl-related deaths.

Across Columns 1-5, estimates are consistent and indicate that SEPs increase drug-related mortality by 12.8-14.6 percent, corresponding to approximately 3 more drug-related deaths per county per year, on average, or 5,500 additional cases across the US. These effects are largely a result of increases in opioidrelated, and, specifically, illicit opioid-related mortality. In particular, I find that SEPs increase opioid-related mortality by 25.4 percent, or about 3 more cases per county per year. Estimates for illicit opioid-related mortality are even larger, and indicate an increase of 46.2 percent, driven by fentanyl-related deaths ${ }^{20}{ }^{21}$ For all outcomes, mortality rates in comparison counties appear to be tracking those in counties with SEP openings in the year prior to the opening (Column 6).

These effects correspond to nearly 2.5 additional fentanyl-related deaths per county over the 0-7 years following a SEP opening, providing support for two stark conclusions: (i) SEPs lead to greater risk of opioid misuse and overdose and/or (ii) the increase in mortality rate among injection drug users simultaneously reduces the probability that these users will spread HIV through needle sharing in the future. In Section 5 I present some evidence that effects on opioid-related mortality are concentrated in different areas than the effects on HIV rates, suggesting that the former is more likely to be driving the results than the latter.

\footnotetext{
${ }^{20}$ Heroin-related deaths are responsible for approximately 20 percent of the effect shown for illicit opioid-related mortality.

${ }^{21}$ In Figure A5 I further explore effects of SEPs on other drug-related mortality rates. Deaths due to methadone, a pain reliever and drug commonly used to treat opioid dependence, are relatively unresponsive to SEP openings, and may even fall slightly. However, I find that SEPs lead to large and increasing mortality rates for both fentanyl and cocaine. While effects on synthetic opioids are expected, given the findings reported above for illicit opioid-related mortality, effects on cocaine-related mortality may be more surprising. However, an increasing public health issue is the recent mixing of cocaine and fentanyl, and increases in injections of both drugs (Lopez, 2018). Over half of cocaine deaths attributable to drugs also have opioids in their system (53.9 percent).
} 


\subsection{Emergency Room Visits and In-Patient Stays}

Despite the fact that data on drug-related mortality is able to capture one measure of how much SEPs can affect opioid overdose, the above effects may not be picking up drug usage if users are injecting more frequently but not at fatal doses. To explore the more comprehensive effects of SEPs on drug use, I use data on drug-related emergency room visits and in-patient stays from the HCUP dataset. One limitation of these publicly available data are that they are only available at the state level, which does not allow for a more granular, county-level analysis ${ }^{22}$

Using the difference-in-differences approach described above, in this state-level analysis I assign the year of treatment to the first SEP clinic opening year between 2009-2016 in a given state. In Figure 5 and Table 4. I provide estimates showing the effects of the opening of a SEP in a state on the rate of opioid-related emergency department (ED) admissions and in-patient stays. ED visits are likely to serve as a proxy for drug use, as these data pick up drug-related overdoses that are easily reversed and result in less than a 24 -hour stay. In-patient data, on the other hand, reflect more high-risk cases requiring the care of a doctor, and may more clearly track patients with a longer history of drug abuse.

Across Table 4 Columns 1-3 estimates mirror those of Figure 5 and indicate that the introduction of a SEP increases drug-related emergency room admission and in-patient stays by approximately 8.9 percent and 3.4 percent, respectively, although estimates in Column 3 are statistically insignificant at conventional levels. However, when separately estimating lagged effects, like those shown in Figure 5 I estimate that SEPs increase emergency room admissions by 18.8 percent, on average, with effects driven by the second through fourth years, corresponding to about 1,600 additional ED visits per state annually, or approximately 30 visits per county 23 Similar to the measured effects for mortality, effects for ED visits grow over time. Similarly, estimates in Columns 1-3 indicate an increase in opioid-related hospital stays ranging from 4.6-13.3 percent, although estimates in Columns 3 and 4 are positive and statistically insignificant. Given that 12.1 percent of ED admits die before or while receiving treatment, these estimates imply an additional 3.6 drug-related deaths per county, which is similar to the magnitudes reported above.

In other words, these findings suggest that SEPs increase emergency visits at ten times the rate that they increase opioid-related mortality. To the extent that SEPs connect users to life-saving technology, such as naloxone, or introduce ways to recognize overdose and encourage calling for help, then any increase in emergency room visits may represent a reduction in opioid-related deaths that would have occurred otherwise. Therefore, my results provide some evidence that SEPs help the marginal client from fatal overdose, but

\footnotetext{
${ }^{22}$ HCUP does not contain data on every state. In particular, I drop Colorado, Louisiana, Michigan, New Mexico, Oregon, Pennsylvania, Texas, Washington, and West Virginia for this analysis.

${ }^{23}$ This is based on the fact that, on average, a given state has 52 counties.
} 
are unable to reverse addiction. Indeed, estimates by hospital condition, shown in Figure A6 are consistent with this notion. At-home drug-related mortality rates and mortality rates for those reaching the ER did not experience a large increase after a SEP opening.

Nonetheless, effects are driven by sharp increases in rates of individuals in in-patient care and those reaching the hospital dead on arrival. Taken together, these findings suggest that while SEPs are successful in reducing disease, lowering the cost of obtaining clean needles and other supplies unintentionally encourages more drug use, leading to more opioid-related overdoses. While many of these overdoses can be reversed in the ER, SEPs do little to prevent mortality rates from rising in subsequent years. These effects become more pronounced over time, indicating that any future cost-benefit analyses of SEPs should consider effects at least $2-4$ years after the introduction of the program.

\section{$5 \quad$ Subgroup Analysis}

Given the abundance of anecdotal and empirical evidence that the opioid crisis has largely affected younger white males in rural and low-income areas, one would reasonably expect the effects of SEPs to be largest in counties with small, mostly white populations and those with a relatively large share of low-income individuals. In the following section, I explore how SEP openings differentially affected groups across counties to provide clarity on the heterogenous effects of SEPs.

\subsection{Effects Across Counties}

In Table 5, I consider to what extent SEPs affect various county subgroups. In Column 1, I replicate estimates from my preferred specification for a baseline comparison. In Columns $2-5$ I split the sample by urbanicity and poverty levels.

When analyzing effects by urban and rural counties with SEPs in Table 5 Columns 2-3, I find a striking result-effects for HIV rates and opioid-related mortality rates are concentrated in rural counties. One reason for this may be that rural areas, which are well-known to be differentially affected by the recent opioid crisis, have relatively little access to HIV testing as well as substance abuse treatment ${ }^{24}$ In particular, distance to a hospital and/or other facilities that can revive individuals when overdosing may be a major barrier in preventing fatal overdoses. To get a better sense of which counties may be driving this effect, I revisit and expand on this finding in the next section.

In Columns 4 and 5 I separately estimate effects on low- and high-poverty counties. I define high-poverty

\footnotetext{
${ }^{24}$ The average number of substance abuse treatment facilities in large urban, medium/small urban and rural counties is 122 and 20 , respectively. By comparison, rural areas have only 2 facilities, on average.
} 
counties as those having more than the county-level median poverty rate and define low-poverty counties as those having rates below this median 25 Estimates for opioid-related mortality rates are statistically significant only for high-poverty areas, and indicate that SEPs increase opioid-related mortality rates by 39.5 percent, implying that SEPs are more likely to affect those that have financial barriers to treatment ${ }^{26}$ While statistically insignificant, reductions in HIV appear to be concentrated in low-poverty counties, indicating that effects for these two health outcomes may be driven by different areas adopting SEPs.

\subsection{Effects Across US Region}

Due to the fact that the opioid crisis has not affected all states and US regions uniformly, I now turn to a discussion on how SEPs affect health outcomes by region ${ }^{27}$ In Table 6 I separately analyze effects of SEPs on HIV rates and opioid-related mortality rates by US Census regions ${ }^{28}$ Additionally, I show estimates from a separate, non-mutually exclusive region, which includes the top ten states most affected by the crisis, as defined by the CDC ${ }^{29}$

Due to sample size, some estimates are less precise than the main findings in Tables 2 and 3 Although statistically insignificant, reductions in HIV rates are most concentrated in Midwest and Western counties. Increases in opioid-related mortality rates are largest in Southern counties as well as those counties in "top 10" states in Appalachia and the eastern seaboard most affected by the crisis 30

Taken with the results in Table 5 , these findings imply that SEPs have differential effects that largely depend on the size of the population and area of the country in which they are located. Next, I discuss this implication in greater detail and present effects across county population. Importantly, these results have significant policy implications given that state and local policies may play a role in shaping the effectiveness of SEPs, and "one size fits all" federal policies could have differing effects across geographies.

\subsection{Effects Across Age, Race, and Gender}

Thus far I have shown that the introduction of a SEP has the potential to reduce the spread of bloodborne illness while generating unintended consequences. However, I note that average effects may be masking

\footnotetext{
${ }^{25}$ Specifically, the median poverty rate across counties with SEPs is 16.1 .

${ }^{26}$ Figure A7 presents the visual results of this analysis, displaying estimates for rural counties, urban counties, low-poverty counties and high-poverty counties separately.

${ }^{27}$ See Ruhm (2017) for a more thorough discussion on geographical variation in drug- and opioid-related mortality.

${ }^{28}$ Notably, for this analysis, I have 17 treated counties in the Midwest, 25 in the South, 13 in the Northeast, and 24 in the West. See https://www.census.gov/geo/reference/webatlas/regions.html for a list of states in each region.

${ }^{29}$ In order of severity, these states are West Virginia, Ohio, Pennsylvania, District of Columbia, New Hampshire, Kentucky, Maine, Connecticut, Delaware, and Massachusetts.

${ }^{30}$ I note that the effects here may be driven by the Census definition of which states are included in the "South" census definition. Generally, effects are large in states in the Midwest/Appalachian region most affected by the crisis, including Kentucky, Indiana, Ohio and West Virginia. However, no one state is solely responsible for the findings. Estimates do not meaningfully change when omitting states one-by-one from the analysis.
} 
effects that differ by demographics, as motivated by Figure 2. Below, I explore effects by age, race, and gender in an attempt to understand who is most likely to be affected by SEPs.

In Table 7 I first present estimates on the effects of SEPs on opioid-related mortality for individuals in their 20s, 30s, 40s, and 50s, respectively. Estimates are driven by older individuals aged 50-59 and indicate a 17.3 percent increase in opioid-related mortality. I find no evidence that SEPs affect mortality rates for those in their 20s, potentially due to the fact that the average SEP client is 38 years old, and/or that younger individuals are less likely to die from a drug overdose. Estimates for those in their 30s are relatively large but statistically insignificant at conventional levels.

Table 7 additionally shows effects separate by race and gender. Effects are largest for white individuals, which is well-known to be a group most affected by the opioid crisis (Hollingsworth, Ruhm, and Simon. 2017; Case and Deaton, 2017). Similar to my main results, estimates indicate an increase in opioid-related mortality rates for white individuals by 12.7 percent, which corresponds to nearly 3,500 additional deaths per year across the US. Effects for black individuals are similarly large, but do not increase until 2-3 years after the SEP opening.

The last two columns of Table 7 display effects by gender. Perhaps unsurprisingly, estimates are driven by male opioid-related mortality, which has increased at faster rates during the opioid crisis than female opioid-related mortality.

Moreover, in Table $8 \mathrm{I}$ also display state-level estimates for hospital visits by gender and age subgroups. Individual-age data is not provided by HCUP; therefore, I use available pre-determined age categories to analyze ED and in-patient stay rates. When observing differences across age, effects are 2-3 times larger for individuals aged 25-44, with no changes in ED visit rates for those aged 45-64. Interestingly, estimates for males are statistically similar to the average effect, and indicate that the hospitalization results are not solely driven by male risky behavior. This could suggest that while men and women visit SEPs at similar frequency, females are less likely to die of a fatal overdose, but more likely to visit the hospital for an opioid-related complication.

\section{Effects on Drug-Related Crime}

If SEPs unintentionally encourage drug usage, as suggested by the aforementioned findings, then one would expect drug-related crime to also increase. Moreover, SEPs may result in areas of a community that draw injection drug users together, creating a "hot spot" for police to patrol, leading to more arrests. On the other hand, if the introduction of a SEP also signifies increasing attitudes of legal leniency towards opioid use, one would expect arrests for drug-related crimes to decrease after a SEP opening. Indeed, in a survey 
of active SEPs, 82 percent reported "very good" or "somewhat good" relationships with law enforcement in 2013, suggesting that local police do not generally attempt to locate near and/or harass SEP clients. In this section, I analyze effects on drug arrests including possession and sales to get a sense of how drug use and/or local attitudes towards drug use respond to the opening of a SEP.

In Figure 6 and Table 9 I show estimates for various drug-related crimes. "Total Drug Crime Rate" refers to a more comprehensive measure of drug crime including possession, sale, and/or manufacturing of drugs of any kind. Across Columns 1-6, I present evidence that the introduction of a SEP has no effect on total drug crime arrests, on average. However, I present some evidence that opioid-related possession arrests increase by 12.7-28.0 percent after the opening of a SEP. When controlling for the year prior to adoption, as in Figure 6. estimates are significant one year after the initial year of the program and increase over time, following trends in drug-related health outcomes reported in the previous section. Notably, I find weak evidence of a reduction in arrests for drug sales, which could indicate that as drug use increases, police target users rather than sellers due to time and/or resource constraints.

These findings suggest that SEPs do not result in greater leniency for drug users. While it is possible that SEPs subsequently increase police monitoring due to heightened saliency of local public health issues, my findings on drug-related mortality and hospital admissions indicate that opioid use increases after a SEP opening, and the proportion of arrests for drug possession also rises. Below, I show additional evidence that this increase in drug-related crime is not mirrored by an increase in other criminal or risk-taking behavior, implying that these effects are not simply a byproduct of compositional changes in population.

\section{Robustness}

The main threat to the validity of the empirical strategy is the possibility that concurrent policy changes and/or shocks to opioid demand or availability is instead responsible for increases in opioid-related mortality. Although changing demographics, economic conditions, and state restrictions should be captured by controls included in the main specification, the degree to which other unobservable changes in county-level opioid use happen at the same time as SEP openings (but not beforehand) is untestable. To better address the validity of the identification strategy, I examine to what extent the main results depend on functional form, the inclusion of various state-level health-related policies, or the definition and inclusion of comparison counties. I additionally provide placebo estimates as a way to check whether the increase in opioid-related mortality is due to changes in risky behavior or population composition.

First, I test how robust my analyses are to functional form. To do so, I provide weighted least squares and Poisson estimates in Table 10 . Notably, these alternative estimates are generally less precise and smaller 
in magnitude than the OLS estimates. Moreover, for HIV rates, WLS and Poisson estimates are positive 31 As described in Solon, Haider, and Wooldridge (2015), this pattern can reflect circumstances in which there are relatively large effects for counties which maintain small populations. Given that I show large effects for HIV and opioid-related mortality rates in rural counties in Table 5 , these estimates remain consistent with my previous findings.

I further explore this heterogeneity in population size directly Table 11 which displays estimates for a more binary measure of population size - counties with less/more than 200,000 people, and in Figure A8 which presents estimates by a more continuous measure of county-level population ${ }^{32}$ Mirroring findings in Table 5 Columns 2 and 3, I note that these estimates do provide some suggestive evidence that estimates for mortality are comparatively large for less-populated counties, which may demonstrate why the OLS estimates are relatively large in magnitude as compared to the WLS estimates. Specifically, Figure A8, which provides the main estimates by county population, shows that estimates for opioid-related mortality rates are positive and statistically significant across counties with populations ranging from $0-1,000,000$, while effects for HIV rates are similar across county size, but are larger and more precise when estimating effects for counties with 100,000-200,000 individuals. Figure A9 which replicates these estimates, weighting them by county population, indicates similar patterns, providing additional support for the idea that effects are concentrated in less densely populated areas ${ }^{33}$

Furthermore, in Figure A10 I show estimates of the effect of SEP openings on rates of HIV diagnoses and drug- and opioid-related mortality, omitting the inclusion of county-specific linear time trends. Without these controls, effects are even more immediate and dramatic, and indicate a large decrease in HIV rates over time as well as an increase in drug-related mortality rates in the years following an opening. Therefore, this gives some indication that the main results present a more conservative estimate of the effects of SEP openings in a given county. For reasons described in Section 3.2, I also provide lagged estimates for all main health and crime outcomes and their averages in Table A3 to fully account for the time-varying treatment effects, suggested by (Wolfers, 2006). Estimates are similar in magnitude to the main results and increase over time, as shown in Figures 36

Second, since the opening of a SEP is not random, in my preferred specifications I account for a number of demographic, economic, and policy variables that are likely correlated with a county's decision to initiate

\footnotetext{
${ }^{31}$ For the Poisson specification when estimating HIV rates, it's worth noting that the number of counties included in the sample falls due to the fact that many counties experience no HIV diagnoses in a given year. This does not occur when estimating drug-related overdoses, as I drop counties that have zero drug-related mortality cases for the main analysis.

${ }^{32} \mathrm{I}$ choose this cutoff for two reasons. First, the median population is 191,972 and second, in Table 5 I find larger effects for mortality in rural areas.

${ }^{33}$ I also show estimates from an OLS model which estimates effects on the inverse hyperbolic sine transformation of HIV diagnoses and opioid-related deaths in Table A2 Estimates for HIV rates are similar to those in Table 2 Estimates for opioid-related mortality rates are positive and range from 2.4-10.4 percent, but are statistically insignificant across all columns, further supporting the idea that rural counties with large increases in mortality may be driving the main results.
} 
a needle exchange program. However, if the addition of these time-varying determinants of HIV rates and mortality rates meaningfully change the main findings, this would suggest that health outcomes in the treatment and comparison groups might have diverged even in the absence of a SEP. To show that these factors are orthogonal to the within-county variation in SEP openings, in Table A4 I estimate the effects of SEP openings on HIV rates and opioid-related mortality rates, adding in controls for relevant state legal restrictions and drug-related laws in separate specifications. Importantly, estimates are similar across Columns 2-10, suggesting that no particular policy changes are driving the main results 34

Additionally, I investigate how much the effects of SEPs vary with state-level policies that affect access to opioid prescriptions and drug treatment facilities. In Table A5, I separately estimate the effects for states that did and did not expand Medicaid eligibility by 2015, according to Simon, Soni, and Cawley (2017). It is unclear whether Medicaid would help to reduce opioid misuse or exacerbate it. For example, expansions Medicaid eligibility increase access to drug treatment facilities for low-income individuals by eliminating financial barriers, which we would expect to reduce opioid-related overdoses. However, Medicaid could also increase opioid-related mortality via increased access to low-cost prescription opioids. In Table A5 I find support for the latter argument. Notably, effects are larger in Medicaid expansion states for both drug- and opioid-related mortality, although I also note that nearly all treated counties (81\%) are located in Medicaid expansion states.

Third, I consider estimates based on alternative difference-in-differences identification strategies to explore the extent to which comparing effects across counties with SEPs yields larger (or smaller) estimates. Table 12 presents estimates based on models using various comparison groups. In Column 1, I provide my main results shown in Table 2 Column 6 for comparison. Importantly, I include estimates for both the average effect and a one-year leading indicator variable, to provide some support for the notion that using other comparison groups doesn't yield a model that is likely to be misspecified 35 In Columns 2-5 I compare counties with SEP openings between 2009-2016 to other US counties with an existing SEP (i.e. a SEP built before 2009), all other US counties, all counties in states that permit SEPs, and counties bordering the defined treated counties, respectively. Indeed, the coefficient estimates for both outcome variables are similar to the baseline results. Moreover, estimates for opioid-related mortality rates are similarly positive and range from 15.4-28.4 percent across specifications. Estimates for the one-year lead is statistically insignificant across all columns.

Fourth, because different types of counties may have adopted SEPs at different times, I similarly test the

\footnotetext{
${ }^{34}$ Data on state policy variables, including laws governing patients, prescribers, or dispensing pharmacists that involve quantitative prescription limits, patient identification requirements, requirements with respect to physician examination or pharmacist verification, doctor-shopping restrictions, PDMPs, requirements related to tamper-resistant prescription forms, and pain-clinic regulations is from Meara, Horwitz, Powell, McClelland, Zhou, O'Malley, and Morden (2016). Data on Naloxone access laws is from Doleac and Mukherjee (2018).

${ }^{35} \mathrm{I}$ additionally present figures with lagged estimates for the two most relevant comparison groups in Figure A11
} 
extent to which earlier adopters differ from later adopters and present these estimates in Table A6. Column 1 displays the baseline results, while Columns 2 and 3 separately show effects for counties with SEP openings between 2009-2012 and 2013-2016 separately. Splitting the sample yields less precise estimates; however, for both HIV rates and opioid-related mortality rates, effects are driven by the later adopters. This suggests that counties that opened SEPs at the height of the opioid crisis during the availability of fentanyl may have had either more clients and/or clients using injection drugs at higher frequencies or more fatal doses.

Fifth, because one may be concerned that the effects I report for opioid-related mortality may be a result of population composition changes due to a SEP opening, in Figure 7 I investigate whether the treatment counties simultaneously experience increases in mortality rates from other causes. In particular, I analyze whether the introduction of a SEP in a county affects vehicle-related and/or alcohol-related mortality, or total mortality 36 I find no statistically significant effects of SEP openings on any of these other mortality rates, implying that SEPs more directly affect outcomes related to drug use.

In this same vein, I have also considered that my findings may simply be driven by overall improvements in healthy living which coincide with the opening of a SEP. To test this hypothesis, in Table A7 I additionally analyze whether SEPs affect another sexually transmitted infections (STIs) that is not contracted through needle sharing: chlamydia. I find no that rates of chlamydia decrease after the introduction of a SEP ${ }^{37}$ These findings provide weak evidence that SEPs do not result in individuals engaging in more risky sexual behavior 3839

Finally, in Table A8 I show estimates from a model analogous to Equation 1 that partials out pretreatment trends, as suggested by Goodman-Bacon (2018). To do so, I calculate residuals from a regression of demeaned variables for all counties and all years and then estimate Equation 1 using these residualized variables to avoid any bias resulting from estimating group specific trends off the full set of data. Estimates for HIV rates are similar across all columns and indicate statistically significant reductions ranging from 17.319.3 percent. These findings are larger in magnitude than the main results presented in Table 2 suggesting that trends in counties with SEPs followed a different trajectory in after the introduction of a new program. Alternatively, mortality estimates are similar to the main results, and indicate an 20.5 percent increase in opioid-related mortality.

\footnotetext{
${ }^{36} \mathrm{I}$ acknowledge that both could be affected by increases in injection drug use. However, since these outcomes rank in the top 10 reasons for death in the United States, and are more likely to pick up compositional changes for adults aged 18-60, or changes in risky behavior.

${ }^{37}$ Similarly, SEP openings have no affect on gonorrhea rates.

${ }^{38}$ Ideally, this analysis would also be able to speak to how SEPs affect rates of hepatitis C, another bloodborne illness that can be contracted through needle sharing. However, county-level data for hepatitis $\mathrm{C}$ are unavailable. When I estimate how SEPs affect state-level diagnoses of hepatitis C, estimates on the effects of SEPs on hepatitis C rates are small and close to zero, and I can rule out reductions greater than 0.03 percent. This is consistent with previous work suggesting that SEPs mostly address the spread of disease through the channel of reducing HIV and are ineffective at reducing hepatitis C (Pollack 2001).

${ }^{39} \mathrm{I}$ additionally find no effects of SEP openings on county-level HIV prevalence, indicating that any reduction in bloodborne illness by SEPs yields small aggregate effects.
} 


\section{Conclusion}

In this paper, I document the effects of expanding access to clean needles and opioid-related counseling through syringe exchange programs. Using county-level data on HIV cases, drug-related mortality, hospitalizations, and drug-related crimes, I compare health outcomes in counties that experienced a SEP opening from 2009-2016 to counties without a SEP. Consistent with the previous literature, I find that syringe exchange programs reduce HIV diagnoses by up to 18.2 percent, or nearly 2 fewer cases of HIV per county per year. However, I present new evidence that SEPs generate unintended consequences. In particular, I find that a SEP opening corresponds to an average increase in drug-related mortality by 11.6 percent and opioidrelated mortality by 25.4 percent, and that these effects grow over time. Moreover, I provide some evidence that opioid-related emergency room visits and arrests for opioid possession increase after the opening of a SEP.

Overall, these estimates correspond to almost 4 more drug-related deaths per county each year, or over 6,000 drug-related deaths across the US. Effects are concentrated in rural and high-poverty areas, suggesting that low-income individuals living in areas with fewer health care resources may face larger hurdles in obtaining drug counseling and/or substance abuse treatment.

I note that my findings imply that SEPs do little to reduce drug overdoses, and may even exacerbate opioid abuse and misuse. However, the results do not suggest that SEPs are ineffective at curbing addiction for all clients. Furthermore, the stated goal of SEPs is to provide counseling and other resources for injection drug users while ensuring the safe disposal of used needles in an effort to reduce bloodborne illness. That being said, SEPs are successful in preventing additional HIV diagnoses, which increases total social welfare. On the other hand, if SEPs perpetuate crime and drug use, the introduction of such programs generate large negative externalities that reduce total social welfare. Since HIV has increasingly become a manageable disease with available treatment, these effects imply the increases in opioid misuse and mortality may largely outweigh the reduction in bloodborne illness in terms of societal costs.

Importantly, the primary goal of SEPs is to provide clean supplies to injection drug users in a safe environment with the intent of reducing needle sharing, while drug counseling and treatment referral are secondary services. Given the aims of harm reduction services, it is perhaps unsurprising that SEPs are more effective at preventing the spread of bloodborne illness than reducing opioid dependence. Given the well-documented benefits of substance abuse treatment facilities, my findings suggest that providing funding for these clinics and increasing access may be a more fruitful avenue for reducing drug-related mortality and financially motivated crimes (Swensen, 2015, Bondurant, Lindo, and Swensen, 2018). Moreover, prescription drugs, such as Buprenorphine that reduce symptoms of opiate addiction and withdrawal, or other opiate 
antagonists, which work in the brain to prevent opiate effects and decreases the desire to take opiate, could be one way for SEPs to mitigate clients' opioid dependence in the future. Policymakers and the public health community more broadly should be careful to consider all costs and benefits of SEPs, including long-run effects generated by lowering the costs of consuming injection drugs. In the wake of increased drug-related deaths and state policies to curb this epidemic, my estimates shed new light on how local policies can affect syringe sharing, drug overdose, and drug-related crime. Thus, it will become increasingly important for future research to determine the extent and scope of how expanding (or reducing) access to SEPs affects bloodborne illness and drug use more broadly. 


\section{References}

Bao, Y., Y. Pan, A. Taylor, S. Radakrishnan, F. Luo, H. Pincus, and B. Schackman (2016): "Prescription Drug Monitoring Programs are Associated with Sustained Reductions in Opioid Prescribing by Physicians," Health Affairs, 35(6), 1045-1051.

Bondurant, S. R., J. M. Lindo, and I. D. Swensen (2018): "Substance Abuse Treatment Centers and Local Crime," Journal of Urban Economics, 104, 124-133.

Borusyak, K., and X. Jaravel (2017): "Revisiting Event Study Designs, with an Application to the Estimation of the Marginal Propensity to Consume," Working paper.

Bradford, A., W. D. Bradford, A. Abraham, and G. B. Adams (2018): "Association Between US State Medical Cannabis Laws and Opioid Prescribing in the Medicare Part D Population," JAMA Internal Medicine, 178(5), 667-672.

Buchmueller, T. C., and C. Carey (2018): "The Effect of Prescription Drug Monitoring Programs on Opioid Utilization in Medicare," American Economic Journal: Economic Policy, 10(1), 77-112.

Case, A., and A. Deaton (2017): "Mortality and Morbidity in the 21st Century," Working paper, Brookings Papers on Economic Activity.

Centers for Disease Control and Prevention (2015): "NCHHSTP Atlas," Accessed 19-November-2016 at http://www.cdc.gov/nchhstp/atlas/.

- (2016): "Use of syringe services programs increases, but access must improve for greater HIV prevention," Accessed 31-July-2018 at https://www.cdc.gov/media/releases/2016/ p1129-HIV-syringe-services.html.

Dave, D. M., A. M. Grecu, and H. Saffer (2017): "Mandatory Access Prescription Drug Monitoring Programs and Prescription Drug Abuse," Working Paper 23537, National Bureau of Economic Research.

DeSimone, J. (2005): "Needle Exchange Programs and Drug Injection Behavior," Journal of Policy Analysis and Management, 24(3), 559-577.

Doleac, J. L., and A. Mukherjee (2018): "The Moral Hazard of Lifesaving Innovations: Naloxone Access, Opioid Abuse, and Crime," "Working Paper. Available at https://justicetechlab.github.io/ jdoleac-website/research/Doleac_Mukherjee_Naloxone.pdf ".

General Accounting Office (1993): "Needle Exchange Programs: Research Suggests Promise as an AIDS Prevention Strategy," Washington DC: US Government Printing Office.

Goodman-Bacon, A. (2018): "Difference-in-Differences with Variation in Treatment Timing," Working Paper 25018, National Bureau of Economic Research.

Haegerich, T., L. Paulozzi, B. Manns, and C. Jones (2014): "What We Know, and Don't Know, About the Impact of State Policy and Systems-Level Interventions on Prescription Drug Overdose," Drug and Alcohol Dependence, $145,34-47$.

Hollingsworth, A., C. J. Ruhm, and K. Simon (2017): "Macroeconomic Conditions and Opioid Abuse," Journal of Health Economics, 56, 222-223.

Jarlais, D. C. D., V. Guardino, A. Nugent, and A. Solberg (2014): "The Dave Purchase Memorial 2014 National Survey of Syringe Exchange Programs: Summary of Results," Discussion paper, Beth Israel Presentation Slides from 2014 Harm Reduction Conference.

LawAtlas (2017): "Syringe Distribution Laws, Policy Surveillance Portal," Accessed 31-August-2017 at lawatlas.org/datasets/syringe-policies-laws-regulating-non-retail-distribution-of-drug-parapherna. 
Lopez, G. (2018): "Why America's Cocaine Problem is now a Fentanyl Problem Too," Accessed 05-July-2019 at https://www.vox.com/science-and-health/2018/5/4/17307296/ cocaine-opioid-crisis-fentanyl-overdose

Mallatt, J. (2017): "The Effect of Prescription Drug Monitoring Programs on Opioid Prescriptions and Heroin Crime Rates," Working Paper.

Meara, E., J. R. Horwitz, W. Powell, L. McClelland, W. Zhou, A. J. O'Malley, and N. E. Morden (2016): "State Legal Restrictions and Prescription Opioid Use among Disabled Adults," The New England Journal of Medicine, 375, 44-53.

Pollack, H. A. (2001): "Cost-Effectiveness of Harm Reduction in Preventing Hepatitis C among Injection Drug Users," Medical Decision Making, 21, 357-367.

Rees, D. I., J. J. Sabia, L. M. Argys, J. Latshaw, and D. Dave (2017): "With a Little Help from My Friends: The Effects of Naloxone Access and Good Samaritan Laws on Opioid-Related Deaths," Working Paper.

Ruhm, C. J. (2017): "Geographic Variation in Opioid and Heroin Involved Drug Poisoning Mortality Rates," American Journal of Preventative Medicine, 53, 745-753.

Schnell, M., and J. Currie (2017): "Addressing the Opioid Epidemic: Is There a Role for Physician Education?," Working Paper 23645, National Bureau of Economic Research.

Sean Cahill and Nathan Schaefer (2009): "Syringe Exchange Programs Around the World: The Global Context," Accessed 31-July-2018 at http://www.gmhc.org/files/editor/file/gmhc_intl_seps.pdf.

Simon, K., A. Soni, and J. Cawley (2017): "The Impact of Health Insurance on Preventative Care and Health Behavior: Evidence from the First Two Years of the ACA Medicaid Expansions," Journal of Policy Analysis and Management, 36, 390-417.

Solon, G., S. Haider, and J. Wooldridge (2015): "What Are We Weighting For," Jounral of Human Resources, $50(2), 301-316$.

Swensen, I. D. (2015): "Substance-Abuse Treatment and Mortality," Journal of Public Economics, 122, $13-30$.

United States Census Bureau (2016): "ACS Demographic and Housing Estimates," Accessed 09-August-2018 at https://factfinder.census.gov/,

U.S. Department of Justice (2015): "2015 National Drug Threat Assessment Summary," Accessed 31-July2018 at https://www.dea.gov/docs/2015\%20NDTA\%20Report.pdf.

Waitemata District Health Borad (2014): "Palliative Care: Opioid Conversion Guide," .

Wolfers, J. (2006): "Did Unilateral Divorce Laws Raise Divorce? A Reconciliation and New Results," American Economic Review, 96, 1802-1820.

World Health Organization (2004): "Effectiveness of Sterile Needle and Syringe Programming in Reducing HIV/AIDS Among Injecting Drug Users," Evidence for Action Technical Papers. 
Table 1: Summary Statistics

\begin{tabular}{lcc}
\hline \hline & $\begin{array}{c}\text { Treated Counties } \\
(N=79)\end{array}$ & $\begin{array}{c}\text { Comparison Counties } \\
(N=1,491)\end{array}$ \\
County-Level Variables & & \\
\hline HIV and Mortality Rates & & 5.82 \\
HIV Diagnoses & 10.78 & 16.57 \\
Drug-Related Mortality & 18.85 & 9.85 \\
Opioid-Related Mortality & 12.34 & 3.53 \\
Illicit Opioid-Related Mortality & 5.35 & \\
Crime Rates & & 377.52 \\
Drug Arrests & 387.92 & 17.23 \\
Opioid-Related Sale Arrests & 29.94 & 0.38 \\
Opioid-Related Possession Arrests & 0.67 & \\
County Characteristics & & 137196 \\
Population & 552762 & 0.60 \\
Rural & 0.35 & 15.96 \\
Percent Poverty Rate & 17.21 & 8.10 \\
Unemployment Rate & 7.59 & 0.07 \\
Percent Hispanic & 0.12 & 0.09 \\
Percent Black & 0.12 & \\
State-Level Variables & & \\
Opioid-Related Hospitalization Rates & & \\
Emergency Department Admissions & 172.61 & 146.59 \\
In-Patient Hospital Visits & 250.40 & 219.14 \\
Policy Indicators & & \\
Prescription Limits & 0.97 & 0.98 \\
Tamper-Resistant Prescription & 0.67 & 0.50 \\
ID Requirement & 0.37 & 0.45 \\
Doctor Shopping Restrictions & 0.29 & 0.31 \\
Physician Exam Requirements & 0.70 & 0.77 \\
Pain Clinic Regulations & 0.56 & 0.15 \\
Pharmacist Verification & 0.30 & 0.45 \\
Paraphernalia Laws & 0.25 & 0.27 \\
Good Samaritan Laws & 0.40 & 0.79 \\
Prescription Drug Monitoring Program & 0.83 & 0.25 \\
Naloxone Laws & 0.30 & \\
\hline \hline
\end{tabular}

Notes: Data on HIV diagnoses is from the CDC NCHHSTP Atlas and 34 state agencies. Drug-related deaths are based on the National Center for Health Statistics (NCHS), Division of Vital Statistics Mortality Files. Unemployment rates are from the BLS. State-by-year opioid-related hopsitalizations data are from the Healthcare Cost Utilization Project (HCUP). Information on state-level policy changes is from Meara, Horwitz, Powell, McClelland, Zhou, O'Malley, and Morden (2016), Doleac and Mukherjee (2018), and the LawAtlas Policy Surveillance Program. Column 1 shows the means for treated counties in the sample, i.e., counties with a syringe exchange program opening from 2009-2016. Column 2 displays the means for the comparison counties, i.e., other US counties without a syringe exchange program. Rates are calculated as cases per 100,000 individuals. 
Table 2: The Effect of a Syringe Exchange Program on HIV Diagnoses Rates, Difference-in-Differences Estimates Using Counties Without SEPs for Comparison

\begin{tabular}{lcccccc}
\hline \hline & $(1)$ & $(2)$ & $(3)$ & $(4)$ & $(5)$ & $(6)$ \\
Average Effect of SEP & $-0.790^{*}$ & -0.697 & -0.563 & -0.530 & -0.038 & 0.277 \\
& $(0.431)$ & $(0.426)$ & $(0.443)$ & $(0.450)$ & $(0.423)$ & $(0.462)$ \\
& & & & & & 0.470 \\
& & & & & $0.375)$ \\
One-Year Lead & & & & & 6.20 \\
& 6.20 & 6.20 & 6.20 & 6.20 & 6.20 & 6.20 \\
Mean & 14094 & 14094 & 14094 & 14094 & 14094 & 14094 \\
Observations & & & & & & Yes \\
County and Year Fixed Effects & Yes & Yes & Yes & Yes & Yes & Yes \\
Demographic and Economic Controls & No & Yes & Yes & Yes & Yes & Yes \\
State-Level Policy Controls & No & No & Yes & Yes & Yes & Yes \\
State-by-Year Fixed Effects & No & No & No & Yes & Yes & Yes \\
County-Specific Linear Time Trends & No & No & No & No & Yes & \\
\hline \hline
\end{tabular}

Notes: Estimates are based CDC and state agency data on HIV diagnoses counts by county for the entire United States from $2008-2016$. Rates are calculated as cases per 100,000 individuals. Economic control variables include the county-level poverty rate and unemployment rate, demographic controls include percent Hispanic and percent black, and state-level policy controls include whether a state imposes quantitative prescription limit, tamper-resistant prescription forms, pain clinic regulations, patient identification requirements, doctor shopping restrictions, requirements with respect to physician examination or pharmacist verification, prescription drug monitoring programs, paraphernalia laws, and good Samaritan laws. Standard errors are clustered at the county level. $*, * *$, and $* * *$ indicate statistical significance at the ten, five, and one percent levels, respectively. 
Table 3: The Effect of a Syringe Exchange Program on Drug-Related Mortality Rates, Difference-in-Differences Estimates Using Counties Without a SEP for Comparison

\begin{tabular}{lcccccc}
\hline \hline & $(1)$ & $(2)$ & $(3)$ & $(4)$ & $(5)$ & $(6)$ \\
Drug-Related Mortality (X40-44) & & & & & \\
Average Effect of SEP & $2.373^{* *}$ & $2.442^{* *}$ & $2.128^{*}$ & $2.296^{* *}$ & $1.927^{*}$ & $2.953^{* *}$ \\
& $(1.133)$ & $(1.123)$ & $(1.111)$ & $(1.101)$ & $(0.989)$ & $(1.468)$ \\
One-Year Lead & & & & & & 1.529 \\
& & & & & & $(1.237)$ \\
Mean & 16.68 & 16.68 & 16.68 & 16.68 & 16.68 & 16.68 \\
Observations & 14121 & 14121 & 14121 & 14121 & 14121 & 14121 \\
& & & & & \\
Opioid-Related Mortality (T40.0-40.4 and T40.6) & & & & & \\
Average Effect of SEP & $2.623^{* *}$ & $2.739^{* *}$ & $2.335^{* *}$ & $2.472^{* *}$ & $2.489^{* * *}$ & $2.912^{* *}$ \\
& $(1.084)$ & $(1.083)$ & $(1.062)$ & $(1.060)$ & $(0.917)$ & $(1.307)$ \\
One-Year Lead & & & & & & 0.630 \\
& & & & & & $(1.034)$ \\
Mean & 9.78 & 9.78 & 9.78 & 9.78 & 9.78 & 9.78 \\
Observations & 14121 & 14121 & 14121 & 14121 & 14121 & 14121 \\
& & & & & \\
Illicit Opioid-Related Mortality & T40.1 and T40.4) & & & & \\
Average Effect of SEP & $3.458^{* * *}$ & $3.495^{* * *}$ & $2.957^{* * *}$ & $3.046^{* * *}$ & $1.720^{* *}$ & $2.234^{* *}$ \\
& $(1.033)$ & $(1.030)$ & $(0.999)$ & $(0.993)$ & $(0.747)$ & $(0.942)$ \\
One-Year Lead & & & & & & 0.766 \\
& & & & & & $(0.630)$ \\
Mean & 3.72 & 3.72 & 3.72 & 3.72 & 3.72 & 3.72 \\
Observations & 14121 & 14121 & 14121 & 14121 & 14121 & 14121 \\
& & & & & & \\
County and Year Fixed Effects & Yes & Yes & Yes & Yes & Yes & Yes \\
Demographic and Economic Controls & No & Yes & Yes & Yes & Yes & Yes \\
State-Level Policy Controls & No & No & Yes & Yes & Yes & Yes \\
State-by-Year Fixed Effects & No & No & No & Yes & Yes & Yes \\
County-Specific Linear Time Trends & No & No & No & No & Yes & Yes \\
\hline \hline
\end{tabular}

Notes: Estimates are based on NCHS restricted mortality files by county for the entire United States from 2008-2016. Rates are calculated as cases per 100,000 individuals. Economic control variables include the county-level poverty rate and unemployment rate, demographic controls include percent Hispanic and percent black, and state-level policy controls include whether a state imposes quantitative prescription limit, tamper-resistant prescription forms, pain clinic regulations, patient identification requirements, doctor shopping restrictions, requirements with respect to physician examination or pharmacist verification, prescription drug monitoring programs, paraphernalia laws, and good Samaritan laws. Standard errors are clustered at the county level.

$*, * *$, and $* * *$ indicate statistical significance at the ten, five, and one percent levels, respectively. 
Table 4: The Effect of a Syringe Exchange Program on Opioid-Related Hospital Visits, Difference-in-Differences Estimates using States Without SEPs for Comparison

\begin{tabular}{lcccc}
\hline \hline & $(1)$ & $(2)$ & $(3)$ & $(4)$ \\
Emergency Room Admission Rate & & & & \\
Average Effect of SEP & $23.822^{* *}$ & $20.775^{* *}$ & 13.484 & 10.462 \\
& $(10.214)$ & $(9.250)$ & $(9.316)$ & $(12.341)$ \\
One-Year Lead & & & & -5.743 \\
& & & & $(7.636)$ \\
Mean & 150.75 & 150.75 & 150.75 & 150.75 \\
Observations & 258 & 258 & 258 & 258 \\
In-Patient Stay Rate & & & & \\
Average Effect of SEP & & & & \\
& $15.053^{* *}$ & $12.502^{*}$ & 7.022 & 10.670 \\
One-Year Lead & $(7.331)$ & $(6.757)$ & $(7.195)$ & $(9.404)$ \\
& & & & 6.994 \\
Mean & 209.26 & 209.26 & 209.26 & 209.26 \\
Observations & 375 & 375 & 375 & 375 \\
County and Year Fixed Effects & Yes & Yes & Yes & Yes \\
Demographic and Economic Controls & No & Yes & Yes & Yes \\
State-Level Policy Controls & No & No & Yes & Yes \\
\hline \hline
\end{tabular}

Notes: Estimates are based on state-level opioid-related emergency room visits from the Healthcare Cost Utilization Project for 20082016. Rates are calculated as cases per 100,000 individuals. Economic control variables include the state-level poverty rate and unemployment rate, demographic controls include percent Hispanic and percent black, and policy controls include whether a state imposes quantitative prescription limit, tamper-resistant prescription forms, pain clinic regulations, patient identification requirements, doctor shopping restrictions, requirements with respect to physician examination or pharmacist verification, prescription drug monitoring programs, paraphernalia laws, and good Samaritan laws. Standard errors are clustered at the state level.

$*^{* *}$, and ${ }^{* *}$ indicate statistical significance at the ten, five, and one percent levels, respectively. 
Table 5: The Effect of a Syringe Exchange Program on HIV Diagnoses Rates and Opioid-Related Mortality Rates by Subgroup

\begin{tabular}{|c|c|c|c|c|c|}
\hline & $\begin{array}{c}\text { Counties W/Out } \\
\text { SEPs }\end{array}$ & $\begin{array}{c}\text { Urban } \\
\text { Counties }\end{array}$ & $\begin{array}{c}\text { Rural } \\
\text { Counties }\end{array}$ & $\begin{array}{l}\text { Low Pov. } \\
\text { Counties }\end{array}$ & $\begin{array}{l}\text { High Pov. } \\
\text { Counties }\end{array}$ \\
\hline & (1) & (2) & (3) & (4) & $(5)$ \\
\hline \multicolumn{6}{|l|}{ HIV Rate } \\
\hline Average Effect of SEP & $\begin{array}{l}-0.038 \\
(0.423)\end{array}$ & $\begin{array}{c}0.379 \\
(0.642)\end{array}$ & $\begin{array}{l}-0.781^{*} \\
(0.432)\end{array}$ & $\begin{array}{l}-0.600 \\
(0.418)\end{array}$ & $\begin{array}{c}0.668 \\
(0.783)\end{array}$ \\
\hline Mean & 6.20 & 9.06 & 4.30 & 5.01 & 7.87 \\
\hline Observations & 14094 & 5643 & 8451 & 8190 & 5904 \\
\hline \multicolumn{6}{|l|}{ Opioid-Related Mortality Rate } \\
\hline Average Effect of SEP & $\begin{array}{c}2.489^{* * *} \\
(0.917)\end{array}$ & $\begin{array}{c}1.851 \\
(1.248)\end{array}$ & $\begin{array}{c}2.794^{* *} \\
(1.288)\end{array}$ & $\begin{array}{c}1.122 \\
(1.026)\end{array}$ & $\begin{array}{c}4.311^{* * *} \\
(1.582)\end{array}$ \\
\hline Mean & 9.78 & 9.46 & 9.99 & 9.00 & 10.86 \\
\hline Observations & 14121 & 5643 & 8478 & 8217 & 5904 \\
\hline County and Year Fixed Effects & Yes & Yes & Yes & Yes & Yes \\
\hline Demographic and Economic Controls & Yes & Yes & Yes & Yes & Yes \\
\hline State-Level Policy Controls & Yes & Yes & Yes & Yes & Yes \\
\hline State-by-Year Fixed Effects & Yes & Yes & Yes & Yes & Yes \\
\hline County-Specific Linear Time Trends & Yes & Yes & Yes & Yes & Yes \\
\hline
\end{tabular}

Notes: See Table 2 and Table 3 Data on urbanicity is from the USDA. "Counties W/Out SEPs" represents the baseline sample, comparing counties with SEP openings to those without SEPs. "Urban" counties include metropolitan areas, while "Rural" counties include micropolitan areas, small towns, and rural areas. "High Pov." counties are defined as counties with poverty rates above the 2016 median poverty rate. "Low Pov." counties are those with poverty rates at or below this median. All specifications limit the sample to include counties with new SEPs or counties without SEPs.

$*, * *$, and ${ }^{* * *}$ indicate statistical significance at the ten, five, and one percent levels, respectively. 
Table 6: The Effect of a Syringe Exchange Program on HIV Diagnoses Rates and Opioid-Related Mortality by Region

\begin{tabular}{|c|c|c|c|c|c|}
\hline & Midwest & South & Northeast & "West & "Top 10" \\
\hline & $(1)$ & $(2)$ & $(3)$ & $(4)$ & $(5)$ \\
\hline \multicolumn{6}{|l|}{ HIV Rate } \\
\hline Average Effect of SEP & $\begin{array}{l}-0.256 \\
(0.712)\end{array}$ & $\begin{array}{c}0.554 \\
(0.988)\end{array}$ & $\begin{array}{c}0.649 \\
(0.832)\end{array}$ & $\begin{array}{l}-0.732 \\
(0.585)\end{array}$ & $\begin{array}{l}-0.054 \\
(0.774)\end{array}$ \\
\hline Mean & 3.03 & 8.56 & 5.70 & 3.43 & 3.09 \\
\hline Observations & 3582.00 & 7209.00 & 1557.00 & 1746.00 & 2628.00 \\
\hline \multicolumn{6}{|l|}{ Opioid-Related Mortality Rate } \\
\hline Average Effect of SEP & $\begin{array}{c}-0.042 \\
(1.570)\end{array}$ & $\begin{array}{c}7.679^{* * *} \\
(2.012)\end{array}$ & $\begin{array}{c}1.213 \\
(0.845)\end{array}$ & $\begin{array}{l}-0.370 \\
(1.028)\end{array}$ & $\begin{array}{c}8.512^{* * *} \\
(2.381)\end{array}$ \\
\hline Mean & 8.30 & 10.80 & 9.09 & 9.23 & 15.55 \\
\hline Observations & 3609.00 & 7209.00 & 1557.00 & 1746.00 & 2628.00 \\
\hline County and Year Fixed Effects & Yes & Yes & Yes & Yes & Yes \\
\hline Demographic and Economic Controls & Yes & Yes & Yes & Yes & Yes \\
\hline State-Level Policy Controls & Yes & Yes & Yes & Yes & Yes \\
\hline State-by-Year Fixed Effects & Yes & Yes & Yes & Yes & Yes \\
\hline County-Specific Linear Time Trends & Yes & Yes & Yes & Yes & Yes \\
\hline
\end{tabular}

Notes: See Table 2 and Table 3 For US Census Bureau definitions of region, see https://www.census.gov/geo/reference/webatlas/ regions.html "Top 10" states include those most affected by the opioid epidemic, according to the CDC. "Top 10" states are West Virginia, Ohio, Pennsylvania, District of Columbia, New Hampshire, Kentucky, Maine, Connecticut, Delaware, Massachusetts.

${ }^{*}, * *$, and ${ }^{* * *}$ indicate statistical significance at the ten, five, and one percent levels, respectively. 
Table 7: The Effect of a Syringe Exchange Program on Opioid-Related Mortality Rates by Age, Race, Ethnicity, and Gender Subgroups

\begin{tabular}{|c|c|c|c|c|c|c|c|c|c|c|}
\hline & All & $20-29$ & 30-39 & $40-49$ & $50-59$ & Black & Hispanic & White & Male & Female \\
\hline & (1) & (2) & (3) & (4) & (5) & (6) & (7) & (8) & (9) & (10) \\
\hline Average Effect of SEP & $\begin{array}{c}2.489^{* * *} \\
(0.917)\end{array}$ & $\begin{array}{c}0.119 \\
(0.095)\end{array}$ & $\begin{array}{c}0.456 \\
(0.335)\end{array}$ & $\begin{array}{c}0.312 \\
(0.346)\end{array}$ & $\begin{array}{l}0.594^{*} \\
(0.336)\end{array}$ & $\begin{array}{c}0.283^{* *} \\
(0.140)\end{array}$ & $\begin{array}{c}0.072 \\
(0.149)\end{array}$ & $\begin{array}{l}1.842^{* *} \\
(0.900)\end{array}$ & $\begin{array}{c}2.011^{* * *} \\
(0.714)\end{array}$ & $\begin{array}{c}0.478 \\
(0.426)\end{array}$ \\
\hline Mean & 9.78 & 0.36 & 2.56 & 3.17 & 3.44 & 0.32 & 0.29 & 14.50 & 6.04 & 3.74 \\
\hline Observations & 14121 & 14121 & 14121 & 14121 & 14121 & 14121 & 14121 & 14121 & 14121 & 14121 \\
\hline County and Year Fixed Effects & Yes & Yes & Yes & Yes & Yes & Yes & Yes & Yes & Yes & Yes \\
\hline Demographic and Economic Controls & Yes & Yes & Yes & Yes & Yes & Yes & Yes & Yes & Yes & Yes \\
\hline State-Level Policy Controls & Yes & Yes & Yes & Yes & Yes & Yes & Yes & Yes & Yes & Yes \\
\hline State-by-Year Fixed Effects & Yes & Yes & Yes & Yes & Yes & Yes & Yes & Yes & Yes & Yes \\
\hline County-Specific Linear Time Trends & Yes & Yes & Yes & Yes & Yes & Yes & Yes & Yes & Yes & Yes \\
\hline
\end{tabular}

Notes: See Table 3 Column 1 presents the baseline estimates. Columns $2-4$ show estimates by age subgroup for individuals aged 20-29, 30-39, 40-49, and 50-59, respectively. "Black" indicates estimates for Black individuals, "Hispanic" indicates estimates for non-White Hispanic individuals, and "White" indicates estimates for White individuals. "Male" indicates estimates for males, "Female" indicates estimates for females.

${ }^{*}, * *$, and ${ }^{* * *}$ indicate statistical significance at the ten, five, and one percent levels, respectively. 
Table 8: The Effect of a Syringe Exchange Program on Opioid-Related Hospital Visits by Age and Gender Subgroups

\begin{tabular}{|c|c|c|c|c|c|}
\hline & All & $25-44$ & 4 45-64 & Male & Female \\
\hline & (1) & $(2)$ & $(3)$ & (4) & (5) \\
\hline \multicolumn{6}{|l|}{ Emergency Room Admission Rate } \\
\hline Average Effect of SEP & $\begin{array}{c}16.250^{*} \\
(9.211)\end{array}$ & $\begin{array}{c}62.818^{* *} \\
(26.715)\end{array}$ & $\begin{array}{c}2.021 \\
(8.722)\end{array}$ & $\begin{array}{c}18.095 \\
(12.089)\end{array}$ & $\begin{array}{c}14.472^{* *} \\
(6.910)\end{array}$ \\
\hline Mean & 150.75 & 288.19 & 149.10 & 166.04 & 136.21 \\
\hline Observations & 258 & 258 & 258 & 258 & 258 \\
\hline \multicolumn{6}{|l|}{ In-Patient Stay Rate } \\
\hline Average Effect of SEP & $\begin{array}{l}10.408 \\
(7.104)\end{array}$ & $\begin{array}{c}23.802^{*} \\
(14.118)\end{array}$ & $\begin{array}{l}15.363 \\
(9.494)\end{array}$ & $\begin{array}{l}10.818 \\
(7.260)\end{array}$ & $\begin{array}{c}9.780 \\
(7.335)\end{array}$ \\
\hline Mean & 209.26 & 299.00 & 285.53 & 204.17 & 214.52 \\
\hline Observations & 375 & 375 & 375 & 375 & 375 \\
\hline County and Year Fixed Effects & Yes & Yes & Yes & Yes & Yes \\
\hline Demographic and Economic Controls & Yes & Yes & Yes & Yes & Yes \\
\hline State-Level Policy Controls & Yes & Yes & Yes & Yes & Yes \\
\hline
\end{tabular}

Notes: See Table 4 Column 1 presents the baseline estimates for all hospital visits. Columns $2-3$ show estimates by age subgroup for individuals aged 25-44 and 45-64, respectively. "Male" indicates estimates for males; "Female" indicates estimates for females.

$*, * *$, and ${ }^{* * *}$ indicate statistical significance at the ten, five, and one percent levels, respectively. 
Table 9: The Effect of a Syringe Exchange Program on Drug-Related Arrest Rates, Difference-in-Differences Estimates using Counties Without SEPs for Comparison

\begin{tabular}{|c|c|c|c|c|c|c|}
\hline & $(1)$ & $\overline{(2)}$ & (3) & (4) & 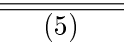 & 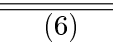 \\
\hline \multicolumn{7}{|l|}{ Total Drug Crime Rate } \\
\hline Average Effect of SEP & $\begin{array}{c}-14.775 \\
(15.953)\end{array}$ & $\begin{array}{l}-13.647 \\
(15.944)\end{array}$ & $\begin{array}{c}-10.940 \\
(15.766)\end{array}$ & $\begin{array}{c}-9.455 \\
(15.642)\end{array}$ & $\begin{array}{l}-25.222 \\
(18.437)\end{array}$ & $\begin{array}{l}-36.025 \\
(23.622)\end{array}$ \\
\hline One-Year Lead & & & & & & $\begin{array}{l}-16.098 \\
(16.770)\end{array}$ \\
\hline Mean & 403.34 & 403.34 & 403.34 & 403.34 & 403.34 & 403.34 \\
\hline Observations & 14115 & 14115 & 14115 & 14115 & 14115 & 14115 \\
\hline \multicolumn{7}{|l|}{ Opioid-Related Drug Sale Rate } \\
\hline Average Effect of SEP & $\begin{array}{c}2.511 \\
(2.608)\end{array}$ & $\begin{array}{c}2.807 \\
(2.598)\end{array}$ & $\begin{array}{c}2.544 \\
(2.570)\end{array}$ & $\begin{array}{c}2.477 \\
(2.575)\end{array}$ & $\begin{array}{l}-4.930 \\
(3.681)\end{array}$ & $\begin{array}{l}-6.971 \\
(5.189)\end{array}$ \\
\hline One-Year Lead & & & & & & $\begin{array}{l}-3.041 \\
(3.615)\end{array}$ \\
\hline Mean & 23.06 & 23.06 & 23.06 & 23.06 & 23.06 & 23.06 \\
\hline Observations & 14115 & 14115 & 14115 & 14115 & 14115 & 14115 \\
\hline \multicolumn{7}{|l|}{ Opioid-Related Possession Rate } \\
\hline Average Effect of SEP & $\begin{array}{c}14.829 * * \\
(6.315)\end{array}$ & $\begin{array}{c}15.058^{* *} \\
(6.296)\end{array}$ & $\begin{array}{c}12.783^{* *} \\
(6.406)\end{array}$ & $\begin{array}{c}12.607^{*} \\
(6.447)\end{array}$ & $\begin{array}{c}5.699 \\
(4.708)\end{array}$ & $\begin{array}{c}7.170 \\
(5.270)\end{array}$ \\
\hline One-Year Lead & & & & & & $\begin{array}{c}2.192 \\
(3.060)\end{array}$ \\
\hline Mean & 44.83 & 44.83 & 44.83 & 44.83 & 44.83 & 44.83 \\
\hline Observations & 14115 & 14115 & 14115 & 14115 & 14115 & 14115 \\
\hline County and Year Fixed Effects & Yes & Yes & Yes & Yes & Yes & Yes \\
\hline Demographic and Economic Controls & No & Yes & Yes & Yes & Yes & Yes \\
\hline State-Level Policy Controls & No & No & Yes & Yes & Yes & Yes \\
\hline State-by-Year Fixed Effects & No & No & No & Yes & Yes & Yes \\
\hline County-Specific Linear Time Trends & No & No & No & No & Yes & Yes \\
\hline
\end{tabular}

Notes: Estimates are based on FBI Uniform Crime Reports by county for the entire United States from 2008-2016. Rates are calculated as cases per 100,000 individuals. Economic control variables include the county-level poverty rate and unemployment rate, demographic controls include percent Hispanic and percent black, and state-level policy controls include whether a state imposes quantitative prescription limit, tamper-resistant prescription forms, pain clinic regulations, patient identification requirements, doctor shopping restrictions, requirements with respect to physician examination or pharmacist verification, prescription drug monitoring programs, paraphernalia laws, and good Samaritan laws. Standard errors are clustered at the county level.

$*,{ }^{* *}$, and ${ }^{* * *}$ indicate statistical significance at the ten, five, and one percent levels, respectively. 
Table 10: OLS, WLS, and Poisson Estimates from a Difference-in-Differences Model using Counties Without SEPs for Comparison

\begin{tabular}{|c|c|c|c|c|c|c|c|c|c|}
\hline & \multicolumn{3}{|c|}{ OLS } & \multicolumn{3}{|c|}{ WLS } & \multicolumn{3}{|c|}{ Poisson } \\
\hline & (1) & (2) & (3) & (4) & (5) & (6) & (7) & (8) & (9) \\
\hline \multicolumn{10}{|l|}{ HIV Diagnoses } \\
\hline Average Effect of SEP & $\begin{array}{l}-0.530 \\
(0.450)\end{array}$ & $\begin{array}{l}-0.038 \\
(0.423)\end{array}$ & $\begin{array}{c}0.277 \\
(0.461)\end{array}$ & $\begin{array}{l}-0.817 \\
(1.075)\end{array}$ & $\begin{array}{l}0.859^{*} \\
(0.492)\end{array}$ & $\begin{array}{c}1.019^{* *} \\
(0.483)\end{array}$ & $\begin{array}{c}0.010 \\
(0.046)\end{array}$ & $\begin{array}{l}0.039^{*} \\
(0.022)\end{array}$ & $\begin{array}{l}0.043^{*} \\
(0.025)\end{array}$ \\
\hline One-Year Lead & & & $\begin{array}{c}0.470 \\
(0.375)\end{array}$ & & & $\begin{array}{c}0.230 \\
(0.455)\end{array}$ & & & $\begin{array}{c}0.006 \\
(0.030)\end{array}$ \\
\hline Mean & 6.20 & 6.20 & 6.20 & 6.20 & 6.20 & 6.20 & 19.30 & 19.30 & 19.30 \\
\hline Observations & 14094 & 14094 & 14094 & 14094 & 14094 & 14094 & 11790 & 11790 & 11790 \\
\hline \multicolumn{10}{|l|}{ Opioid-Related Deaths } \\
\hline Average Effect of SEP & $\begin{array}{r}2.461^{* *} \\
(1.056)\end{array}$ & $\begin{array}{c}2.493^{* * *} \\
(0.917)\end{array}$ & $\begin{array}{c}2.916^{* *} \\
(1.308)\end{array}$ & $\begin{array}{c}0.940 \\
(0.792)\end{array}$ & $\begin{array}{c}0.334 \\
(0.566)\end{array}$ & $\begin{array}{c}0.255 \\
(0.742)\end{array}$ & $\begin{array}{c}0.022 \\
(0.059)\end{array}$ & $\begin{array}{c}-0.012 \\
(0.047)\end{array}$ & $\begin{array}{l}-0.039 \\
(0.064)\end{array}$ \\
\hline One-Year Lead & & & $\begin{array}{c}0.630 \\
(1.034)\end{array}$ & & & $\begin{array}{l}-0.113 \\
(0.455)\end{array}$ & & & $\begin{array}{l}-0.038 \\
(0.038)\end{array}$ \\
\hline Mean & 9.79 & 9.79 & 9.79 & 9.79 & 9.79 & 9.79 & 12.86 & 12.86 & 12.86 \\
\hline Observations & 14085 & 14085 & 14085 & 14085 & 14085 & 14085 & 14085 & 14085 & 14085 \\
\hline County and Year Fixed Effects & Yes & Yes & Yes & Yes & Yes & Yes & Yes & Yes & Yes \\
\hline Demographic and Economic Controls & Yes & Yes & Yes & Yes & Yes & Yes & Yes & Yes & Yes \\
\hline State-Level Policy Controls & Yes & Yes & Yes & Yes & Yes & Yes & Yes & Yes & Yes \\
\hline State-by-Year Fixed Effects & Yes & Yes & Yes & Yes & Yes & Yes & Yes & Yes & Yes \\
\hline County-Specific Linear Time Trends & No & Yes & Yes & No & Yes & Yes & No & Yes & Yes \\
\hline
\end{tabular}

Notes: See Table 2 and Table 3 Columns 1-6 display the effects of SEPs on HIV and opioid-related mortality rates, while Columns 7-9 show estimates for HIV cases and opioid-related deaths. Estimates in Columns 4-6 are weighted by county population. $*, * *$, and ${ }^{* * *}$ indicate statistical significance at the ten, five, and one percent levels, respectively. 
Table 11: The Effect of a Syringe Exchange Program on HIV Diagnoses Rates and Opioid-Related Mortality Rates by Population Size

\begin{tabular}{|c|c|c|c|c|c|c|c|c|c|c|c|c|}
\hline \multirow[b]{3}{*}{ HIV Rate } & \multicolumn{4}{|c|}{$\begin{array}{c}\text { All } \\
\text { Counties }\end{array}$} & \multicolumn{4}{|c|}{$\begin{array}{c}\text { Counties with Population } \\
>\text { Median }\end{array}$} & \multicolumn{4}{|c|}{$\begin{array}{c}\text { Counties with Population } \\
<\text { Median }\end{array}$} \\
\hline & (1) & $(2)$ & (3) & $(4)$ & $(5)$ & $(6)$ & $(7)$ & $(8)$ & $(9)$ & $(10)$ & $(11)$ & $(12)$ \\
\hline & & & & & & & & & & & & \\
\hline Average Effect of SEP & $\begin{array}{l}-0.207 \\
(0.413)\end{array}$ & $\begin{array}{l}-0.184 \\
(0.422)\end{array}$ & $\begin{array}{l}-0.046 \\
(0.422)\end{array}$ & $\begin{array}{l}-0.038 \\
(0.423)\end{array}$ & $\begin{array}{c}0.638 \\
(0.652)\end{array}$ & $\begin{array}{c}0.698 \\
(0.635)\end{array}$ & $\begin{array}{c}0.719 \\
(0.633)\end{array}$ & $\begin{array}{c}0.744 \\
(0.632)\end{array}$ & $\begin{array}{c}-1.033^{* *} \\
(0.503)\end{array}$ & $\begin{array}{c}-1.052^{* *} \\
(0.509)\end{array}$ & $\begin{array}{c}-0.927^{*} \\
(0.514)\end{array}$ & $\begin{array}{r}-0.946^{*} \\
(0.511)\end{array}$ \\
\hline Mean & 6.20 & 6.20 & 6.20 & 6.20 & 13.20 & 13.20 & 13.20 & 13.20 & 4.69 & 4.69 & 4.69 & 4.69 \\
\hline Observations & 14094 & 14094 & 14094 & 14094 & 2501 & 2501 & 2501 & 2501 & 11589 & 11589 & 11589 & 11589 \\
\hline \multicolumn{13}{|l|}{ Opioid-Related Mortality Rate } \\
\hline Average Effect of SEP & $\begin{array}{l}2.199^{* *} \\
(0.908)\end{array}$ & $\begin{array}{c}2.264^{* *} \\
(0.903)\end{array}$ & $\begin{array}{c}2.419^{* * *} \\
(0.911)\end{array}$ & $\begin{array}{c}2.489^{* * *} \\
(0.917)\end{array}$ & $\begin{array}{c}0.581 \\
(0.863)\end{array}$ & $\begin{array}{c}0.547 \\
(0.866)\end{array}$ & $\begin{array}{c}0.488 \\
(0.865)\end{array}$ & $\begin{array}{c}0.481 \\
(0.855)\end{array}$ & $\begin{array}{l}3.585^{* *} \\
(1.548)\end{array}$ & $\begin{array}{c}3.747^{* *} \\
(1.538)\end{array}$ & $\begin{array}{l}3.824^{* *} \\
(1.554)\end{array}$ & $\begin{array}{l}3.943^{* *} \\
(1.568)\end{array}$ \\
\hline Mean & 9.78 & 9.78 & 9.78 & 9.78 & 8.77 & 8.77 & 8.77 & 8.77 & 10.00 & 10.00 & 10.00 & 10.00 \\
\hline Observations & 14121 & 14121 & 14121 & 14121 & 2501 & 2501 & 2501 & 2501 & 11616 & 11616 & 11616 & 11616 \\
\hline County and Year Fixed Effects & Yes & Yes & Yes & Yes & Yes & Yes & Yes & Yes & Yes & Yes & Yes & Yes \\
\hline Demographic and Economic Controls & No & Yes & Yes & Yes & No & Yes & Yes & Yes & No & Yes & Yes & Yes \\
\hline State-Level Policy Controls & No & No & Yes & Yes & No & No & Yes & Yes & No & No & Yes & Yes \\
\hline State-by-Year Fixed Effects & No & No & No & Yes & No & No & No & Yes & No & No & No & Yes \\
\hline County-Specific Linear Time Trends & No & No & No & Yes & No & No & No & Yes & No & No & No & Yes \\
\hline
\end{tabular}

Notes: See Table 2 and Table 3 The median population is 191,972.

$*, * *$, and $* * *$ indicate statistical significance at the ten, five, and one percent levels, respectively. 
Table 12: The Effect of a Syringe Exchange Program on HIV Diagnoses Rates and Opioid-Related Mortality Rates Using Various Comparison Groups

\begin{tabular}{|c|c|c|c|c|c|}
\hline & $\begin{array}{c}\text { Counties } \\
\text { W/Out SEPs }\end{array}$ & $\begin{array}{c}\text { All } \\
\text { Counties }\end{array}$ & $\begin{array}{l}\text { Counties } \\
\text { W/ SEPs }\end{array}$ & $\begin{array}{l}\text { Counties in } \\
\text { SEP States }\end{array}$ & $\begin{array}{c}\text { Border } \\
\text { Counties }\end{array}$ \\
\hline & (1) & $(2)$ & $(3)$ & $(4)$ & $(5)$ \\
\hline \multicolumn{6}{|l|}{ HIV Rate } \\
\hline Average Effect of SEP & $\begin{array}{c}0.277 \\
(0.462)\end{array}$ & $\begin{array}{c}0.321 \\
(0.460)\end{array}$ & $\begin{array}{c}0.467 \\
(0.522)\end{array}$ & $\begin{array}{c}0.232 \\
(0.451)\end{array}$ & $\begin{array}{c}0.257 \\
(0.455)\end{array}$ \\
\hline One-Year Lead & $\begin{array}{c}0.470 \\
(0.375)\end{array}$ & $\begin{array}{c}0.495 \\
(0.375)\end{array}$ & $\begin{array}{c}0.438 \\
(0.464)\end{array}$ & $\begin{array}{c}0.387 \\
(0.357)\end{array}$ & $\begin{array}{c}0.410 \\
(0.370)\end{array}$ \\
\hline Mean & 6.20 & 6.31 & 9.00 & 5.46 & 6.44 \\
\hline Observations & 14094 & 14922 & 1539 & 10917 & 4248 \\
\hline \multicolumn{6}{|l|}{ Opioid-Related Mortality Rate } \\
\hline Average Effect of SEP & $\begin{array}{c}2.912^{* *} \\
(1.307)\end{array}$ & $\begin{array}{c}2.870^{* *} \\
(1.306)\end{array}$ & $\begin{array}{l}1.815^{*} \\
(1.054)\end{array}$ & $\begin{array}{c}2.761^{* *} \\
(1.302)\end{array}$ & $\begin{array}{c}2.546^{* *} \\
(1.268)\end{array}$ \\
\hline One-Year Lead & $\begin{array}{c}0.630 \\
(1.034)\end{array}$ & $\begin{array}{c}0.606 \\
(1.033)\end{array}$ & $\begin{array}{c}0.827 \\
(0.758)\end{array}$ & $\begin{array}{c}0.625 \\
(1.052)\end{array}$ & $\begin{array}{c}0.231 \\
(0.994)\end{array}$ \\
\hline Mean & 9.78 & 9.85 & 11.77 & 10.68 & 8.96 \\
\hline Observations & 14121 & 14949 & 1539 & 10917 & 4248 \\
\hline County and Year Fixed Effects & Yes & Yes & Yes & Yes & Yes \\
\hline Demographic and Economic Controls & Yes & Yes & Yes & Yes & Yes \\
\hline State-Level Policy Controls & Yes & Yes & Yes & Yes & Yes \\
\hline State-by-Year Fixed Effects & Yes & Yes & Yes & Yes & Yes \\
\hline County-Specific Linear Time Trends & Yes & Yes & Yes & Yes & Yes \\
\hline
\end{tabular}

Notes: See Table 2 and Table 3 "Counties W/Out SEPs" represent the baseline results comparing counties with SEP openings to those without SEPs, "Counties W/ SEPs" compares counties with recent SEPs openings to counties in the US with an existing SEP, "All Counties" represents a full sample of US counties comparing counties with recent SEP openings to all other US counties, "Counties in SEP States" represents a subsample of all counties in US states with legal access to SEPs, and "Border Counties" shows estimates from a model comparing counties with SEP openings to their respective bordering counties.

$*, * *$, and $* * *$ indicate statistical significance at the ten, five, and one percent levels, respectively. 
Figure 1: Number of SEPs and Syringes Exchanged Over Time
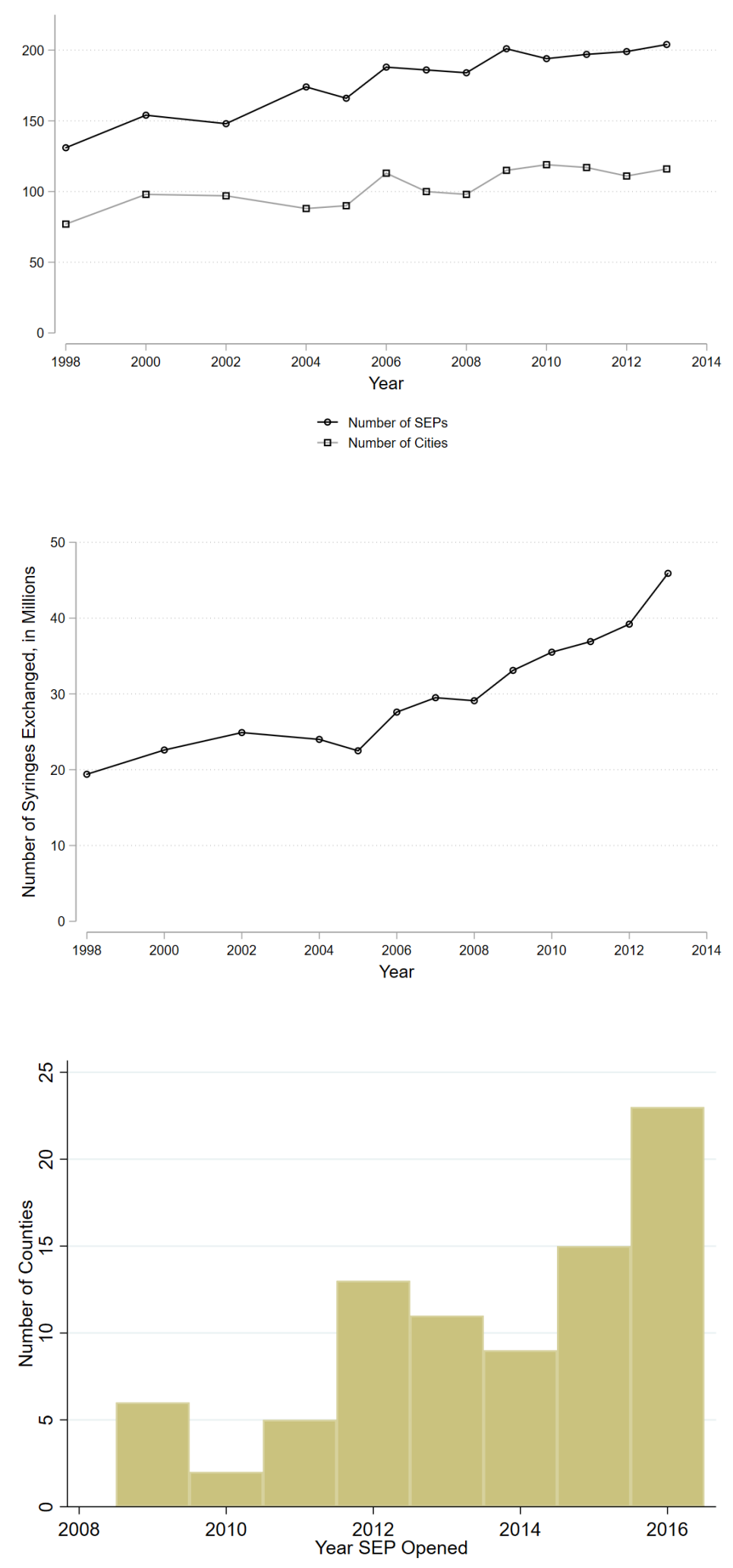

Notes: Data is from the NASEN 2014 National Survey of Syringe Exchange Programs and from the NASEN directory of syringe exchange programs. 
Figure 2: Opioid-Related Deaths and HIV Cases Over Time
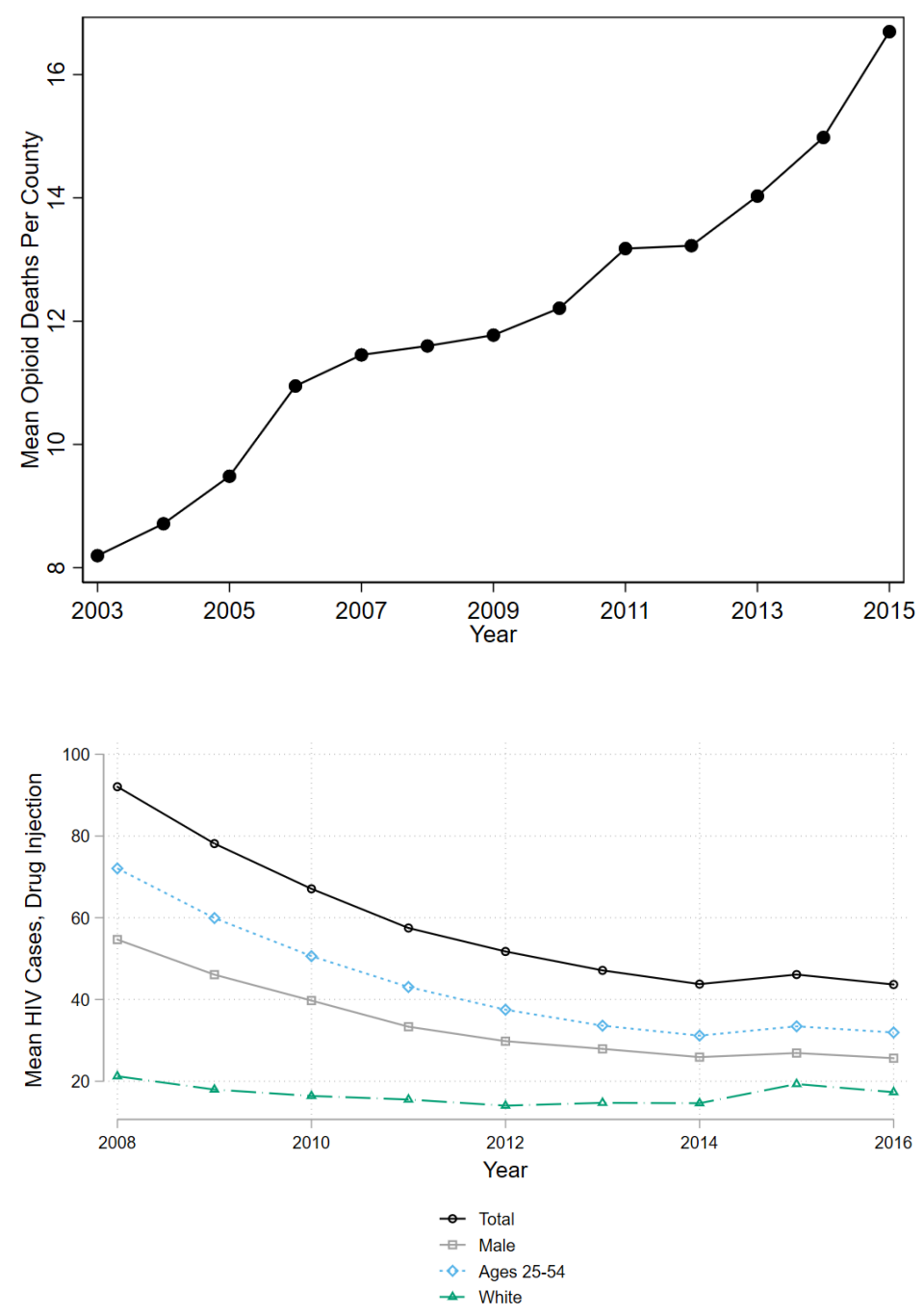

Notes: County-level data on drug-related mortality from 2008-2016 is from the National Center for Health Statistics Mortality Files. Data on HIV cases contracted via drug injection is from the CDC Atlas. 
Figure 3: Difference-in-Differences Estimates of the Effect of Opening a Syringe Exchange Program on HIV Rates

HIV Rate

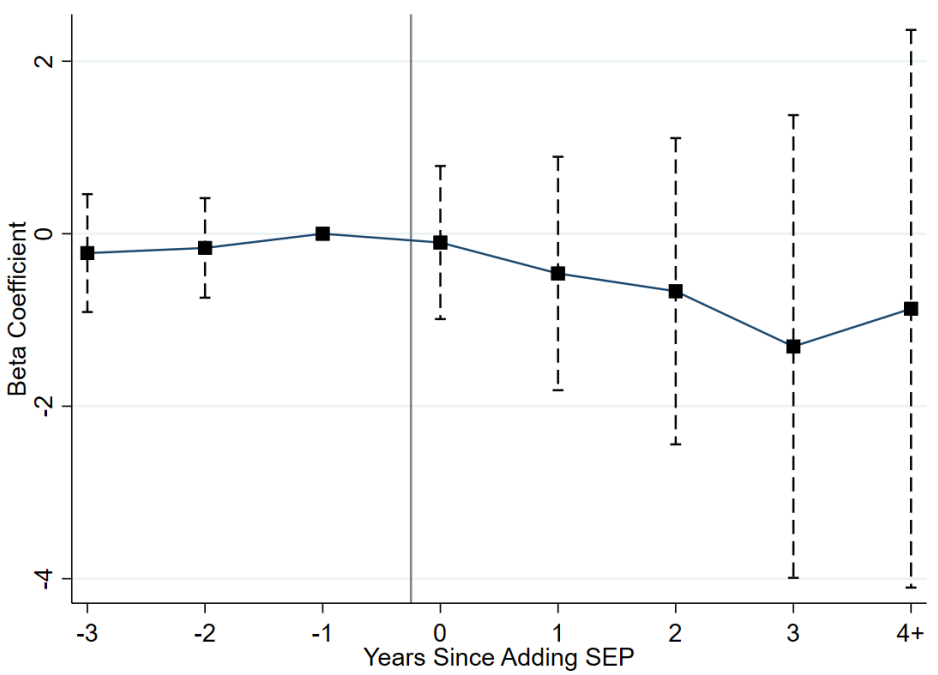

Notes: The above figure displays the coefficients and their respective $95 \%$ confidence intervals for the leading indicators and lagged treatment effects from OLS regressions, as specified in Equation 1 The vertical line represents the first year during the sample period that a county experienced a syringe exchange program opening. Estimates are based on HIV diagnoses counts by county for the entire United States from 2008-2016. HIV diagnoses rates are from the Center for Disease Control and Prevention's NCHHSTP Atlas and 34 state agencies. Economic control variables include the county-level poverty rate and unemployment rate, demographic controls include percent Hispanic and percent black, and state-level policy controls include whether a state imposes quantitative prescription limit, tamper-resistant prescription forms, pain clinic regulations, patient identification requirements, doctor shopping restrictions, requirements with respect to physician examination or pharmacist verification, prescription drug monitoring programs, paraphernalia laws, and good Samaritan laws. Standard errors are clustered at the county level. 
Figure 4: Difference-in-Differences Estimates of the Effect of Opening a

Syringe Exchange Program on Drug-Related Mortality Rates

\section{Drug-Related Mortality Rate}

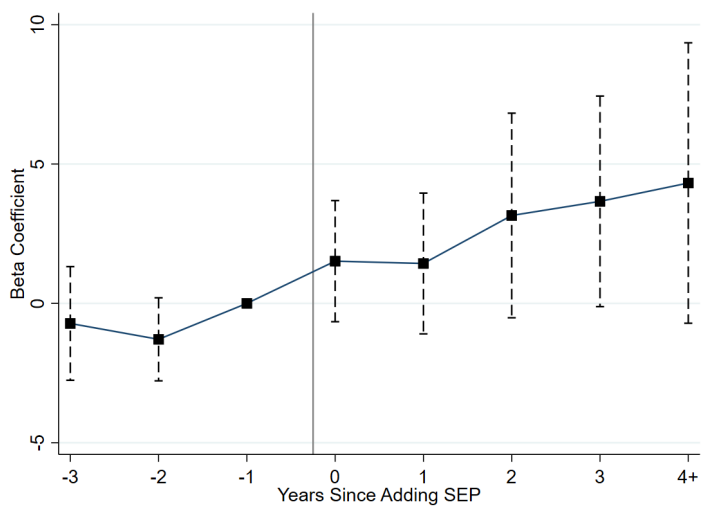

Opioid-Related Mortality Rate

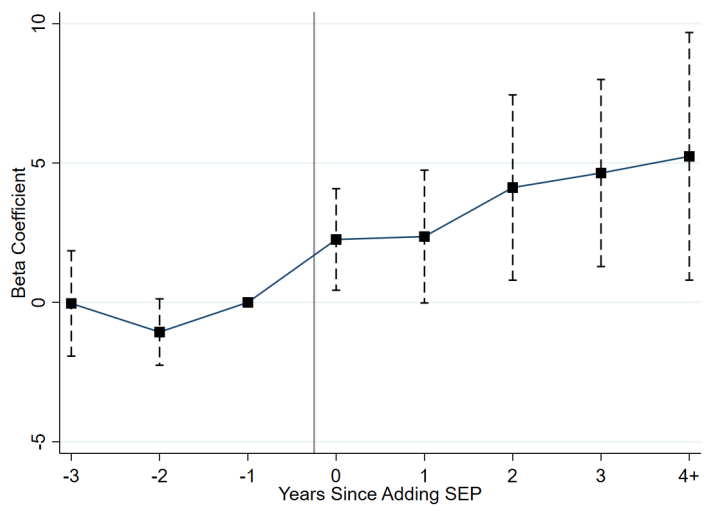

Illicit Opioid-Related Mortality Rate

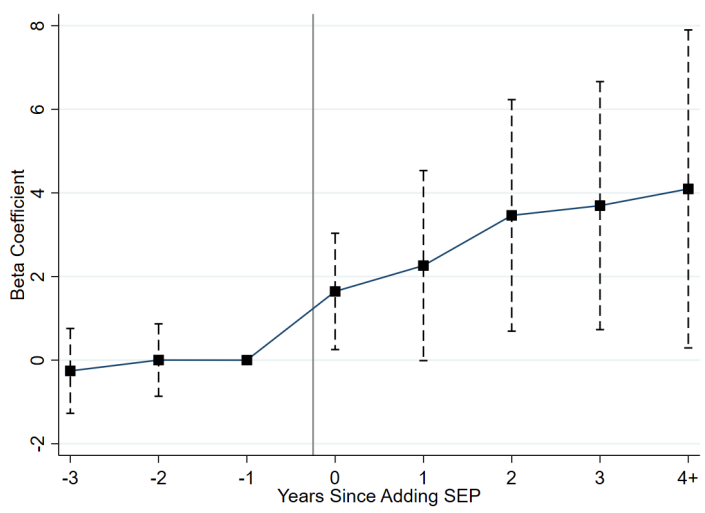

Notes: Each figure displays the coefficients and their respective $95 \%$ confidence intervals for the leading indicators and lagged treatment effects from OLS regressions, as specified in Equation 1 The vertical line represents the first year during the sample period that a county experienced a syringe exchange program opening. Estimates are based on restricted mortality files by county for the entire United States from 2008-2016. Economic control variables include the county-level poverty rate and unemployment rate, demographic controls include percent Hispanic and percent black, and state-level policy controls include whether a state imposes quantitative prescription limit, tamper-resistant prescription forms, pain clinic regulations, patient identification requirements, doctor shopping restrictions, requirements with respect to physician examination or pharmacist verification, prescription drug monitoring programs, paraphernalia laws, and good Samaritan laws. Standard errors are clustered at the county level. 
Figure 5: Difference-in-Differences Estimates of the Effect of Opening a Syringe Exchange Program on Opioid-Related Hospital Visits (State-Level)

\section{Opioid-Related Emergency Department Rate}

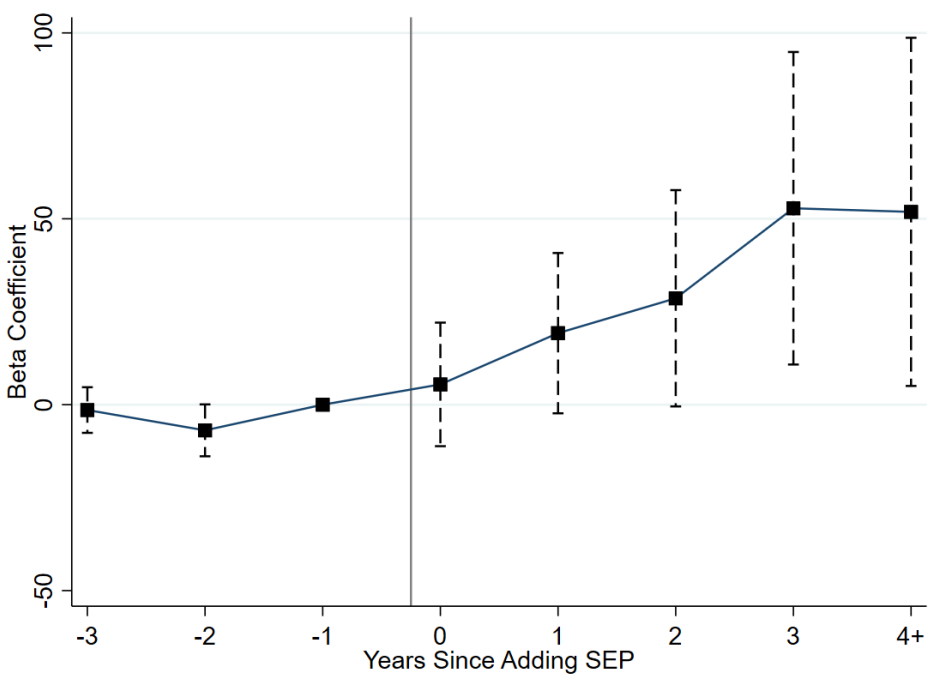

\section{Opioid-Related In-Patient Stay Rate}

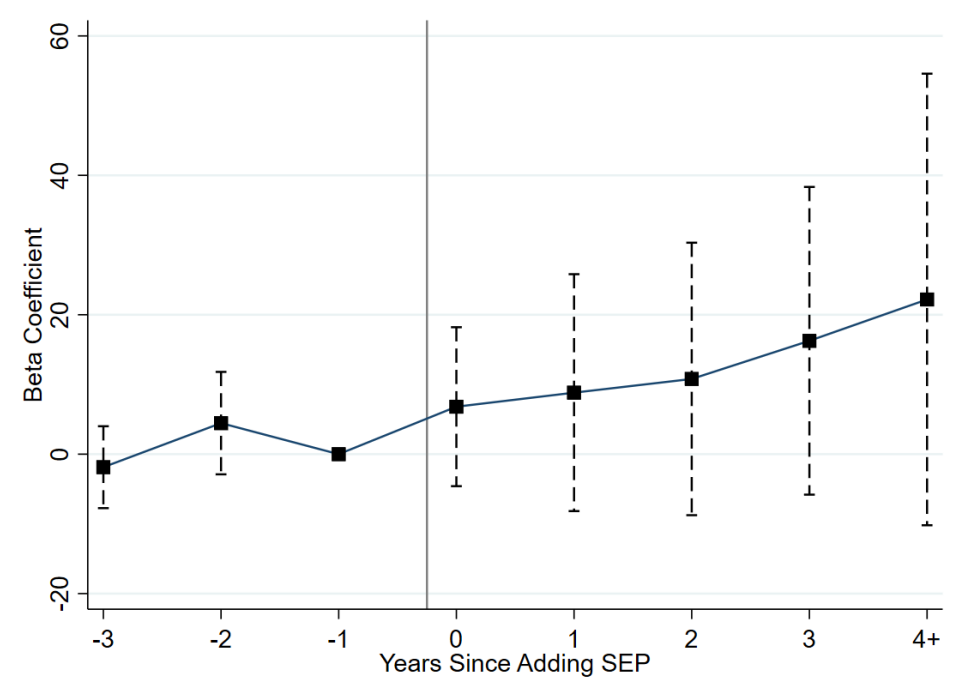

Notes: Each figure displays the coefficients and their respective $95 \%$ confidence intervals for the leading indicators and lagged treatment effects from OLS regressions, as specified in Equation 1 The vertical line represents the first year during the sample period that a state experienced a syringe exchange program opening. Estimates are based on state-level data on emergency department (ED) visits and in-patient (IP) hospital stays from 2008-2016 from the Healthcare Cost and Utilization Project (HCUP). Economic control variables include poverty rate, unemployment rate, demographic controls include percent Hispanic and percent black, and state-level policy controls include whether a state imposes quantitative prescription limit, tamperresistant prescription forms, pain clinic regulations, patient identification requirements, doctor shopping restrictions, requirements with respect to physician examination or pharmacist verification, prescription drug monitoring programs, paraphernalia laws, and good Samaritan laws. Standard errors are clustered at the state level. 
Figure 6: Difference-in-Differences Estimates of the Effect of Opening a Syringe Exchange Program on Drug-Related Crime Rates

Total Drug Crime Rate

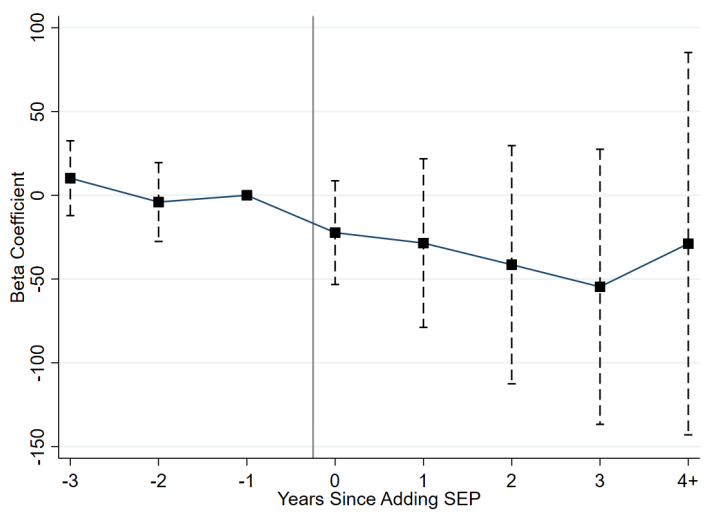

Opioid-Related Drug Sale Rate

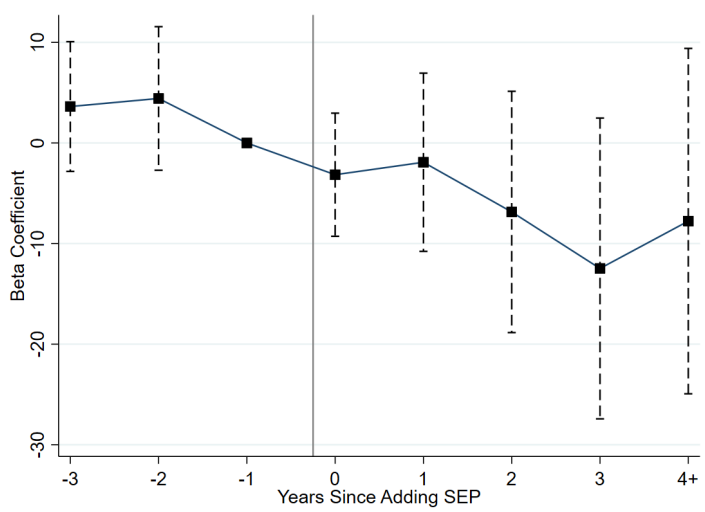

Opioid-Related Possession Rate

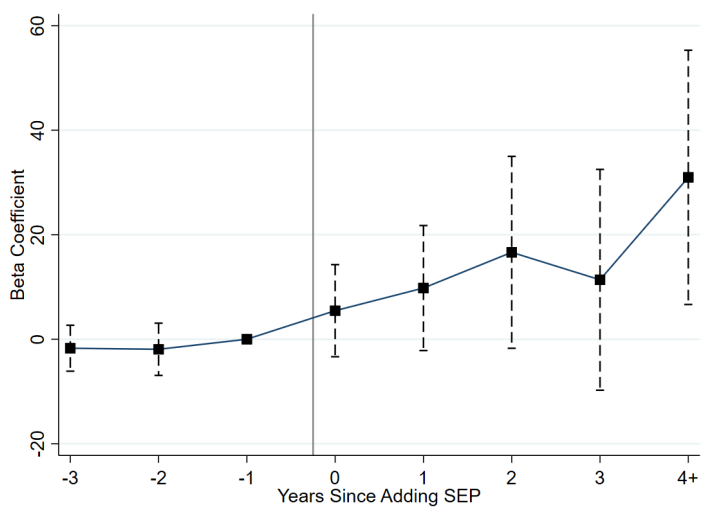

Notes: Each figure displays the coefficients and their respective $95 \%$ confidence intervals for the leading indicators and lagged treatment effects from OLS regressions, as specified in Equation 1 The vertical line represents the first year during the sample period that a county experienced a syringe exchange program opening. County-level arrest data from 2008-2016 is from the FBI Uniform Crime Reports. Economic control variables include the county-level poverty rate and unemployment rate, demographic controls include percent Hispanic and percent black, and state-level policy controls include whether a state imposes quantitative prescription limit, tamper-resistant prescription forms, pain clinic regulations, patient identification requirements, doctor shopping restrictions, requirements with respect to physician examination or pharmacist verification, prescription drug monitoring programs, paraphernalia laws, and good Samaritan laws. Standard errors are clustered at the county level. 
Figure 7: Difference-in-Differences Estimates of the Effect of Opening a

Syringe Exchange Program on Alcohol-Related Mortality, Traffic-Related Mortality, and Total Mortality Rates

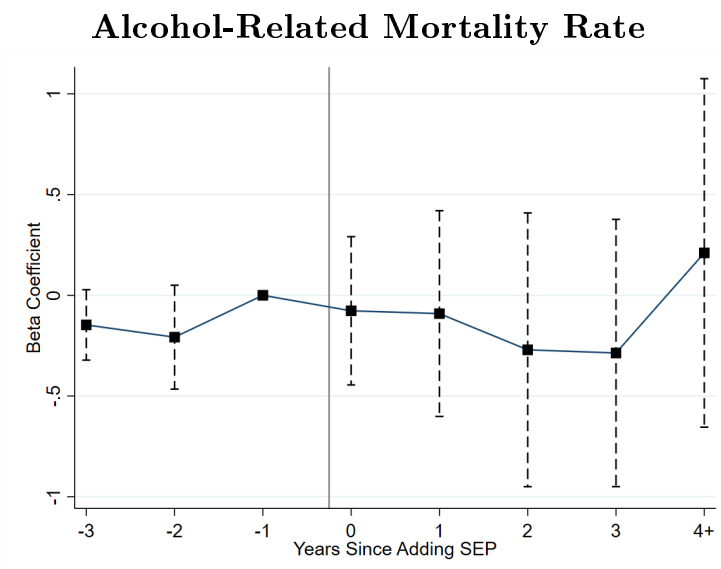

Traffic-Related Morality Rate

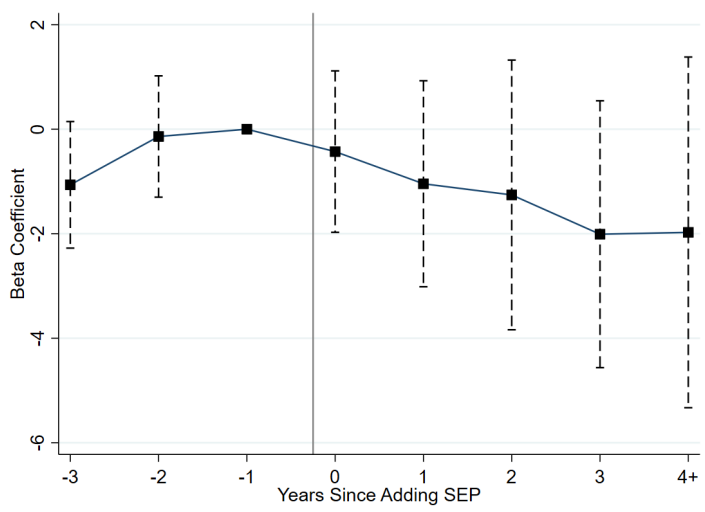

Total Morality Rate

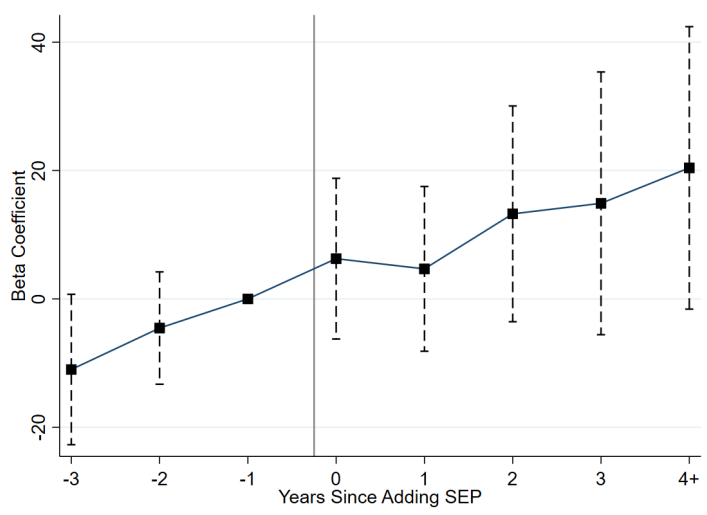

Notes: See Figure 4 
Appendix 
Table A1: Summary Statistics for a Rural Midwest Syringe Exchange Program

\begin{tabular}{lcc}
\hline \hline Client Characteristics & Mean & St.Dev. \\
Age & 37.84 & 10.13 \\
Percent White & 0.97 & 0.18 \\
Percent Male & 0.59 & 0.49 \\
First Injection Age & 27.14 & 10.25 \\
Previously Sought Addiction Treatment & 0.22 & 0.41 \\
Percent Ever Overdosed & 0.32 & 0.47 \\
Number of Times Overdosed & 3.42 & 4.83 \\
Percent Injected Heroin at First Use & 0.49 & 0.50 \\
Percent Injected Opioid Pills at First Use & 0.29 & 0.46 \\
Percent Prescribed Opioid Pain Pills & 0.26 & 0.44 \\
Percent Carry Naloxone & 0.67 & 0.47 \\
Visit Characteristics & & \\
First Exchange & & \\
Number of Syringes Exchanged & 0.22 & 0.42 \\
Percent Inject Heroin & 30.15 & 11.49 \\
Percent Inject Fentanyl & 0.80 & 0.40 \\
Percent Inject Opioid Pills & 0.16 & 0.37 \\
Percent Diagnosed with HIV & 0.02 & 0.15 \\
Percent Diagnosed with Hepatitis C & 0.01 & 0.07 \\
Percent Given a Referral & 0.21 & 0.41 \\
Percent Given Naloxone & 0.01 & 0.07 \\
Percent Received HIV Education & 0.14 & 0.34 \\
Number of Clients & 0.14 & 0.35 \\
Distance Traveled, in Miles & 144.59 & 30.27 \\
\hline \hline
\end{tabular}

Notes: Data is from the Portsmouth syringe exchange program from 2018. 
Table A2: The Effect of a Syringe Exchange Program on Inverse Hyperbolic Sine Transformations of HIV Diagnoses and Opioid-Related Mortality

\begin{tabular}{lcccccc}
\hline \hline & $(1)$ & $(2)$ & $(3)$ & $(4)$ & $(5)$ & $(6)$ \\
$\begin{array}{l}\text { HIV Diagnoses } \\
\text { Average Effect of SEP }\end{array}$ & -0.008 & -0.011 & -0.010 & -0.015 & -0.123 & -0.053 \\
& $(0.076)$ & $(0.073)$ & $(0.072)$ & $(0.071)$ & $(0.075)$ & $(0.094)$ \\
One-Year Lead & & & & & & 0.105 \\
& 14103 & 14094 & 14094 & 14094 & 14094 & 14094 \\
Observations & & & & & & \\
& & & & & & \\
$\begin{array}{l}\text { Opioid-Related Deaths } \\
\text { Average Effect of SEP }\end{array}$ & 0.093 & 0.104 & 0.065 & 0.076 & 0.024 & 0.045 \\
& $(0.067)$ & $(0.067)$ & $(0.068)$ & $(0.068)$ & $(0.055)$ & $(0.081)$ \\
One-Year Lead & & & & & & 0.030 \\
& 14130 & 14121 & 14121 & 14121 & 14121 & 14121 \\
Observations & Yes & Yes & Yes & Yes & Yes & Yes \\
County and Year Fixed Effects & No & Yes & Yes & Yes & Yes & Yes \\
$\begin{array}{l}\text { Demographic and Economic Controls } \\
\text { State-Level Policy Controls }\end{array}$ & No & No & Yes & Yes & Yes & Yes \\
$\begin{array}{l}\text { State-by-Year Fixed Effects } \\
\text { County-Specific Linear Time Trends }\end{array}$ & No & No & No & Yes & Yes & Yes \\
\hline \hline
\end{tabular}

Notes: See Table 2 and Table 3 Estimates are from Equation 1 using the inverse hyperbolic sine transformation of the listed outcome variables.

${ }^{*},{ }^{* *}$, and ${ }^{* * *}$ indicate statistical significance at the ten, five, and one percent levels, respectively. 
Table A3: The Effect of a Syringe Exchange Program on Drug-Related Health and Crime Rates, Lagged Difference-in-Differences Estimates Using Counties Without a SEP for Comparison

\begin{tabular}{|c|c|c|c|c|c|c|c|}
\hline & $\begin{array}{c}\text { HIV } \\
\text { Diagnoses }\end{array}$ & $\begin{array}{c}\text { Drug-Related } \\
\text { Mortality }\end{array}$ & $\begin{array}{c}\text { Opioid-Related } \\
\text { Mortality }\end{array}$ & $\begin{array}{c}\text { Opioid-Related } \\
\text { ED Visits }\end{array}$ & $\begin{array}{l}\text { Opioid-Related } \\
\text { IP Stays }\end{array}$ & $\begin{array}{c}\text { Drug Sale } \\
\text { Arrests }\end{array}$ & $\begin{array}{c}\text { Drug Poss. } \\
\text { Arrests }\end{array}$ \\
\hline & $(1)$ & (2) & (3) & $(4)$ & $(5)$ & $(6)$ & $(7)$ \\
\hline \multirow[t]{2}{*}{ Effect of SEP in First Year } & -0.021 & $2.132^{* *}$ & $2.647^{* * *}$ & 9.841 & 8.082 & -6.009 & 0.052 \\
\hline & $(0.443)$ & $(1.038)$ & $(0.930)$ & $(7.908)$ & $(5.672)$ & $(3.836)$ & $(0.045)$ \\
\hline \multirow[t]{2}{*}{ Effect of SEP in Second Year } & -0.407 & $2.065^{*}$ & $2.770^{* *}$ & $27.262^{* * *}$ & 11.746 & -5.335 & 0.081 \\
\hline & $(0.649)$ & $(1.207)$ & $(1.217)$ & $(9.860)$ & $(8.520)$ & $(4.505)$ & $(0.063)$ \\
\hline \multirow[t]{2}{*}{ Effect of SEP in Third Year } & -0.653 & $3.768^{* *}$ & $4.523^{* * *}$ & $34.725^{* *}$ & 15.181 & $-10.841^{*}$ & 0.131 \\
\hline & $(0.887)$ & $(1.741)$ & $(1.672)$ & $(14.293)$ & $(9.857)$ & $(6.113)$ & $(0.105)$ \\
\hline \multirow[t]{2}{*}{ Effect of SEP in Fourth + Year } & -1.170 & $4.515^{* *}$ & $5.280^{* * *}$ & $58.201 * * *$ & $21.251^{*}$ & $-15.320^{*}$ & 0.133 \\
\hline & $(1.369)$ & $(1.869)$ & $(1.743)$ & $(20.140)$ & $(11.716)$ & $(7.888)$ & $(0.111)$ \\
\hline Average Lagged Effect & -0.56 & 3.12 & 3.81 & 32.51 & 14.07 & -9.38 & 0.10 \\
\hline$P$-value (test average effect $=0$ ) & 0.45 & 0.02 & 0.00 & 0.01 & 0.09 & 0.07 & 0.18 \\
\hline Mean & 6.20 & 16.68 & 9.78 & 150.75 & 209.26 & 23.06 & 0.45 \\
\hline Observations & 14094 & 14121 & 14121 & 258 & 375 & 14115 & 14115 \\
\hline County and Year Fixed Effects & Yes & Yes & Yes & Yes & Yes & Yes & Yes \\
\hline Demographic and Economic Controls & Yes & Yes & Yes & Yes & Yes & Yes & Yes \\
\hline State-Level Policy Controls & Yes & Yes & Yes & Yes & Yes & Yes & Yes \\
\hline State-by-Year Fixed Effects & Yes & Yes & Yes & Yes & No & No & Yes \\
\hline County-Specific Linear Time Trends & Yes & Yes & Yes & No & No & Yes & Yes \\
\hline
\end{tabular}

Notes: See Tables 23 and 9 .

$*, * *$, and $*^{* *}$ indicate statistical significance at the ten, five, and one percent levels, respectively. 
Table A4: The Effect of a Syringe Exchange Program on HIV Diagnoses Rates and Opioid-Related Mortality Rates, Controlling for State Legal Restrictions

\begin{tabular}{|c|c|c|c|c|c|c|c|c|c|c|}
\hline & (1) & (2) & (3) & (4) & (5) & (6) & (7) & (8) & (9) & (10) \\
\hline \multicolumn{11}{|l|}{ HIV Rate } \\
\hline Average Effect of SEP & $\begin{array}{c}-0.697 \\
(0.426)\end{array}$ & $\begin{array}{c}-0.665 \\
(0.433)\end{array}$ & $\begin{array}{c}-0.169 \\
(0.423)\end{array}$ & $\begin{array}{c}-0.156 \\
(0.424)\end{array}$ & $\begin{array}{l}-0.127 \\
(0.422)\end{array}$ & $\begin{array}{c}-0.127 \\
(0.422)\end{array}$ & $\begin{array}{l}-0.127 \\
(0.422)\end{array}$ & $\begin{array}{c}-0.121 \\
(0.420)\end{array}$ & $\begin{array}{c}-0.038 \\
(0.423)\end{array}$ & $\begin{array}{l}-0.035 \\
(0.422)\end{array}$ \\
\hline Mean & 6.20 & 6.20 & 6.20 & 6.20 & 6.20 & 6.20 & 6.20 & 6.20 & 6.20 & 6.20 \\
\hline Observations & 14094 & 14094 & 14094 & 14094 & 14094 & 14094 & 14094 & 14094 & 14094 & 14094 \\
\hline \multicolumn{11}{|l|}{ Opioid-Related Mortality Rate } \\
\hline Average Effect of SEP & $\begin{array}{c}2.739^{* *} \\
(1.083)\end{array}$ & $\begin{array}{c}2.895^{* * *} \\
(1.077)\end{array}$ & $\begin{array}{c}2.319^{* *} \\
(0.908)\end{array}$ & $\begin{array}{c}2.288^{* *} \\
(0.911)\end{array}$ & $\begin{array}{c}2.280^{* *} \\
(0.908)\end{array}$ & $\begin{array}{c}2.276^{* *} \\
(0.908)\end{array}$ & $\begin{array}{c}2.281^{* *} \\
(0.907)\end{array}$ & $\begin{array}{c}2.287^{* *} \\
(0.907)\end{array}$ & $\begin{array}{c}2.489^{* * * *} \\
(0.917)\end{array}$ & $\begin{array}{c}2.487^{* * *} \\
(0.917)\end{array}$ \\
\hline Mean & 9.78 & 9.78 & 9.78 & 9.78 & 9.78 & 9.78 & 9.78 & 9.78 & 9.78 & 9.78 \\
\hline Observations & 14121 & 14121 & 14121 & 14121 & 14121 & 14121 & 14121 & 14121 & 14121 & 14121 \\
\hline County and Year Fixed Effects & Yes & Yes & Yes & Yes & Yes & Yes & Yes & Yes & Yes & Yes \\
\hline Demographic and Economic Controls & No & Yes & Yes & Yes & Yes & Yes & Yes & Yes & Yes & Yes \\
\hline County-Specific Linear Time Trends & No & No & Yes & Yes & Yes & Yes & Yes & Yes & Yes & Yes \\
\hline Rx Limits, Tamper Resistant Forms, ID Laws & No & No & No & Yes & Yes & Yes & Yes & Yes & Yes & Yes \\
\hline Doctor Shopping Restrictions & No & No & No & No & Yes & Yes & Yes & Yes & Yes & Yes \\
\hline Physician Exam, Pharmacist Verification & No & No & No & No & No & Yes & Yes & Yes & Yes & Yes \\
\hline Pain Clinic Regulations & No & No & No & No & No & No & Yes & Yes & Yes & Yes \\
\hline Prescription Drug Monitoring Programs & No & No & No & No & No & No & No & Yes & Yes & Yes \\
\hline Paraphernalia and Good Samaritan Laws & No & No & No & No & No & No & No & No & Yes & Yes \\
\hline Naloxone Laws & No & No & No & No & No & No & No & No & No & Yes \\
\hline
\end{tabular}

Notes: See Table 2 and Table 3 Standard errors are clustered at the county level.

$*, * *$, and $* * *$ indicate statistical significance at the ten, five, and one percent levels, respectively. 
Table A5: The Effect of a Syringe Exchange Program on Drug-Related Health and Crime Outcomes by 2015 Medicaid Expansion Status

\begin{tabular}{|c|c|c|c|c|c|c|c|}
\hline & $\begin{array}{c}\text { HIV } \\
\text { Diagnoses }\end{array}$ & $\begin{array}{c}\text { Drug-Related } \\
\text { Mortality }\end{array}$ & $\begin{array}{c}\text { Opioid-Related } \\
\text { Mortality }\end{array}$ & $\begin{array}{l}\text { Opioid-Related } \\
\text { ED Visits }\end{array}$ & $\begin{array}{l}\text { Opioid-Related } \\
\text { IP Stays }\end{array}$ & $\begin{array}{c}\text { Drug Sale } \\
\text { Arrests }\end{array}$ & $\begin{array}{c}\text { Drug Poss. } \\
\text { Arrests }\end{array}$ \\
\hline & (1) & $(2)$ & $(3)$ & $(4)$ & $(5)$ & (6) & $(7)$ \\
\hline \multicolumn{8}{|l|}{ Medicaid Expansion } \\
\hline Average Effect of SEP & $\begin{array}{l}-0.327 \\
(0.407)\end{array}$ & $\begin{array}{l}2.296^{* *} \\
(1.092)\end{array}$ & $\begin{array}{c}3.274^{* * *} \\
(1.011)\end{array}$ & $\begin{array}{c}15.848 \\
(11.373)\end{array}$ & $\begin{array}{c}7.418 \\
(8.908)\end{array}$ & $\begin{array}{l}-5.518 \\
(4.035)\end{array}$ & $\begin{array}{c}0.078 \\
(0.057)\end{array}$ \\
\hline Mean & 3.78 & 17.72 & 10.90 & 168.68 & 239.17 & 25.87 & 0.51 \\
\hline Observations & 7002 & 7002 & 7002 & 159 & 220 & 7002 & 7002 \\
\hline \multicolumn{8}{|l|}{ No Medicaid Expansion } \\
\hline Average Effect of SEP & $\begin{array}{c}1.128 \\
(1.426)\end{array}$ & $\begin{array}{c}-0.063 \\
(1.766)\end{array}$ & $\begin{array}{l}-1.207 \\
(1.545)\end{array}$ & $\begin{array}{c}19.753 \\
(13.950)\end{array}$ & $\begin{array}{c}-0.303 \\
(13.199)\end{array}$ & $\begin{array}{l}-1.133 \\
(8.235)\end{array}$ & $\begin{array}{c}0.007 \\
(0.059)\end{array}$ \\
\hline Mean & 8.60 & 15.66 & 8.68 & 121.95 & 166.81 & 20.76 & 0.44 \\
\hline Observations & 7092 & 7119 & 7119 & 99 & 155 & 7113 & 7113 \\
\hline County and Year Fixed Effects & Yes & Yes & Yes & Yes & Yes & Yes & Yes \\
\hline Demographic and Economic Controls & Yes & Yes & Yes & Yes & Yes & Yes & Yes \\
\hline State-Level Policy Controls & Yes & Yes & Yes & Yes & Yes & Yes & Yes \\
\hline State-by-Year Fixed Effects & Yes & Yes & Yes & Yes & No & No & Yes \\
\hline County-Specific Linear Time Trends & Yes & Yes & Yes & No & No & Yes & Yes \\
\hline
\end{tabular}

Notes: See Tables 234 and 9 Data on Medicaid expansion status is from Simon, Soni, and Cawley (2017). Expansion states include AK, AZ, AR, CA, CO, CT, DE, HI, IL, IA, IN, KY, MD, MA, MI, MN, NV, NH, NJ, NM, NY, ND, OH, OR, PA, RI, VT, WA, WV, and WI. Standard errors are clustered at the county level.

$*, * *$, and $* * *$ indicate statistical significance at the ten, five, and one percent levels, respectively. 
Table A6: The Effect of a Syringe Exchange Program on HIV Diagnoses Rates and Opioid-Related Mortality Rates, by Treatment Year

\begin{tabular}{|c|c|c|c|}
\hline $\begin{array}{l}\text { Treated Year } \\
\text { (\# Treated Counties) }\end{array}$ & $\begin{array}{c}\begin{array}{c}\mathbf{2 0 0 9 - 2 0 1 6} \\
(n=79)\end{array} \\
\end{array}$ & $\begin{array}{c}2009-\mathbf{2 0 1 2} \\
(n=24)\end{array}$ & $\begin{array}{c}2013-2016 \\
(n=55)\end{array}$ \\
\hline & (1) & $(2)$ & $(3)$ \\
\hline \multicolumn{4}{|l|}{ HIV Rate } \\
\hline Average Effect of SEP & $\begin{array}{l}-0.046 \\
(0.422)\end{array}$ & $\begin{array}{c}0.057 \\
(0.785)\end{array}$ & $\begin{array}{l}-0.074 \\
(0.503)\end{array}$ \\
\hline Mean & 6.20 & 6.35 & 5.80 \\
\hline Observations & 14094 & 13599 & 13878 \\
\hline \multicolumn{4}{|l|}{ Opioid-Related Mortality Rate } \\
\hline Average Effect of SEP & $\begin{array}{c}2.419^{* * *} \\
(0.911)\end{array}$ & $\begin{array}{c}0.137 \\
(1.012)\end{array}$ & $\begin{array}{c}3.349^{* * *} \\
(1.191)\end{array}$ \\
\hline Mean & 9.78 & 8.40 & 11.37 \\
\hline Observations & 14121 & 13626 & 13905 \\
\hline County and Year Fixed Effects & Yes & Yes & Yes \\
\hline Demographic and Economic Controls & Yes & Yes & Yes \\
\hline State-Level Policy Controls & Yes & Yes & Yes \\
\hline
\end{tabular}

Notes: See Table 2 and Table 3. "Treated Year" represents the first year a county experiences a SEP opening. Column 1 displays the main estimates for counties with an opening between 2009-2016, while Column 2 displays estimates comparing counties with an opening between 2009-2012 to counties without a SEP and Column 3 displays estimates comparing counties with an opening between 2013-2016 to counties without a SEP.

$*, * *$, and $* * *$ indicate statistical significance at the ten, five, and one percent levels, respectively. 
Table A7: The Effect of a Syringe Exchange Program on Chlamydia Rates, Difference-in-Differences Estimates using Counties Without SEPs for Comparison

\begin{tabular}{lcccccc}
\hline \hline & $(1)$ & $(2)$ & $(3)$ & $(4)$ & $(5)$ & $(6)$ \\
Average Effect of SEP & -9.821 & -7.589 & -6.811 & -6.517 & -6.902 & -10.091 \\
& $(11.028)$ & $(11.039)$ & $(10.989)$ & $(10.952)$ & $(10.110)$ & $(15.755)$ \\
One-Year Lead & & & & & & -4.756 \\
& & & & & & $(11.163)$ \\
Mean & 351.17 & 351.17 & 351.17 & 351.17 & 351.17 & 351.17 \\
Observations & 14948 & 14948 & 14948 & 14948 & 14948 & 14948 \\
& & & & & & \\
County and Year Fixed Effects & Yes & Yes & Yes & Yes & Yes & Yes \\
Demographic and Economic Controls & No & Yes & Yes & Yes & Yes & Yes \\
State-Level Policy Controls & No & No & Yes & Yes & Yes & Yes \\
State-by-Year Fixed Effects & No & No & No & Yes & Yes & Yes \\
County-Specific Linear Time Trends & No & No & No & No & Yes & Yes \\
\hline \hline
\end{tabular}

Notes: Estimates are based on CDC NCHHSTP Atlas data on county-level rates of chlamydia for the entire United States from 20082016. Economic control variables include the county-level poverty rate and unemployment rate, demographic controls include percent Hispanic and percent black, and state-level policy controls include whether a state imposes quantitative prescription limit, tamperresistant prescription forms, pain clinic regulations, patient identification requirements, doctor shopping restrictions, requirements with respect to physician examination or pharmacist verification, prescription drug monitoring programs, paraphernalia laws, and good Samaritan laws. Standard errors are clustered at the county level.

$*, * *$, and ${ }^{* *}$ indicate statistical significance at the ten, five, and one percent levels, respectively. 
Table A8: The Effect of a Syringe Exchange Program on HIV Rates and Opioid-Related Mortality Rates, Accounting for Pre-Trends

\begin{tabular}{lccccc}
\hline \hline & $(1)$ & $(2)$ & $(3)$ & $(4)$ & $(5)$ \\
HIV Rate & & & & & \\
Average Effect of SEP & $-1.188^{* * *}$ & $-1.127^{* * *}$ & $-1.074^{* * *}$ & $-1.071^{* * *}$ & $-1.060^{* *}$ \\
& $(0.405)$ & $(0.390)$ & $(0.392)$ & $(0.392)$ & $(0.429)$ \\
One-Year Lead & & & & & 0.041 \\
& & & & & $(0.392)$ \\
Mean & 6.14 & 6.14 & 6.14 & 6.14 & 6.14 \\
Observations & 14085 & 14085 & 14085 & 14085 & 14085 \\
Opioid-Related Mortality Rate & & & & & \\
Average Effect of SEP & $1.873^{* *}$ & $1.920^{* *}$ & $1.981^{* *}$ & $2.010^{* *}$ & $2.145^{* *}$ \\
& $(0.914)$ & $(0.911)$ & $(0.911)$ & $(0.913)$ & $(1.023)$ \\
One-Year Lead & & & & & 0.513 \\
& & & & & $0.804)$ \\
Mean & 9.79 & 9.79 & 9.79 & 9.79 & 9.79 \\
Observations & 14085 & 14085 & 14085 & 14085 & 14085 \\
County and Year Fixed Effects & Yes & Yes & Yes & Yes & Yes \\
$\begin{array}{l}\text { Demographic and Economic Controls } \\
\text { State-Level Policy Controls }\end{array}$ & No & Yes & Yes & Yes & Yes \\
State-by-Year Fixed Effects & No & No & Yes & Yes & Yes \\
\hline \hline
\end{tabular}

Notes: See Table 2 and Table 3 Estimates are from a model analogous to Equation 1 that partials out pre-treatment trends. ${ }^{*}, * *$, and ${ }^{* * *}$ indicate statistical significance at the ten, five, and one percent levels, respectively. 
Figure A1: Map of Portsmouth SEP Visitor Zip Codes

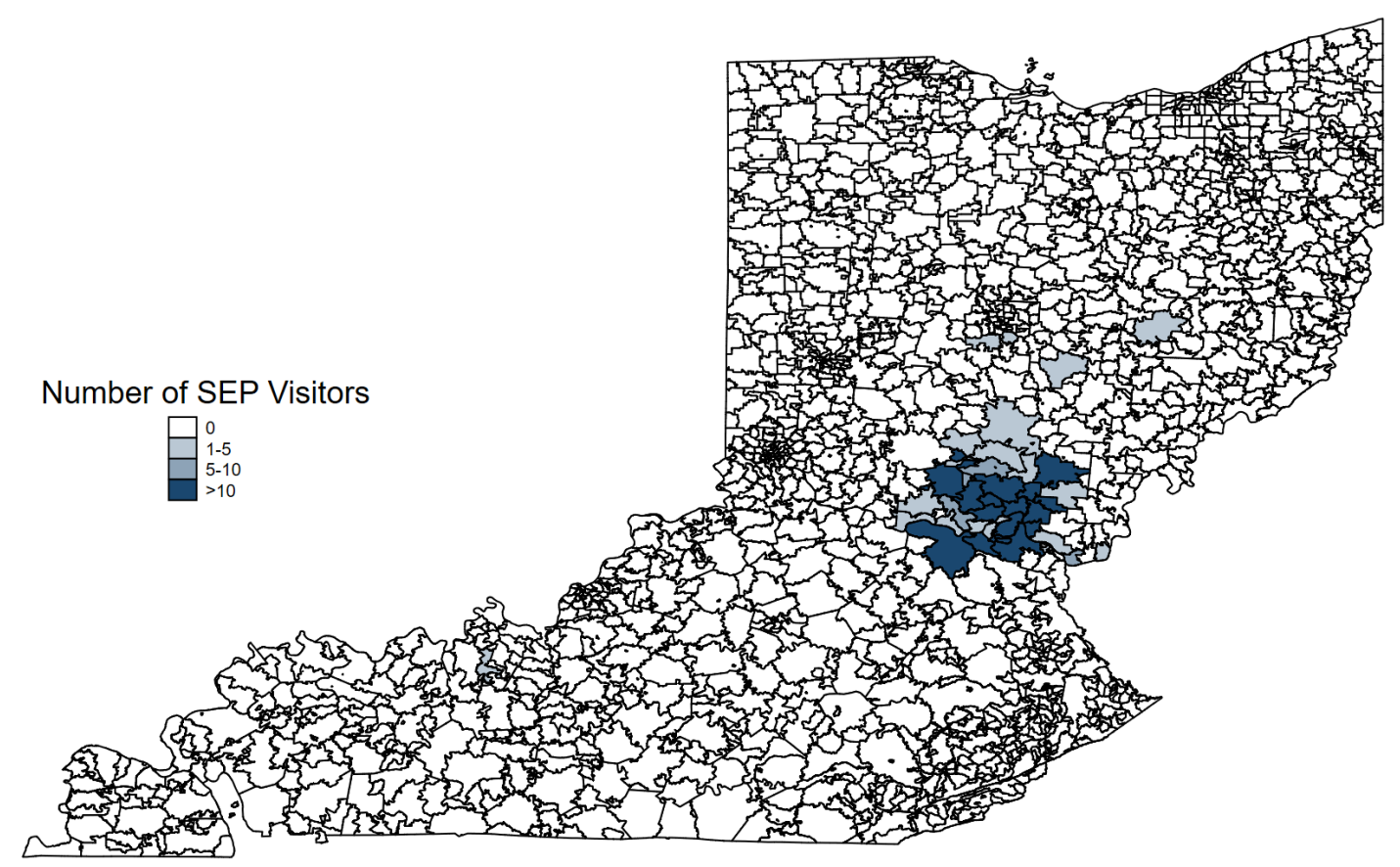

Notes: Geocoded clinic-level data on patient residence zip code is from the Portsmouth, Ohio SEP. 
Figure A2: County-Level Locations of SEPs

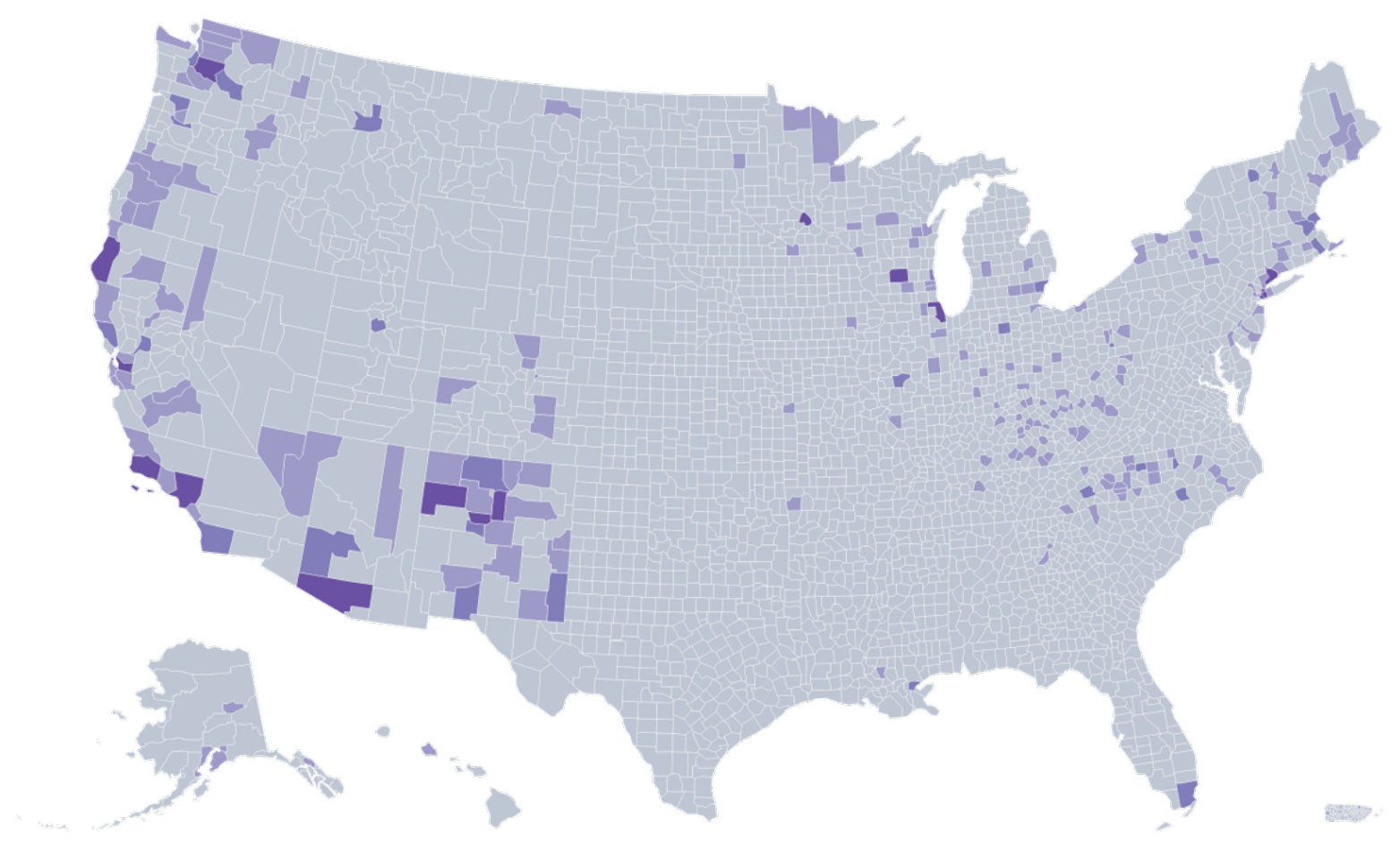

Notes: Geocoded data on SEP location by county is from NASEN. Shaded counties represent those with SEPs as of 2016. 
Figure A3: Locations of Existing SEPs and Recent SEP Openings

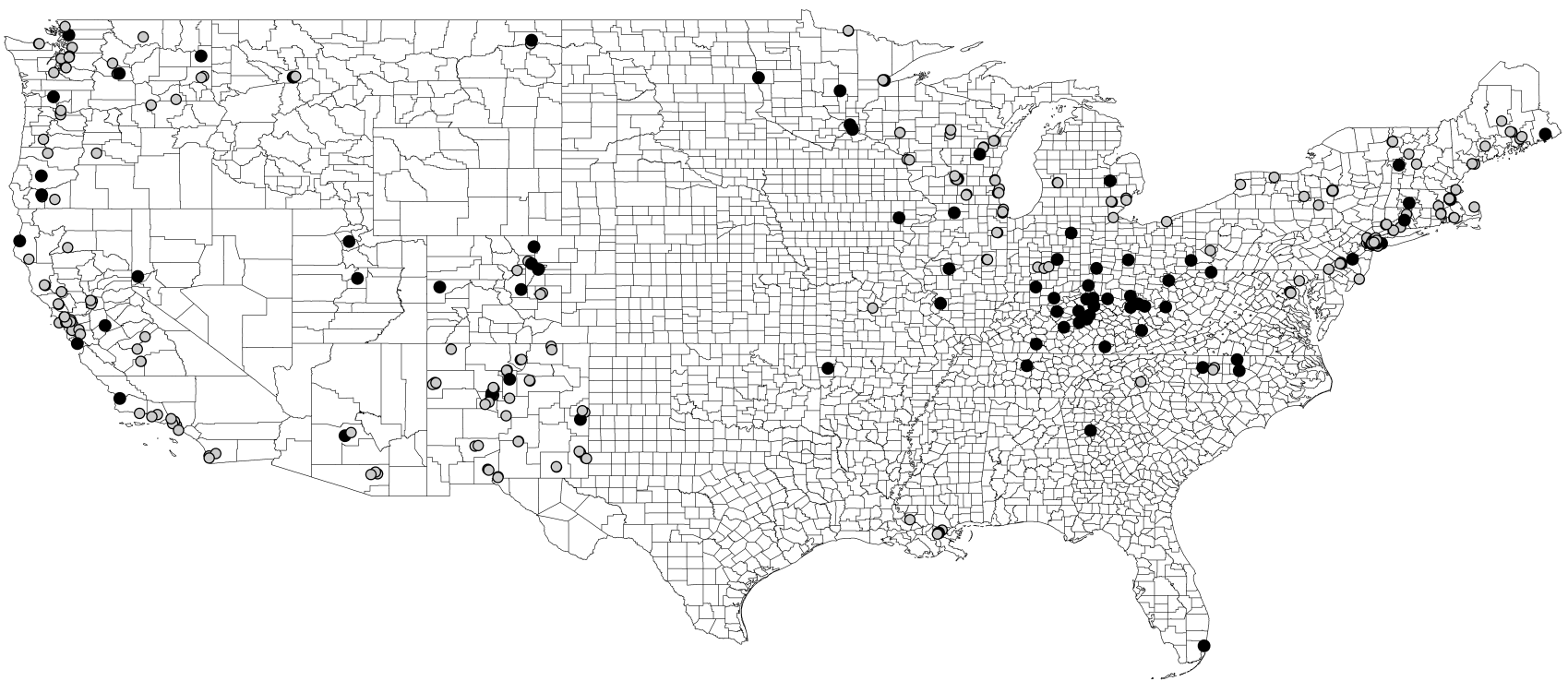

Notes: Geocoded data on SEP location is from the NASEN directory. Darker shaded circles represent SEPs opened between 2009-2016. Lighter shaded circles represent SEPs opened prior to 2009. 
Figure A4: Difference-in-Differences Estimates of the Effect of Opening a Syringe Exchange Program, Using Data from 2003-2016

\section{HIV Rate}

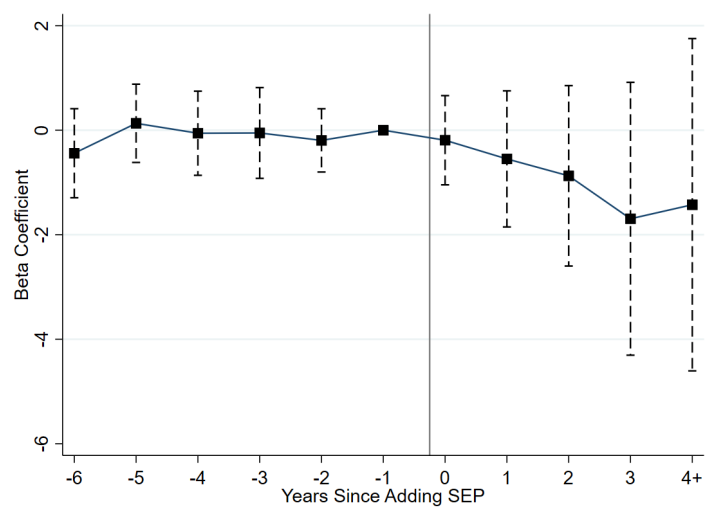

Drug-Related Mortality Rate

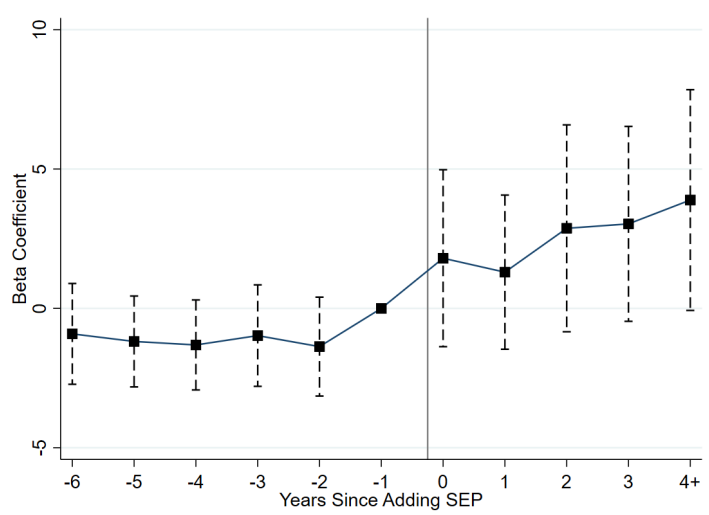

Opioid-Related Mortality Rate

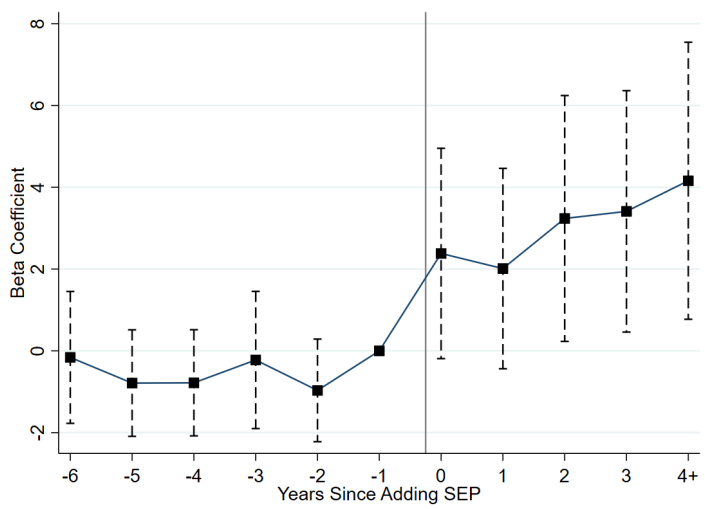

Notes: See Figure 4 Estimates are based on restricted mortality files for the entire United States from 2003-2016. 
Figure A5: Difference-in-Differences Estimates of the Effect of Opening a Syringe Exchange Program on Other Drug-Related Mortality Rates

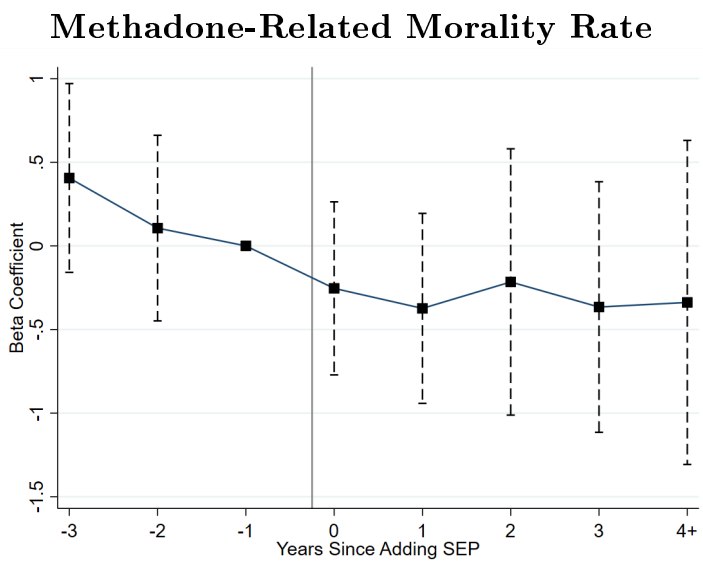

\section{Fentanyl-Related Morality Rate}

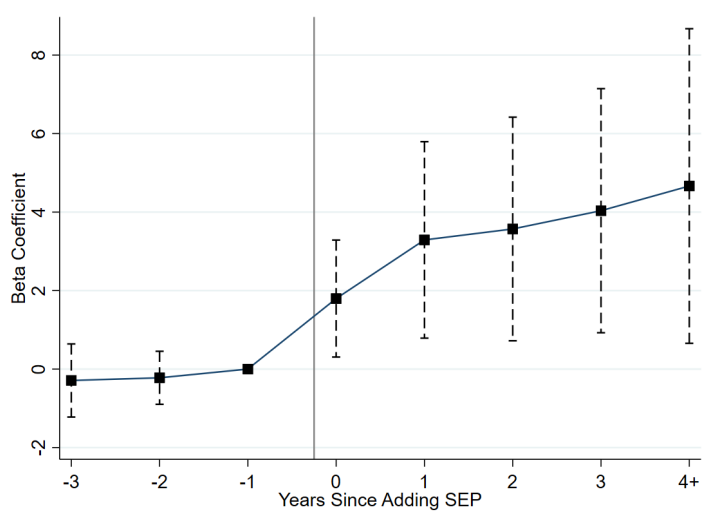

Cocaine-Related Mortality Rate

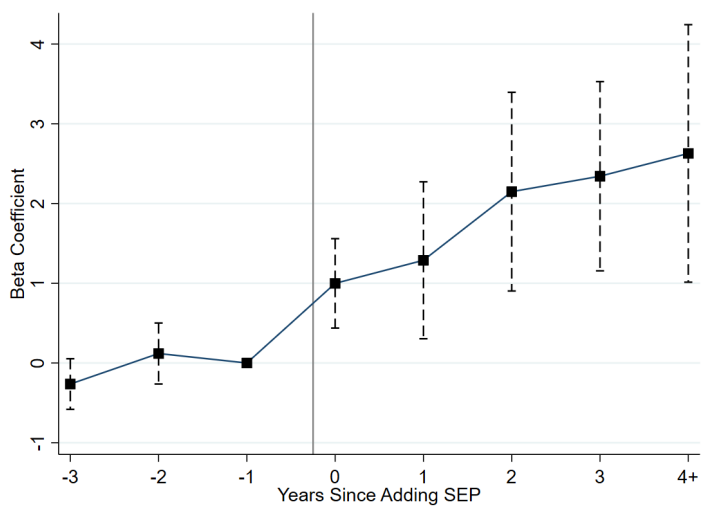

Notes: See Figure 4 
Figure A6: Difference-in-Differences Estimates of the Effect of Opening a Syringe Exchange Program on Drug-Related Mortality Rates, by Hospital Condition

Inpatient Drug-Related Mortality Rate

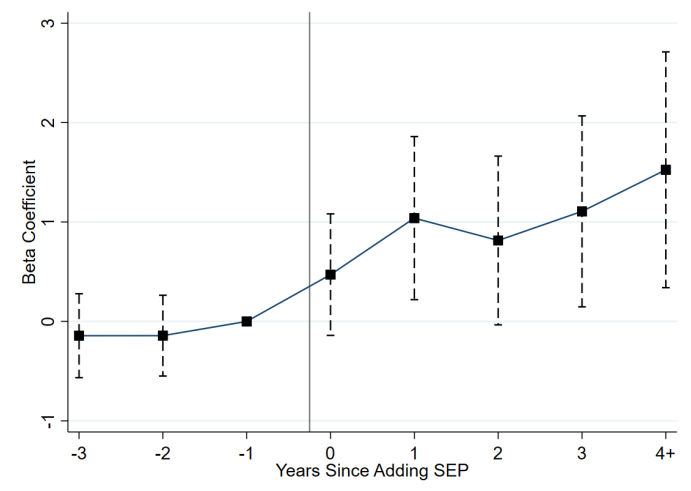

Hospital DOA Drug-Related Mortality Rate

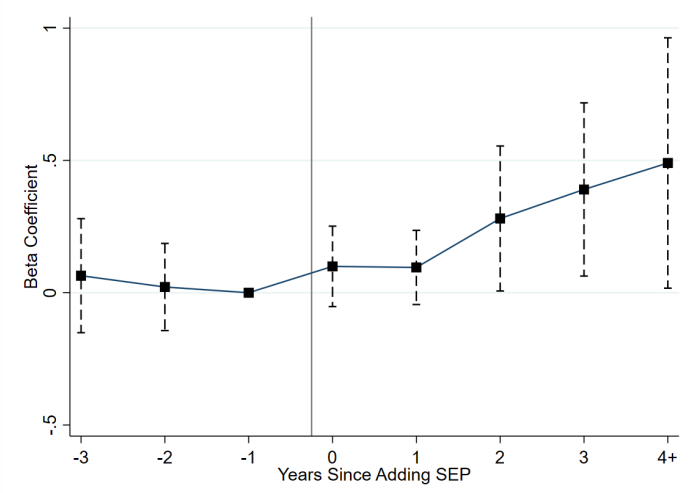

Outpatient/ER Drug-Related Mortality Rate

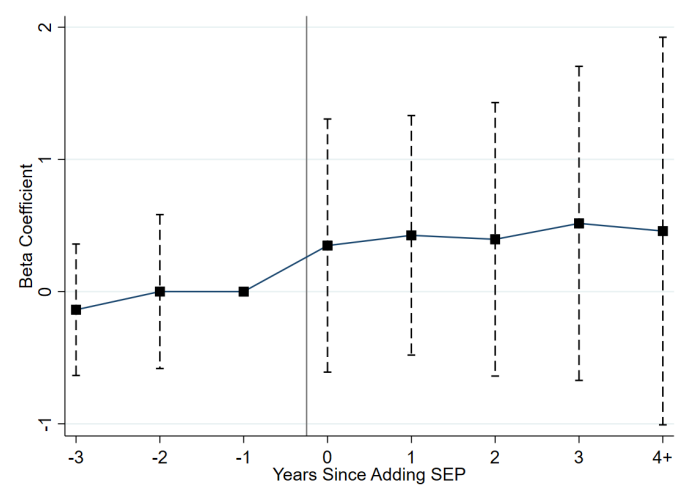

At-Home Drug-Related Mortality Rate

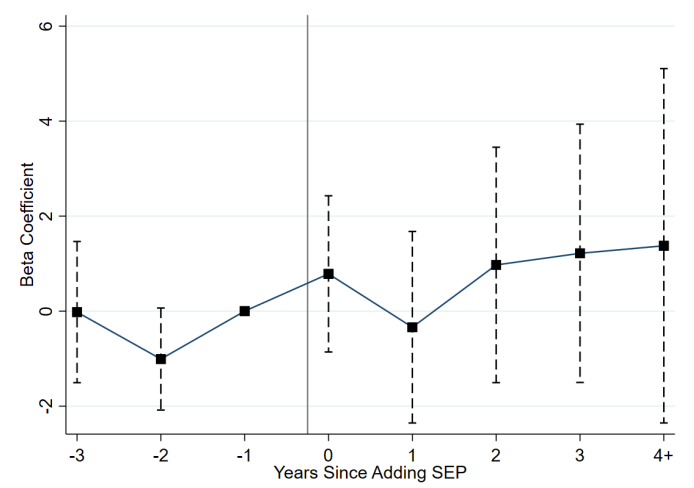

Notes: See Figure 4 
Figure A7: Difference-in-Differences Estimates of the Effect of Opening a Syringe Exchange Program on Opioid-Related Mortality Rates, by County Subgroup

Urban Counties

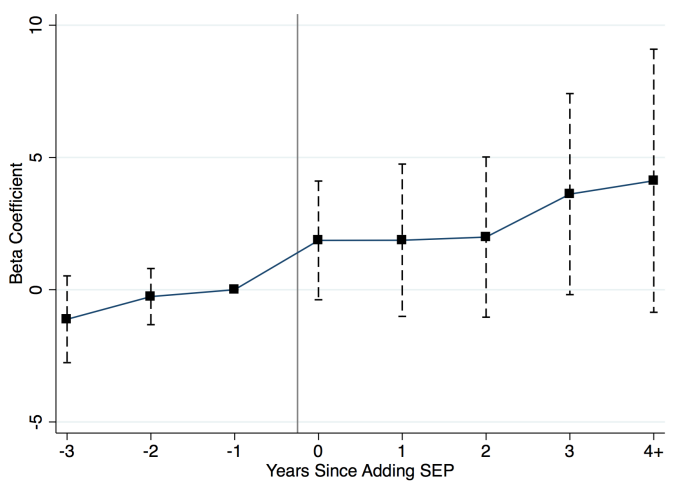

Low-Poverty Counties

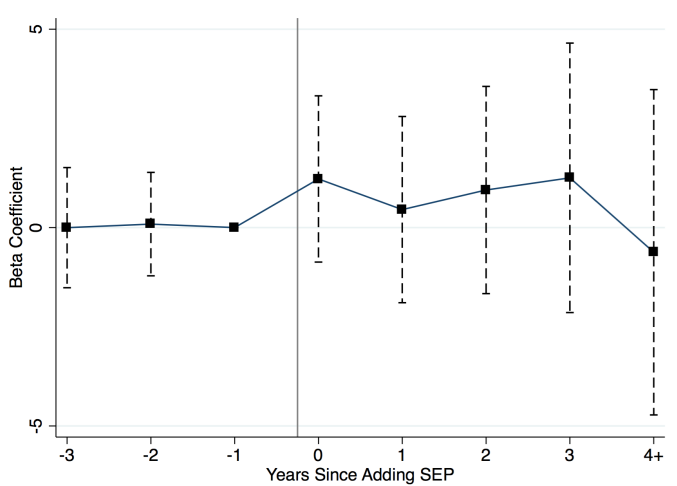

Rural Counties

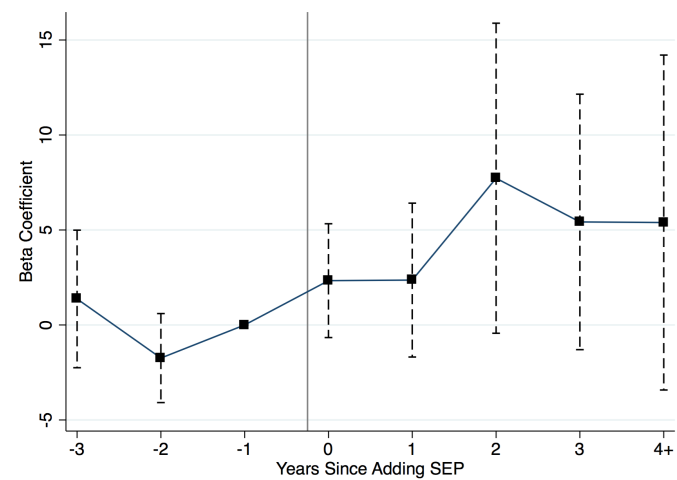

High-Poverty Counties

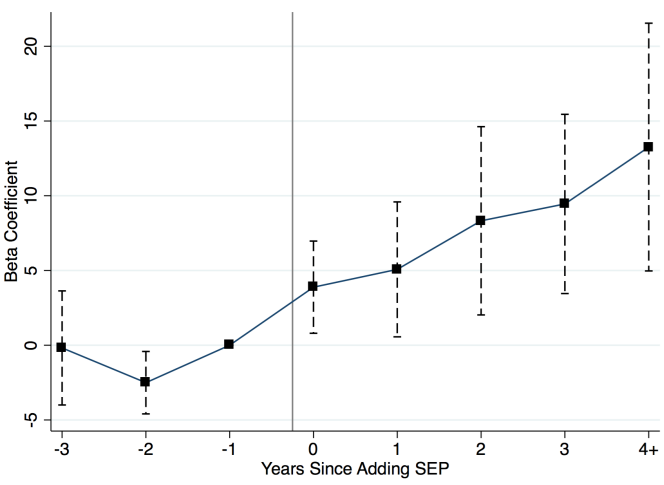

Notes: See Figure4. Data on urbanicity is from the USDA. "Urban" counties include metropolitan areas, while "Rural" counties include micropolitan areas, small towns, and rural areas. "High-Poverty" counties are defined as counties with poverty rates above the sample 2016 median poverty rate. "Low-Poverty" counties are those with poverty rates at or below this median. 
Figure A8: Difference-in-Differences Estimates for HIV Rates and

Opioid-Related Mortality Rates by County Population Size

HIV Rate

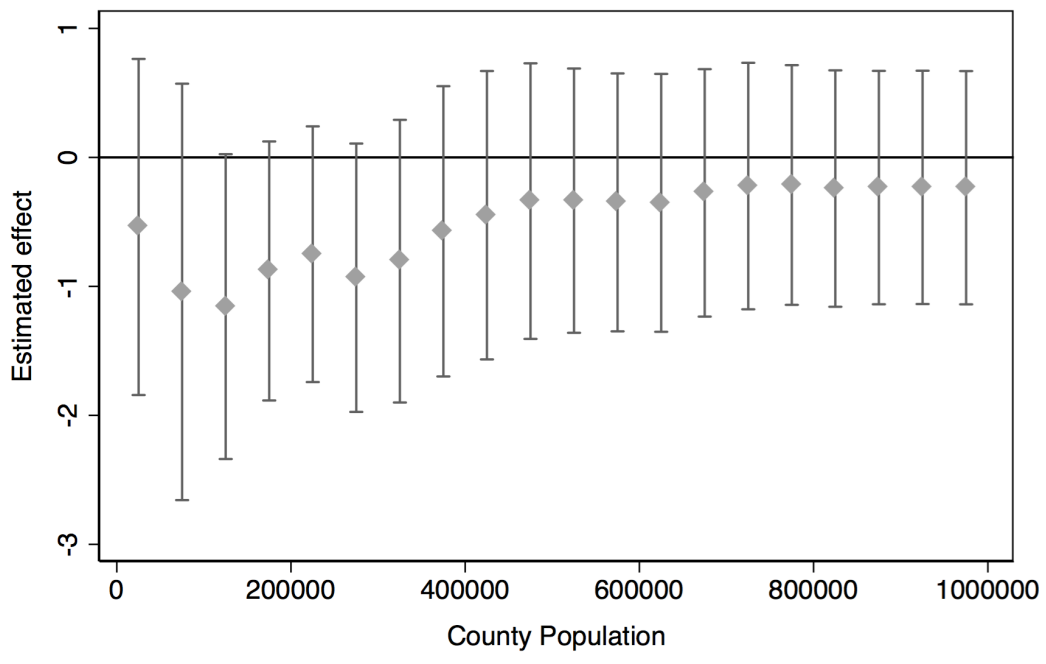

$95 \% \mathrm{Cl}>$ Coefficient

Opioid-Related Mortality Rate

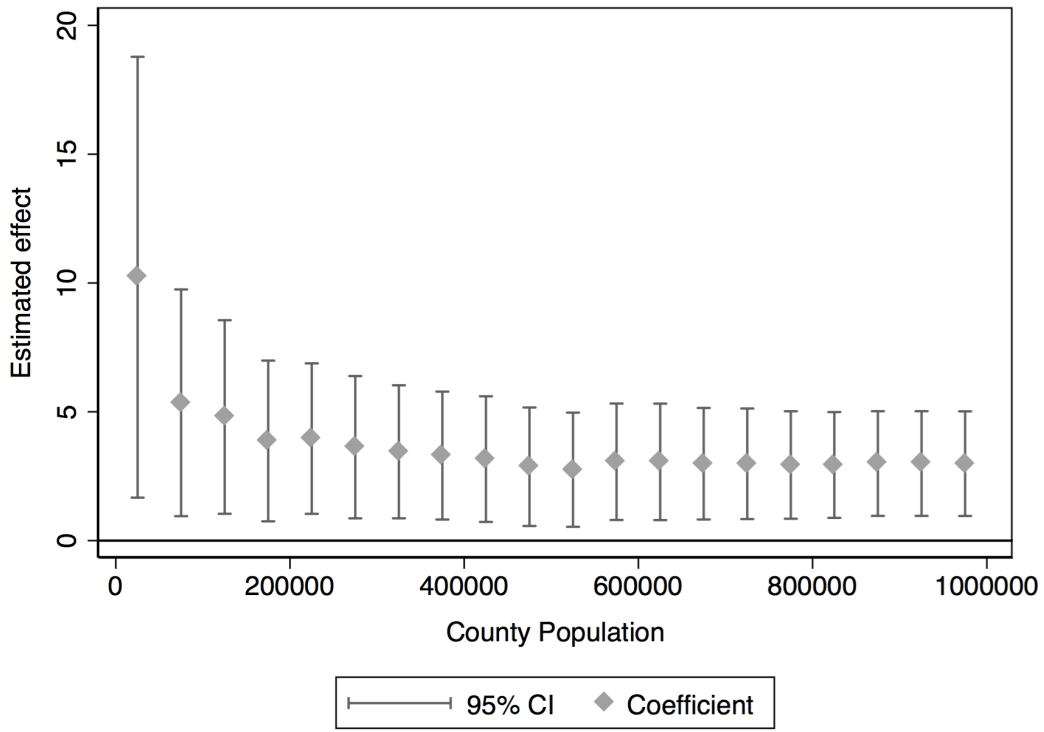

Notes: Each figure displays the coefficients and their respective 95\% confidence intervals for the effects from OLS regressions, as specified in Equation 1. by population size. A x-axis value of " $i$ " where $i=25,000,75,000,125,000, \ldots 1,000,000$ indicates an estimate from a difference-in-differences analysis comparing health outcomes in treated and comparison counties with less than $i$ individuals. Estimates are based on restricted mortality files and CDC HIV diagnoses counts by county for the entire United States from 2008-2016. HIV diagnoses rates are from the Center for Disease Control and Prevention's NCHHSTP Atlas and 34 state agencies. Economic control variables include the county-level poverty rate and unemployment rate, demographic controls include percent Hispanic and percent black, and state-level policy controls include whether a state imposes quantitative prescription limit, tamper-resistant prescription forms, pain clinic regulations, patient identification requirements, doctor shopping restrictions, requirements with respect to physician examination or pharmacist verification, prescription drug monitoring programs, paraphernalia laws, and good Samaritan laws. Standard errors are clustered at the county level. 
Figure A9: Difference-in-Differences Estimates for HIV Rates and Opioid-Related Mortality Rates by County Population Size (WLS)

\section{HIV Rate}

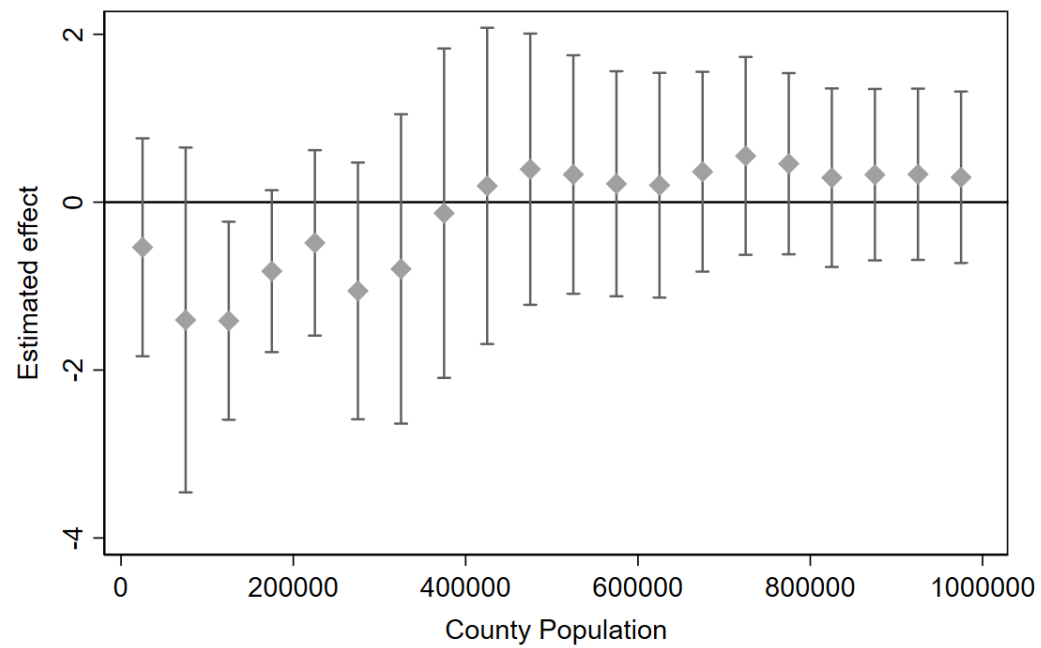

$95 \% \mathrm{Cl} \vee$ Coefficient

\section{Opioid-Related Mortality Rate}

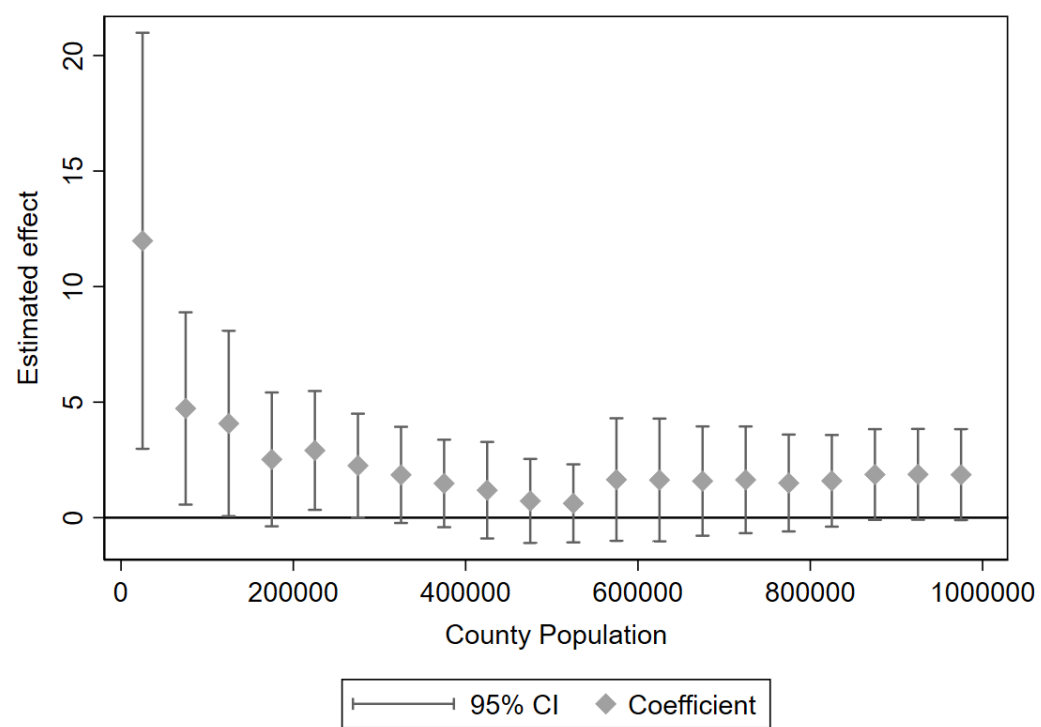

Notes: Each figure displays the coefficients and their respective $95 \%$ confidence intervals for the effects from WLS regressions, as specified in Equation 1 weighted by county population size. A x-axis value of " $i$ " where $i=25,000,75,000,125,000, \ldots 1,000,000$ indicates an estimate from a difference-in-differences analysis comparing health outcomes in treated and comparison counties with less than $i$ individuals. Estimates are based on restricted mortality files and CDC HIV diagnoses counts by county for the entire United States from 2008-2016. HIV diagnoses rates are from the Center for Disease Control and Prevention's NCHHSTP Atlas and 34 state agencies. Economic control variables include the county-level poverty rate and unemployment rate, demographic controls include percent Hispanic and percent black, and state-level policy controls include whether a state imposes quantitative prescription limit, tamper-resistant prescription forms, pain clinic regulations, patient identification requirements, doctor shopping restrictions, requirements with respect to physician examination or pharmacist verification, prescription drug monitoring programs, paraphernalia laws, and good Samaritan laws. Standard errors are clustered at the county level. 
Figure A10: Difference-in-Differences Estimates of the Effect of Opening a Syringe Exchange Program on Drug-Related Mortality Rates,

Without County-Specific Linear Trends

\section{HIV Rate}

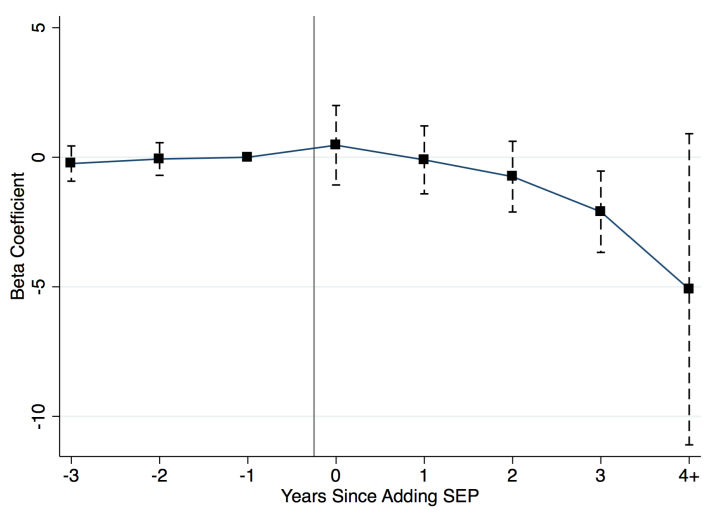

Drug-Related Mortality Rate

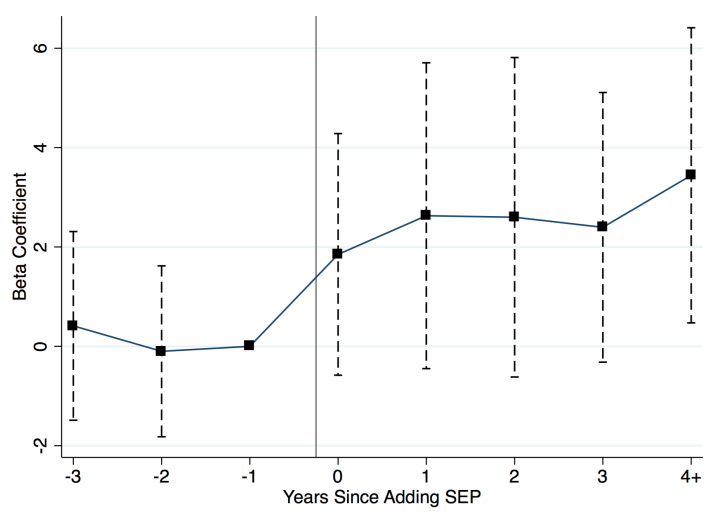

Opioid-Related Mortality Rate

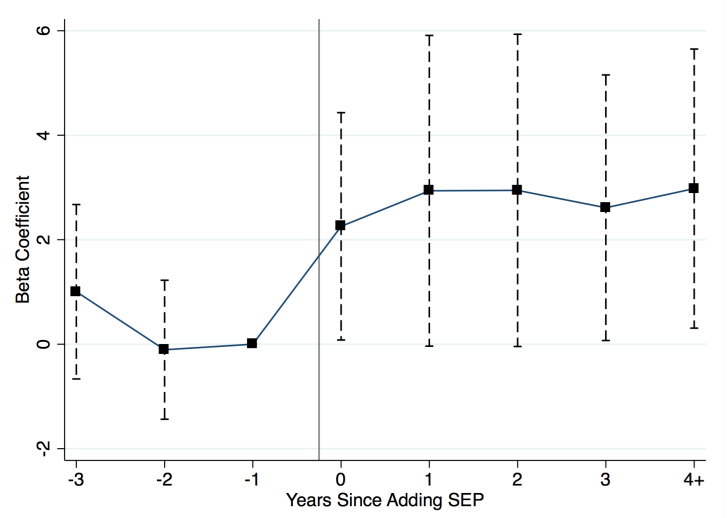

Notes: See Figures 3 and 4 Each figure displays the coefficients and their respective $95 \%$ confidence intervals for the leading indicators and lagged treatment effects from OLS regressions, as specified in Equation 1 omitting controls for county-specific linear time trends. 
Figure A11: Difference-in-Differences Estimates of the Effect of Opening a Syringe Exchange Program on Opioid-Related Mortality Rates,

by Various Comparison Groups
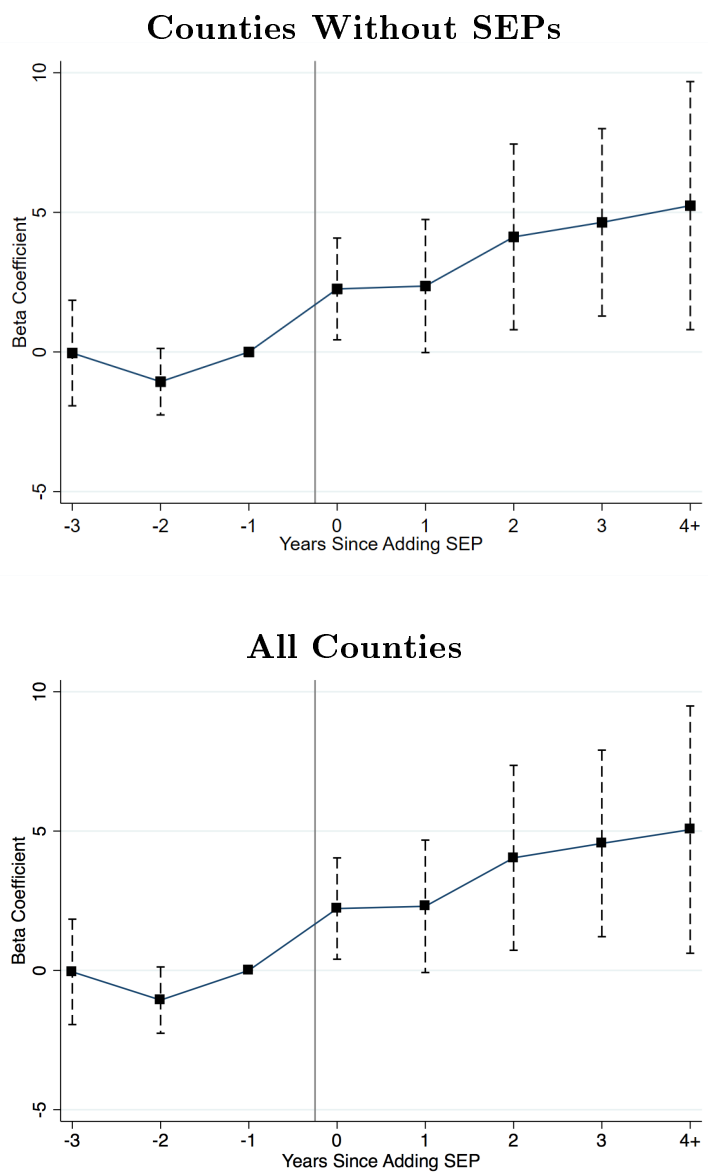

\section{Counties with Existing SEPs}

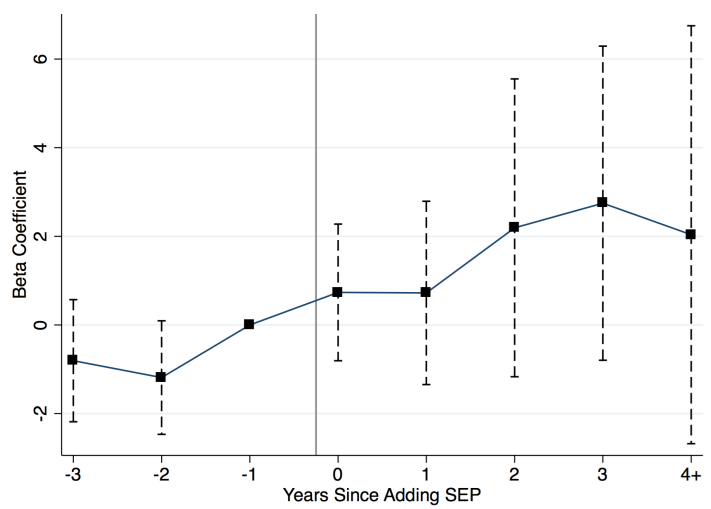

Notes: See Figure 4. The top panel displays coefficients and their 95\% confidence intervals from a model specified by Equation 1 . comparing counties with SEP openings to those without SEPs. The middle panel displays coefficients and their $95 \%$ confidence intervals from a model specified by Equation 1 comparing counties with SEP openings to all other US counties. The bottom panel displays coefficients and their $95 \%$ confidence intervals from a model specified by Equation 1 comparing counties with SEP openings to those with existing SEPs. 